Supporting Information, Part E

\title{
Small-Molecule Inhibitors of Protein Geranylgeranyltransferase Type I
}

Sabrina Castellano, Hannah D. G. Fiji, Sape S. Kinderman, Masaru Watanabe, ${ }^{1}$ Fuyuhiko Tamanoi, ${ }^{1}$ Ohyun Kwon*

Department of Chemistry and Biochemistry, Department of Microbiology, Immunology and Molecular Genetics, Jonsson Comprehensive Cancer Center and Molecular Biology Institute, University of California, Los Angeles, 607 Charles E. Young Drive East, Los Angeles, CA 90095-1569

ohyun@chem.ucla.edu

\section{Contents}

Spectral Data for Table 17

${ }^{1}$ Department of Microbiology, Immunology and Molecular Genetics 


\section{A04C11}
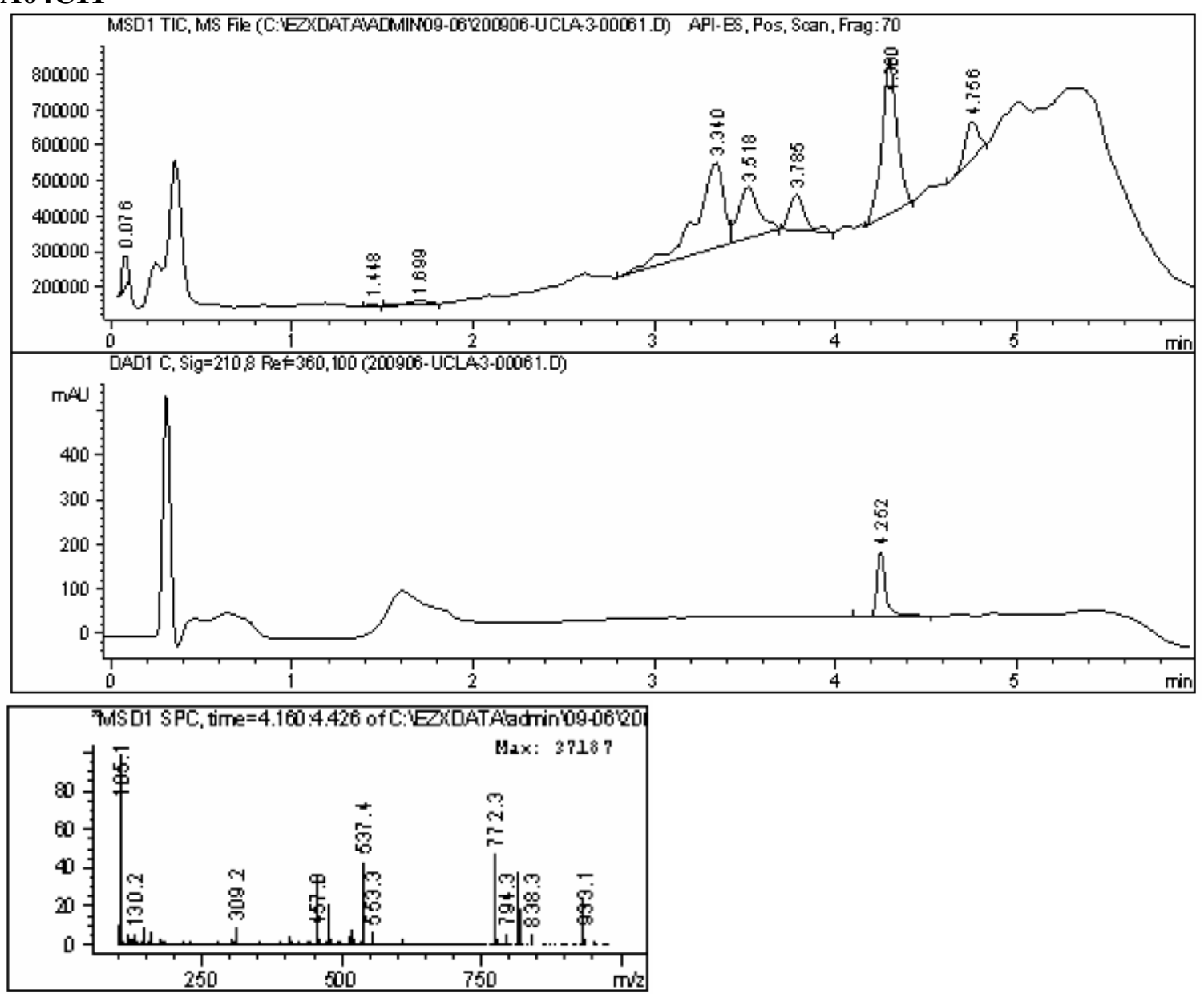

Component 1: Peak at Scan 241.4. Top ions are 454929931 


\section{A03C11}
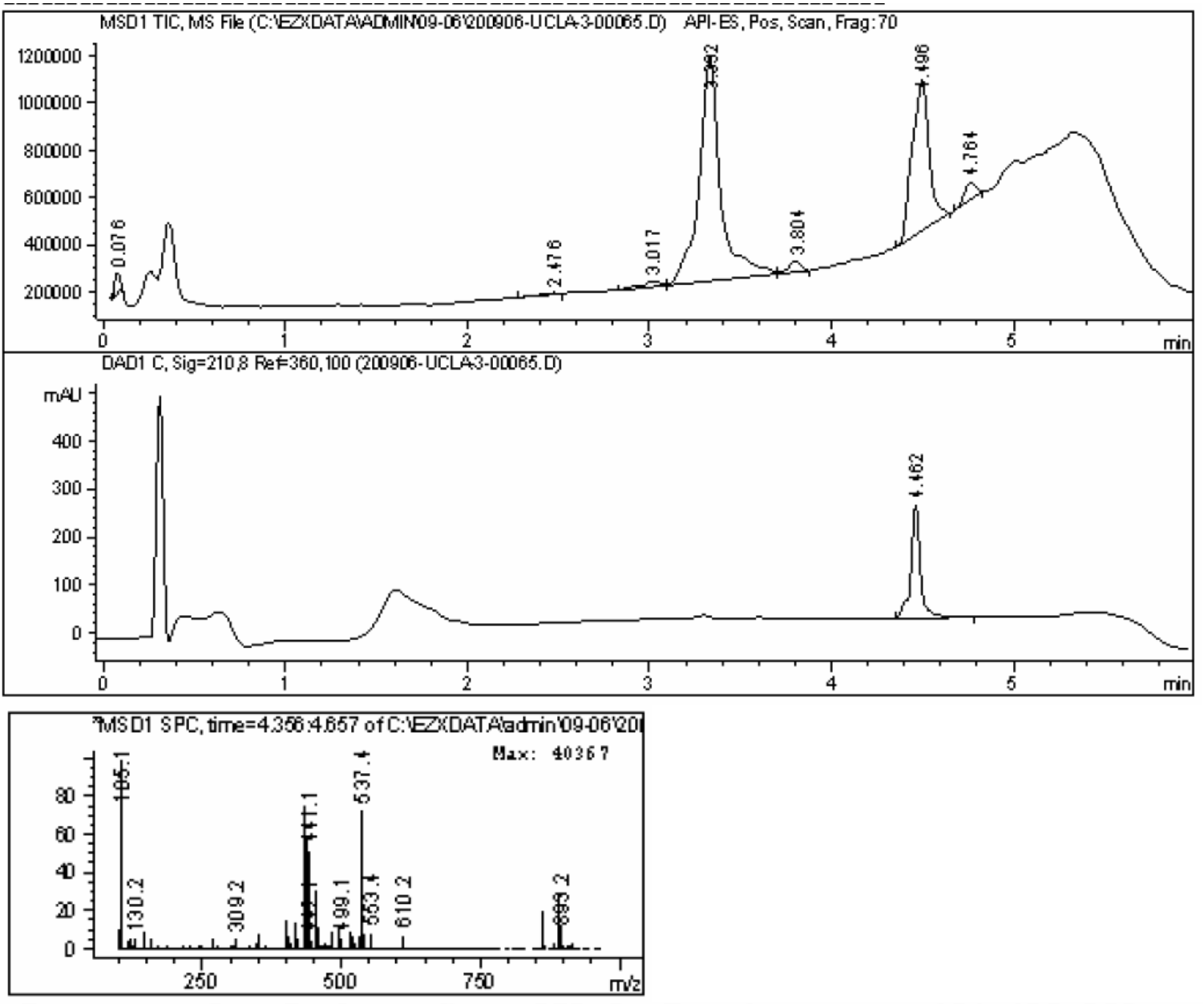

Component 2: Peak at Scan 253.2. Top ions are 434436889 


\section{A10C11}
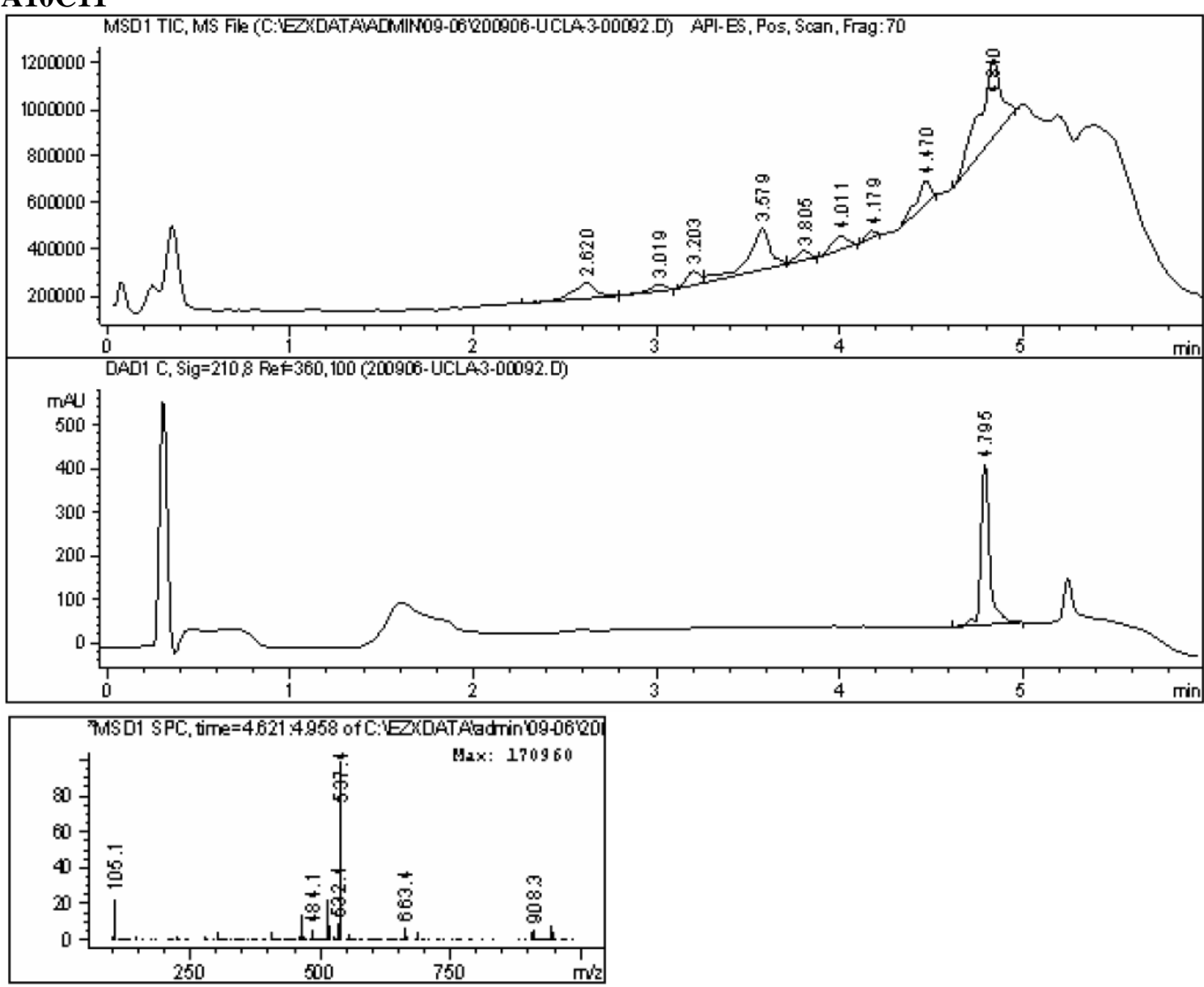

Component 3: Peak at Scan 272.2. Top ions are 462945947 


\section{A03C13}
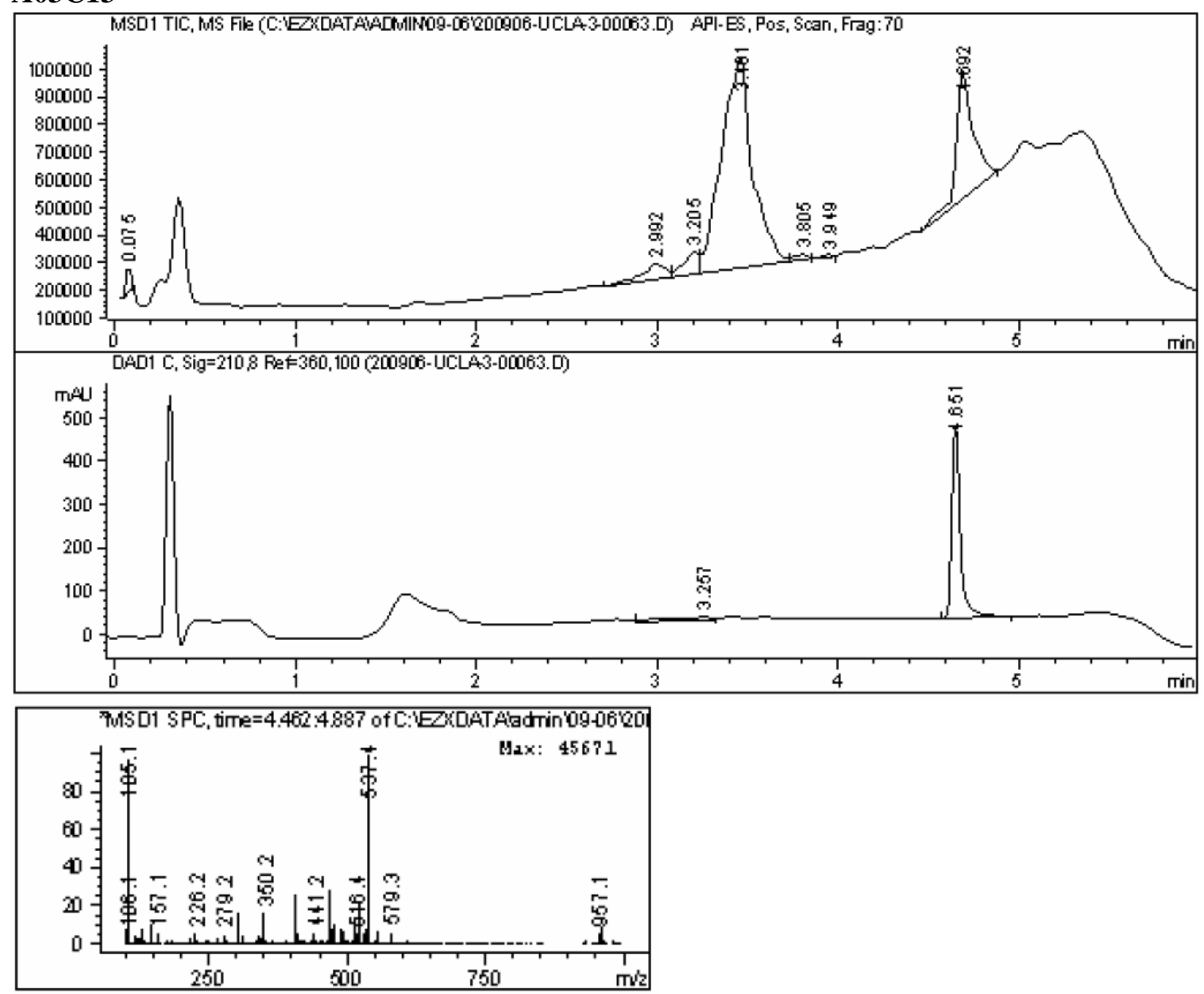

Comoonent 2: Peak at scan 263.6. Tov ions are 468470475 


\section{A06C01}
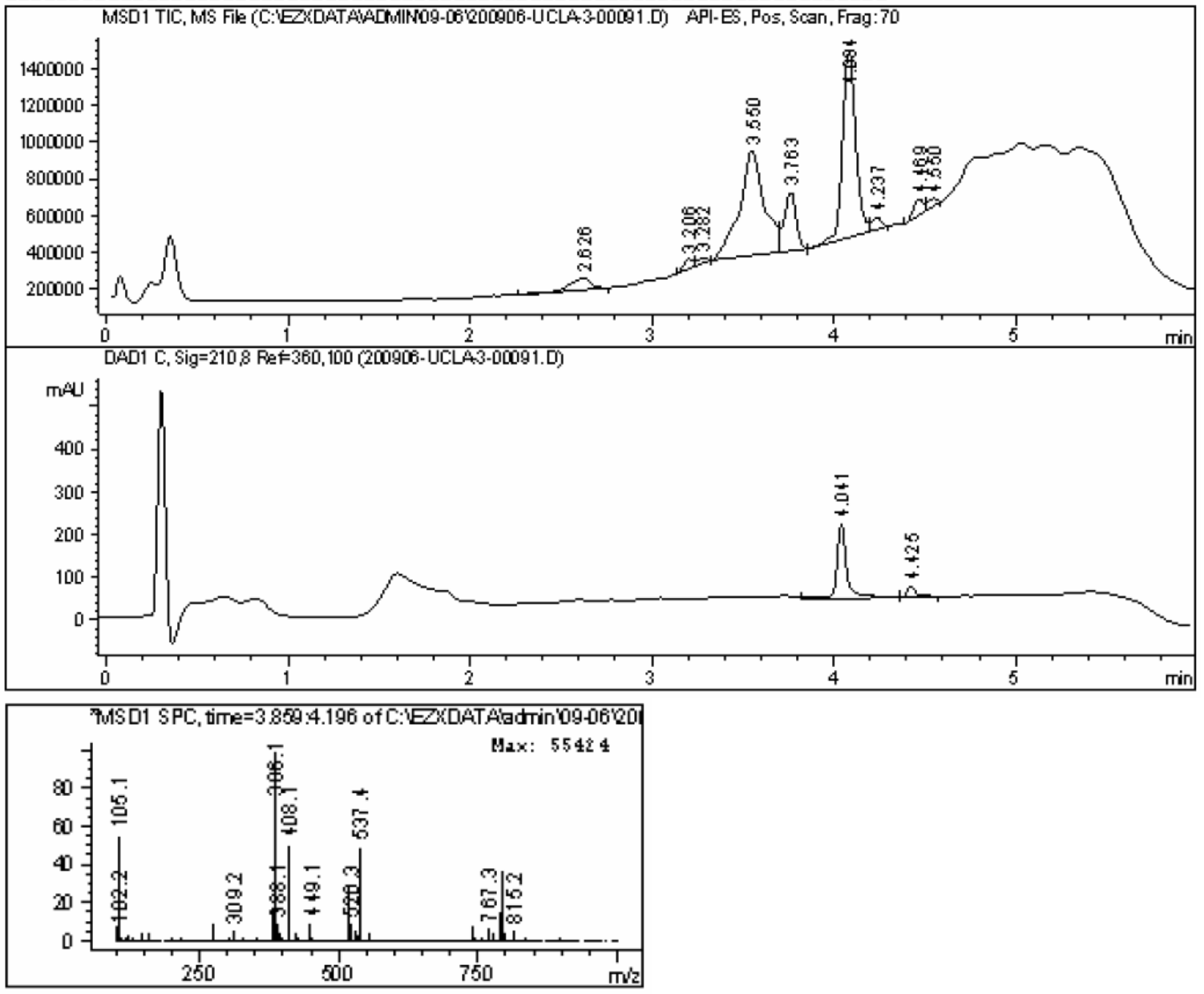


\section{A06C09}
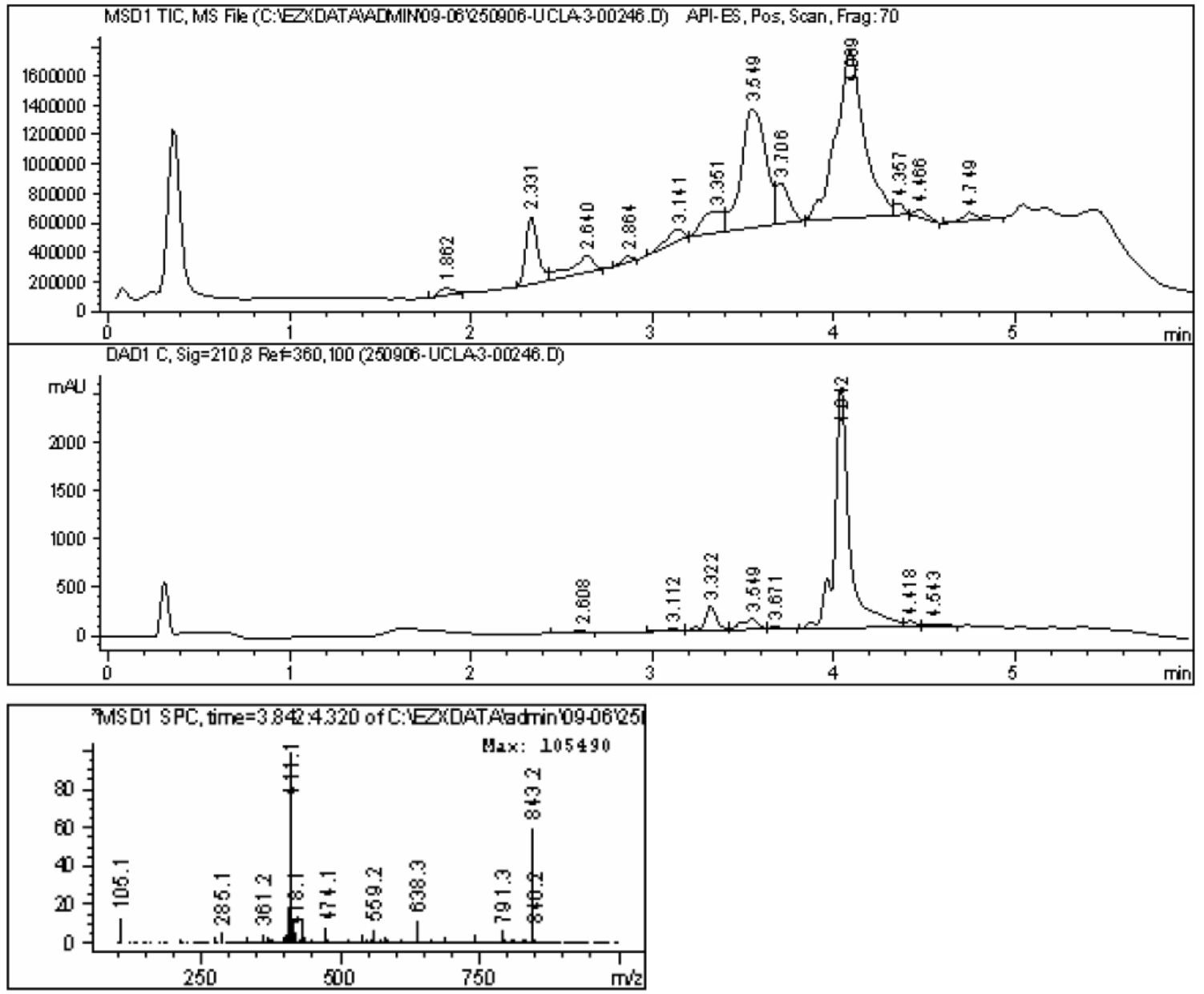


\section{A08C11}
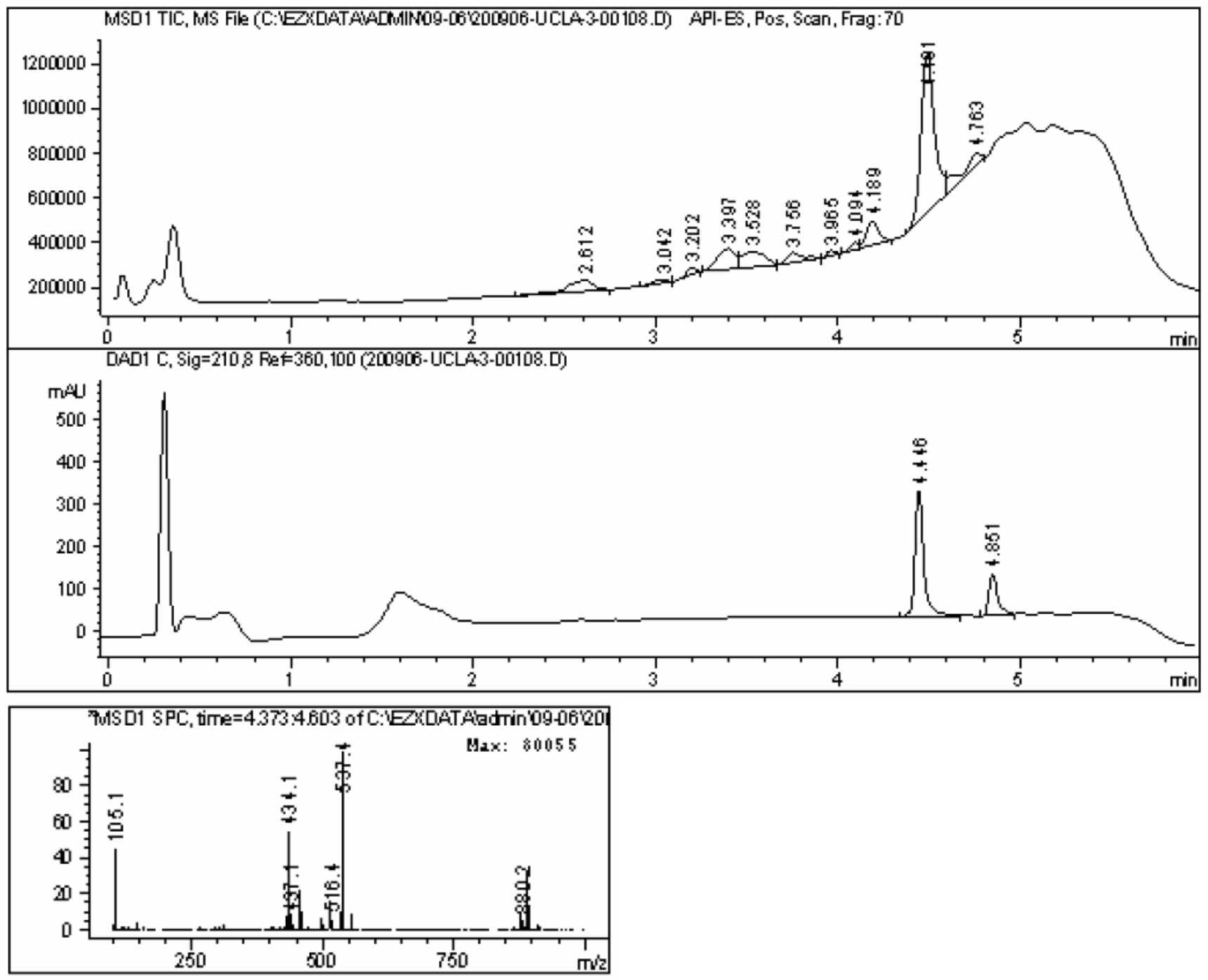


\section{A03C20}
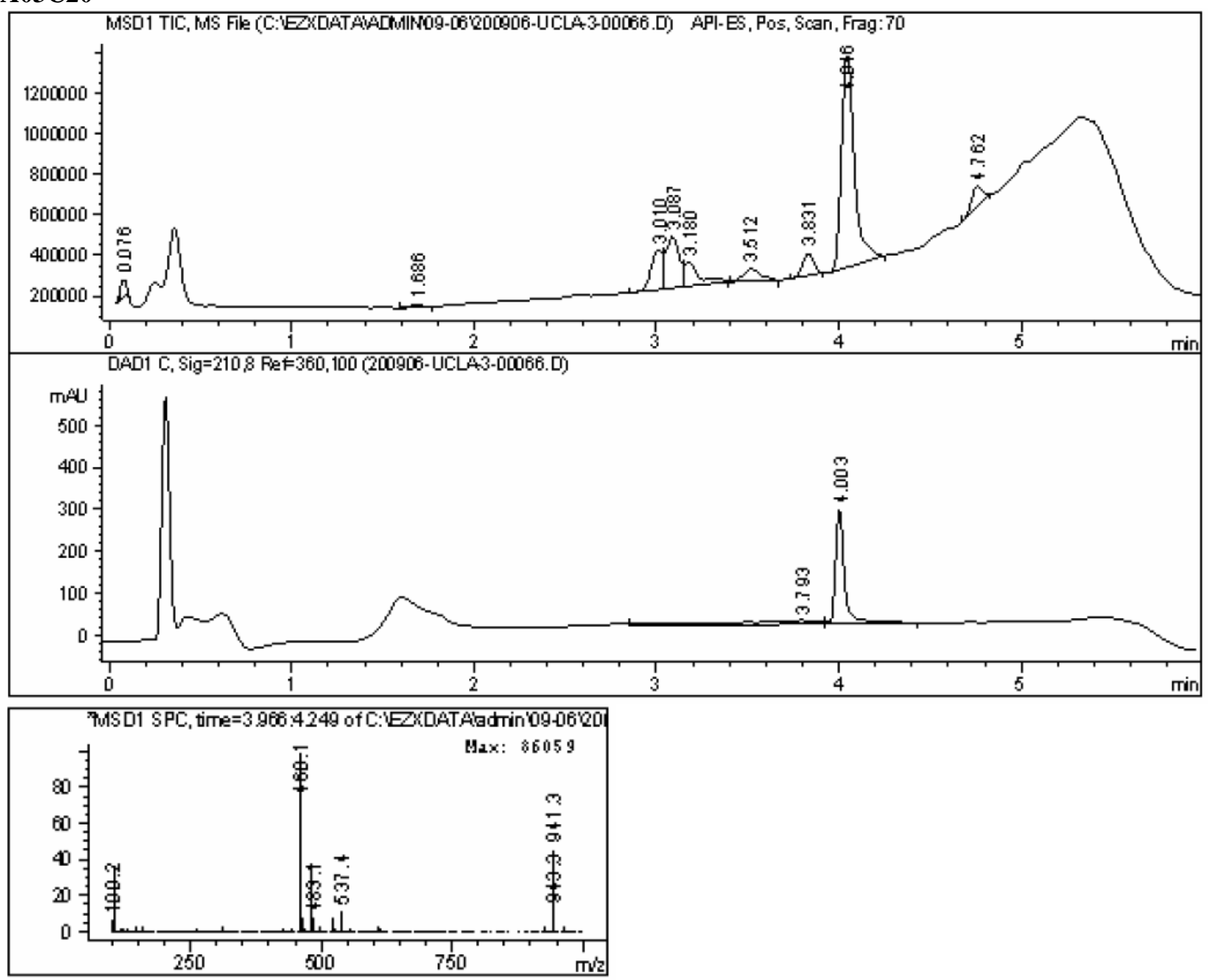


\section{A07C09}
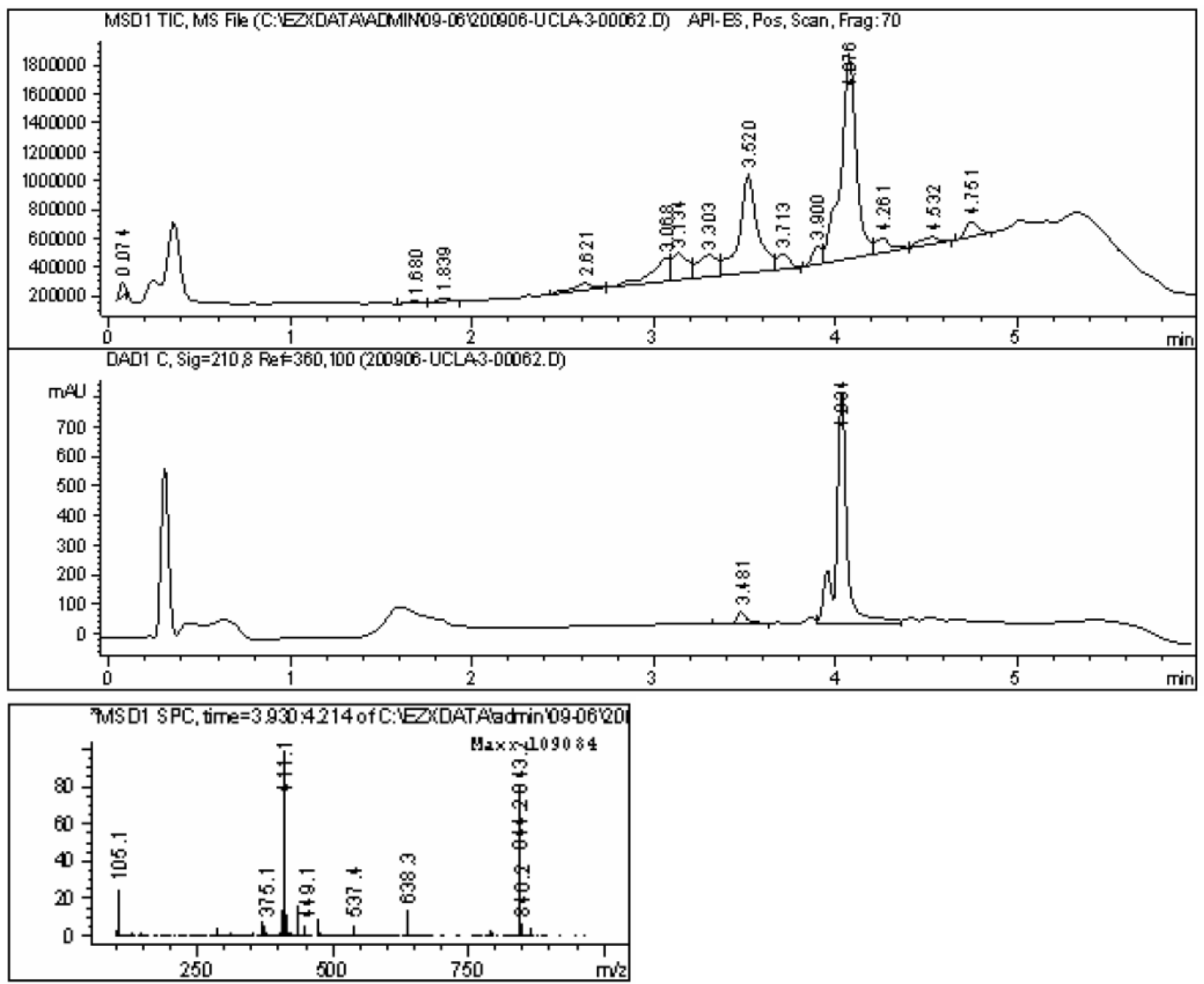


\section{A08C09}
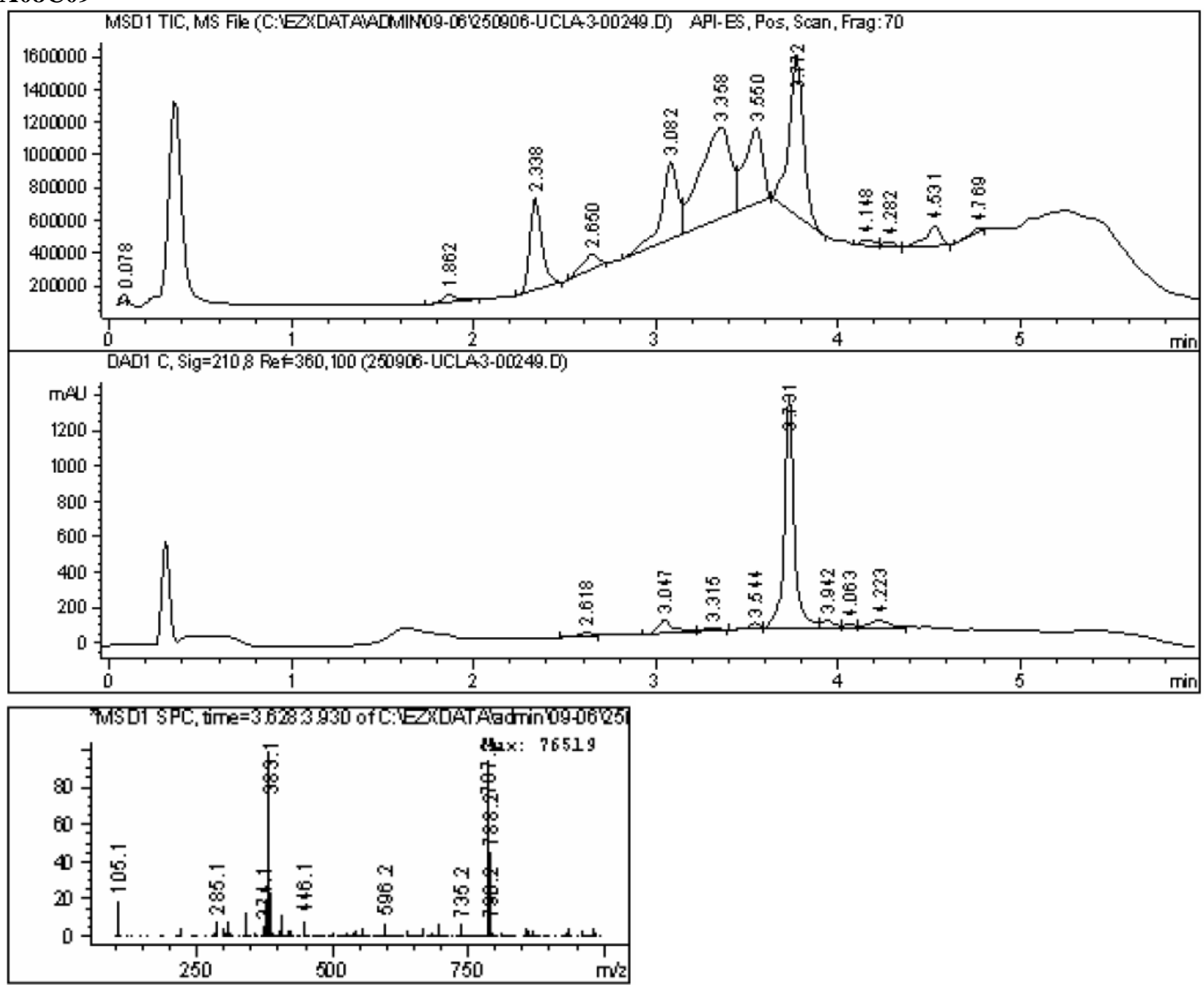


\section{A09C09}
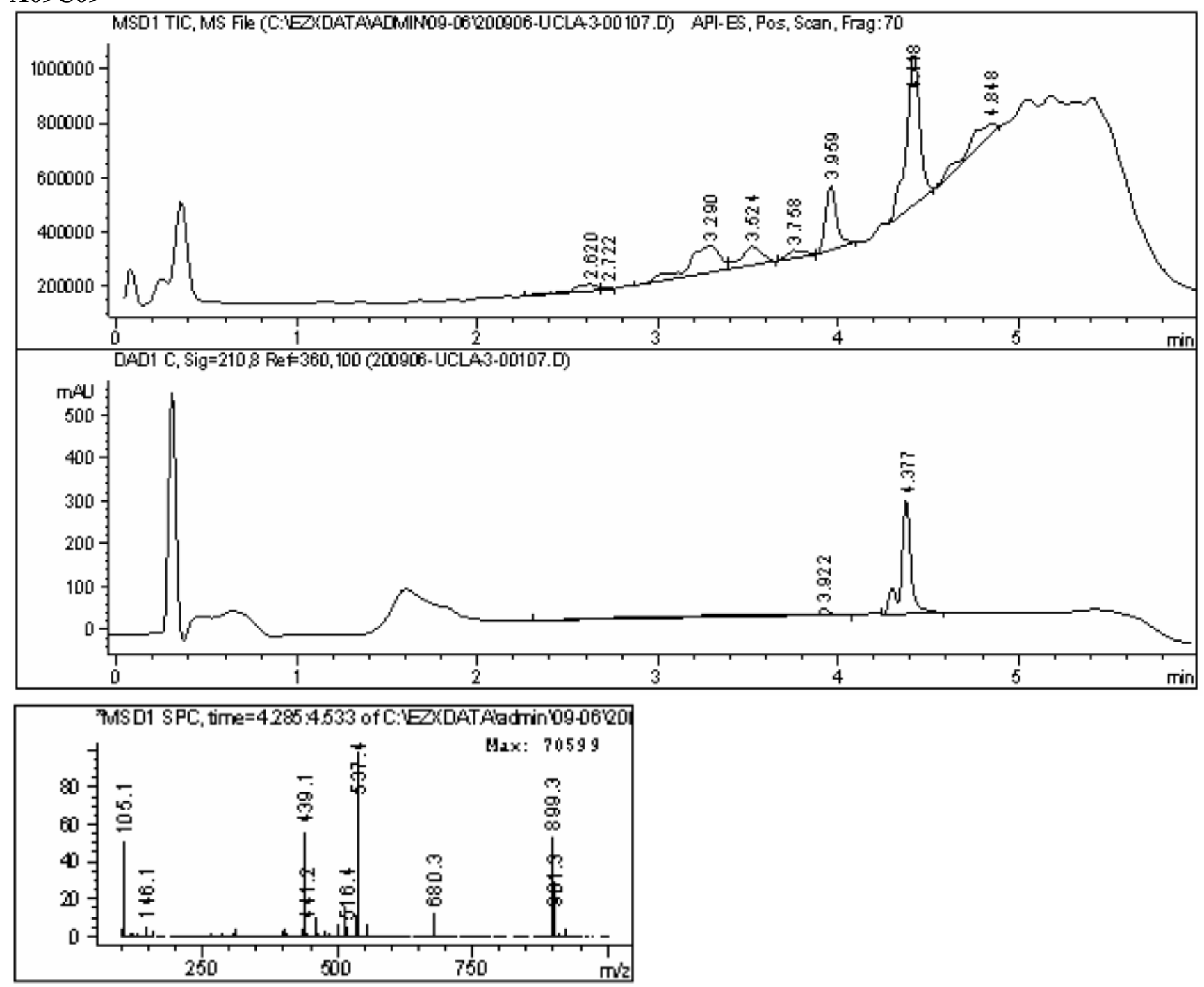


\section{A07C13E01}
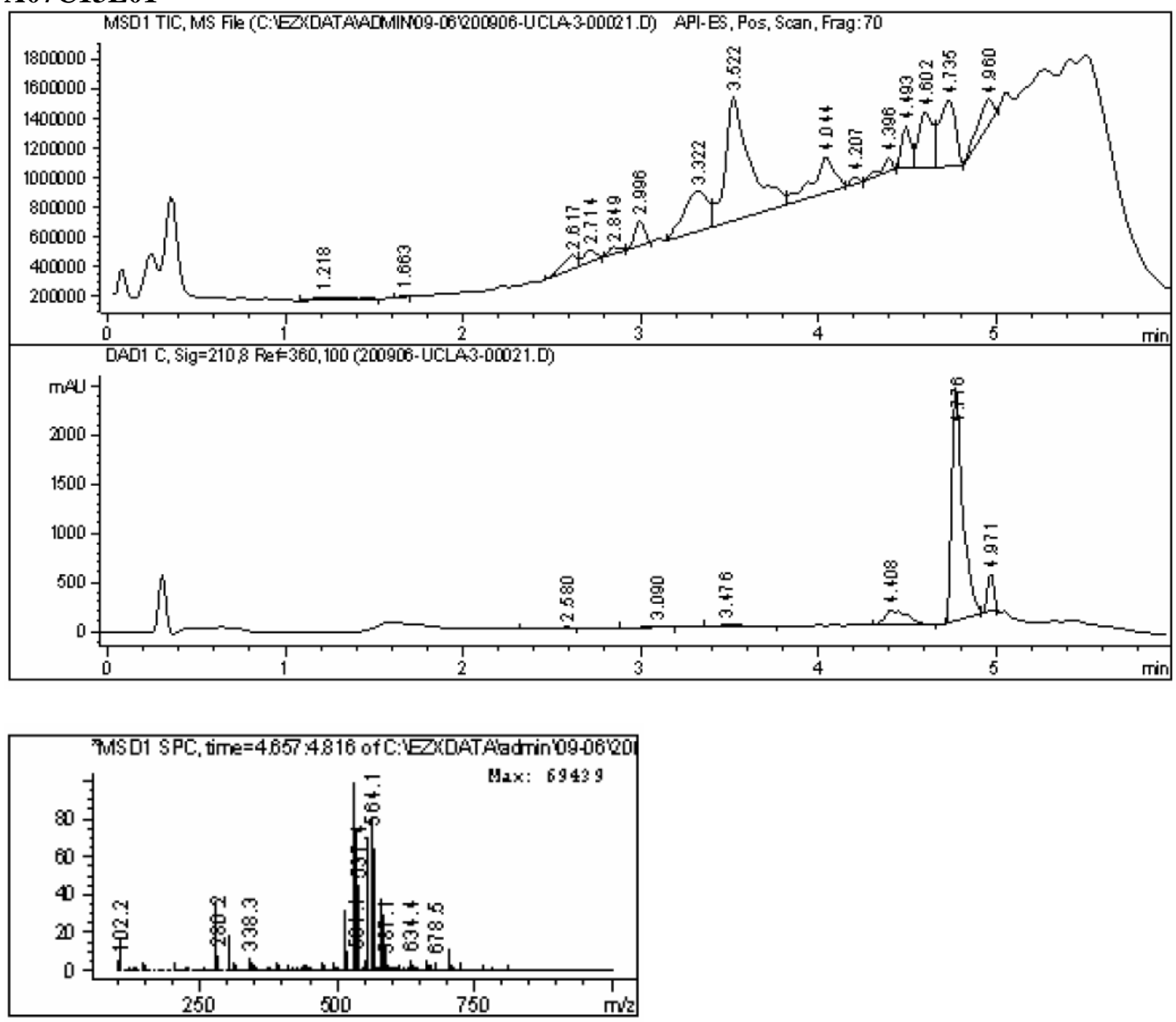


\section{A05C13E01}
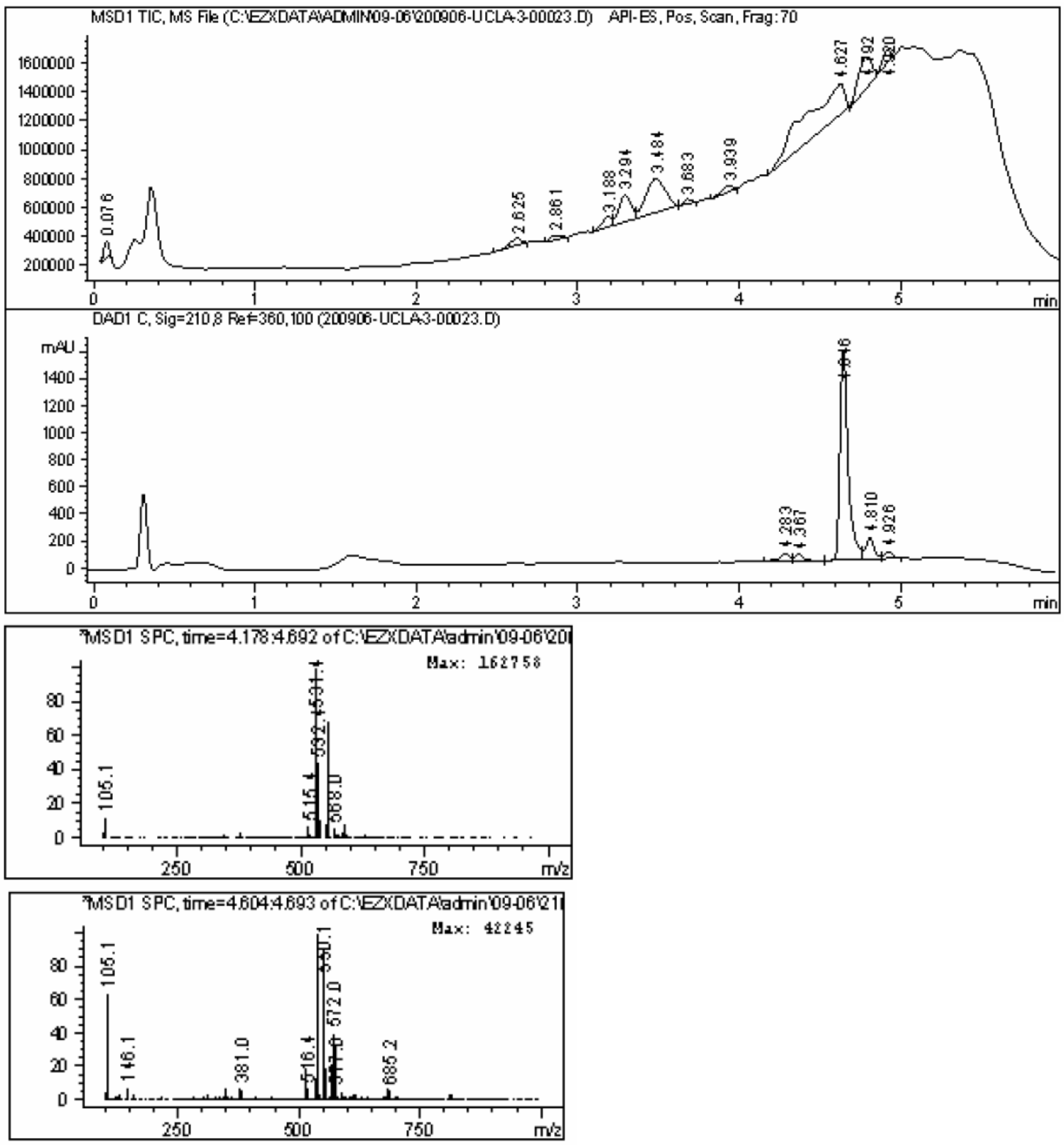


\section{A05C14E01}
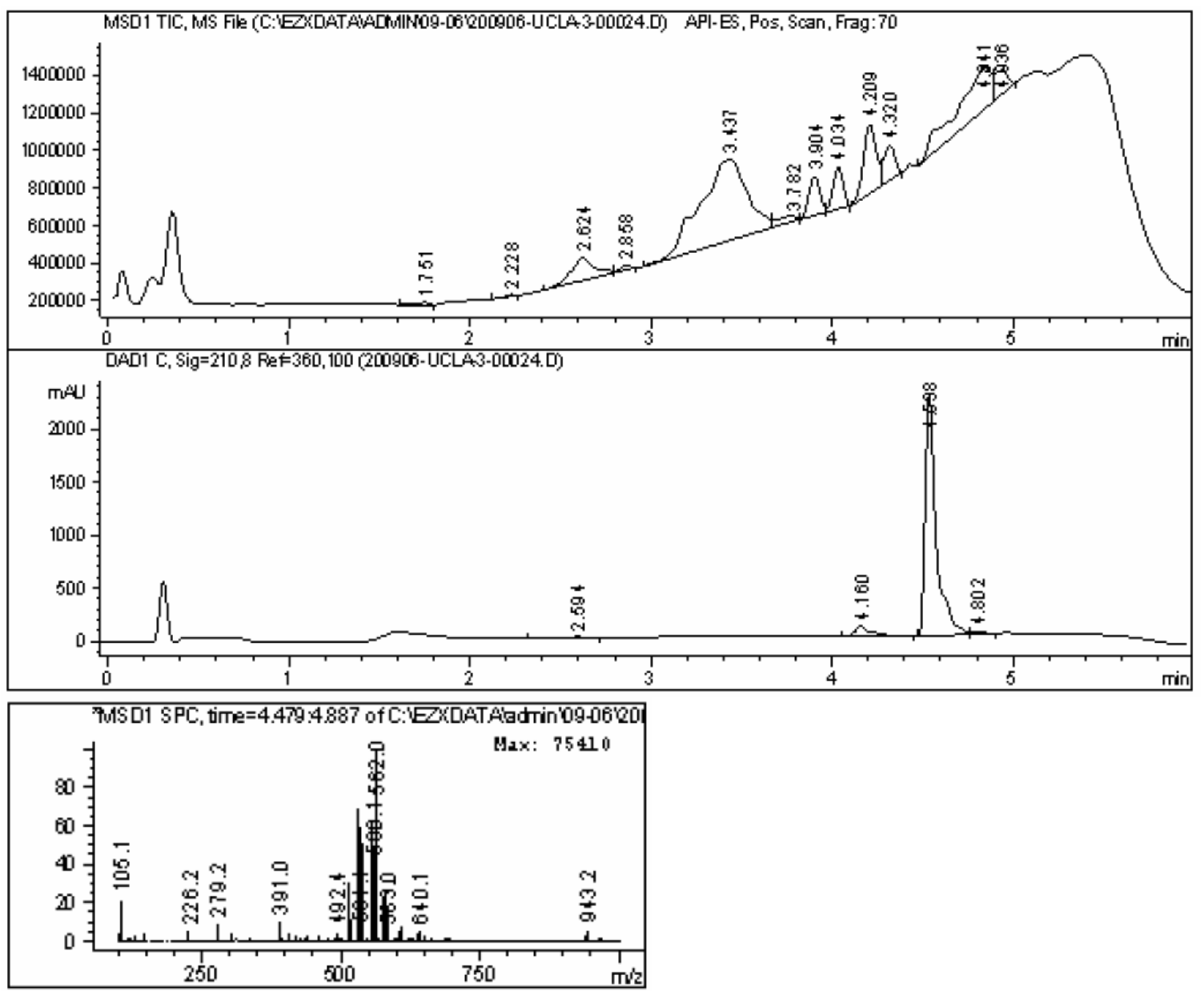

Combonent 1: Peak at Scan 257.6. Tov ions are 562560579 


\section{A06C09E01}
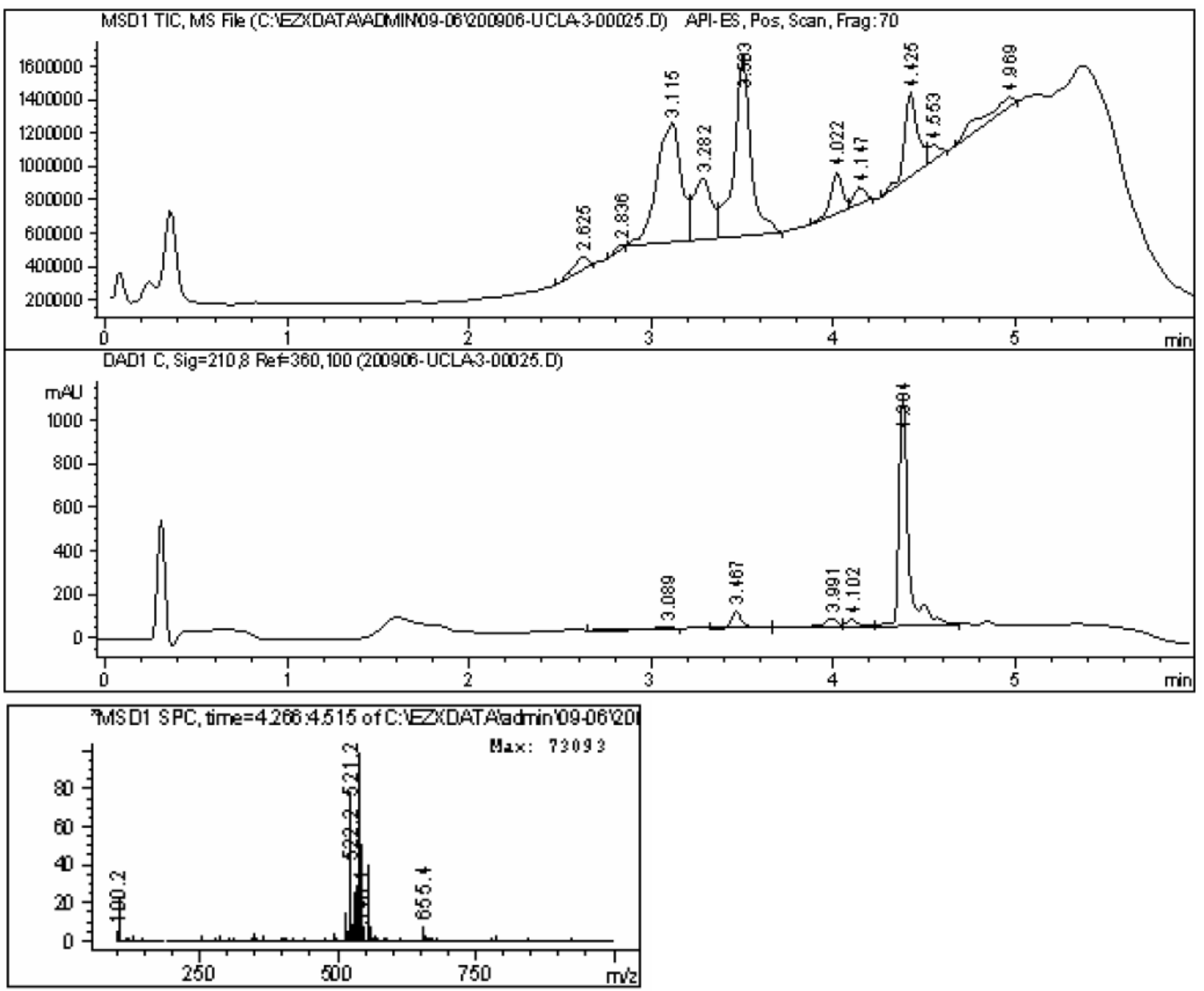


\section{A06C11E01}
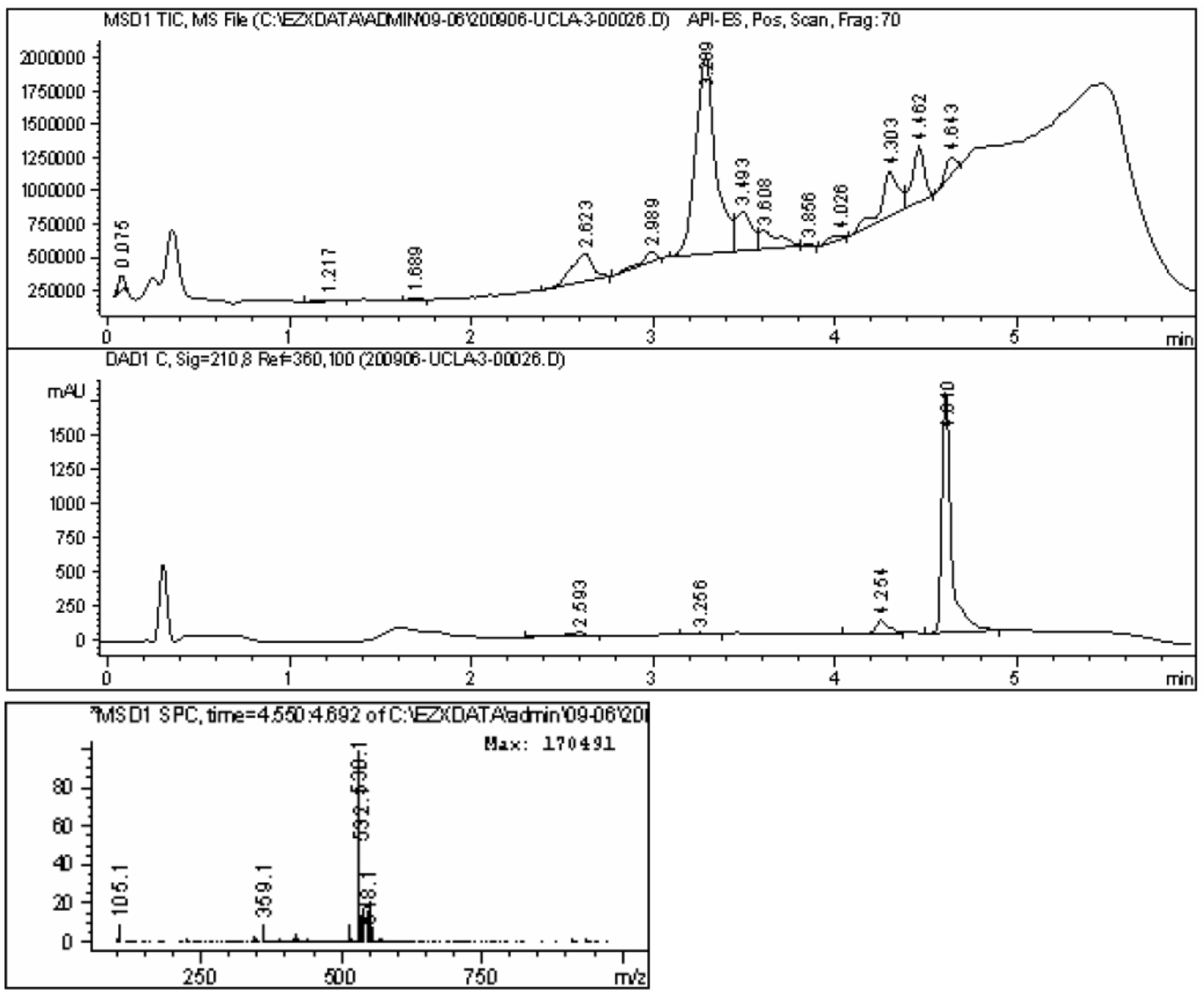


\section{A07C11E01}
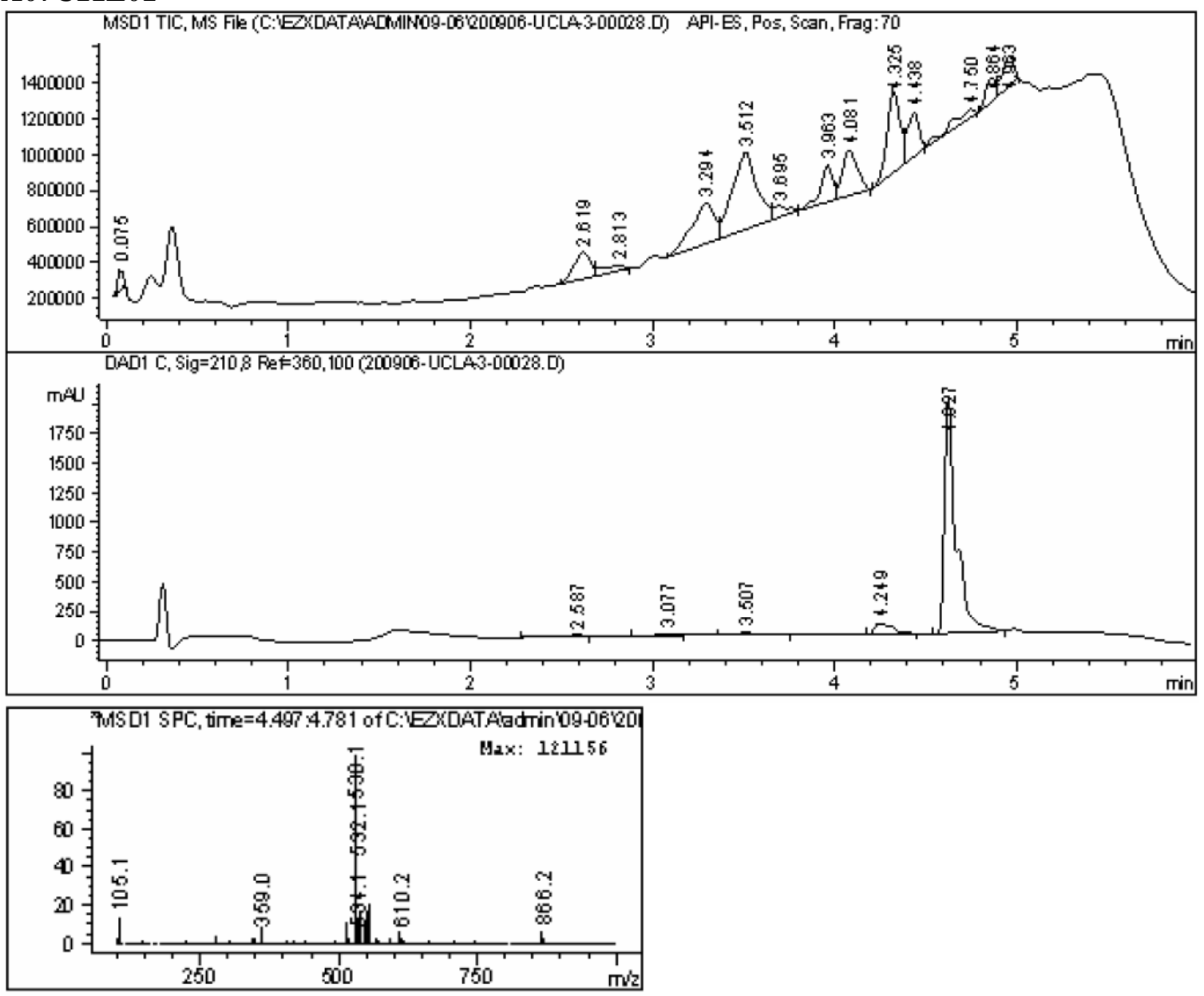


\section{A07C14E01}
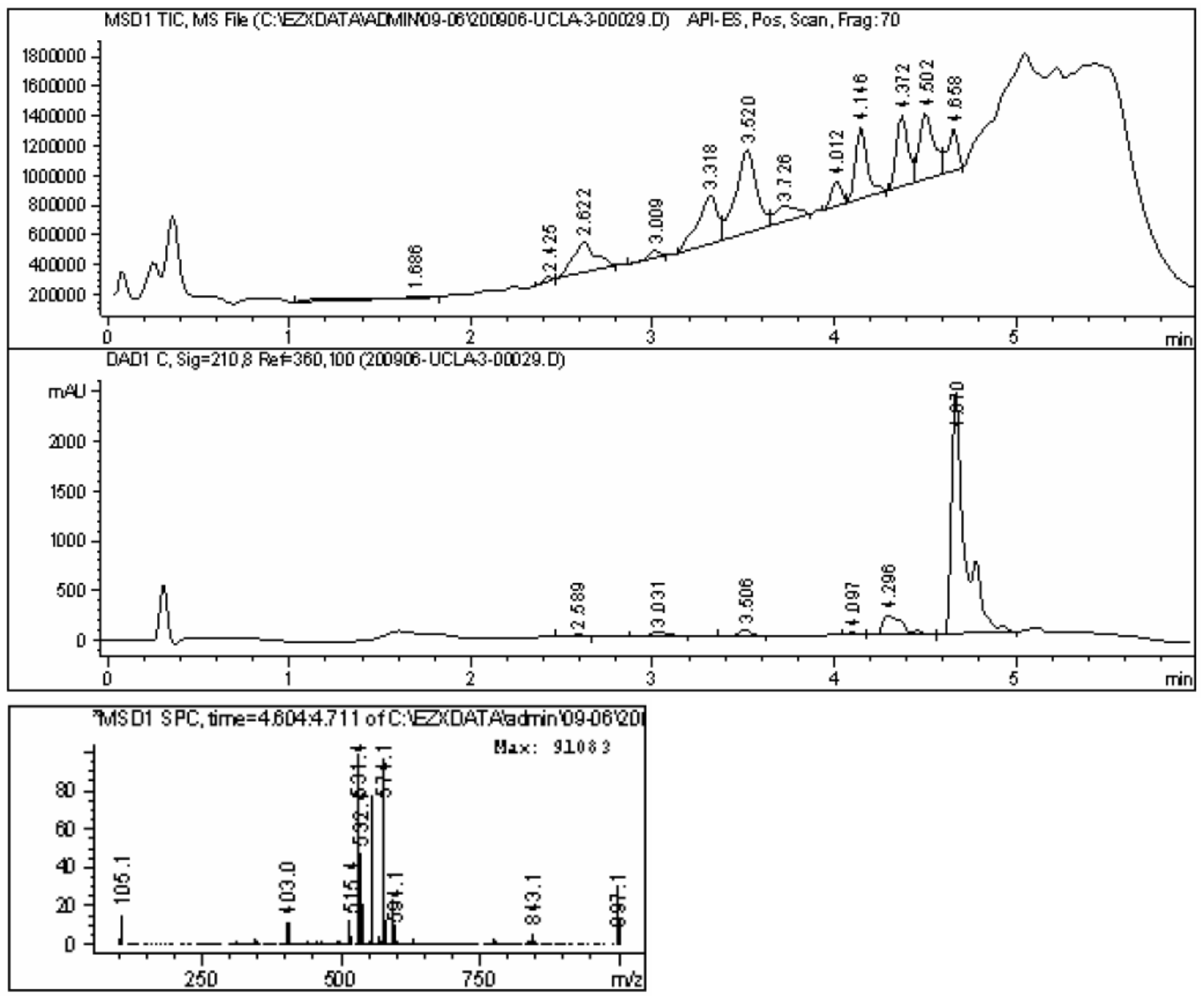


\section{A08C09E01}

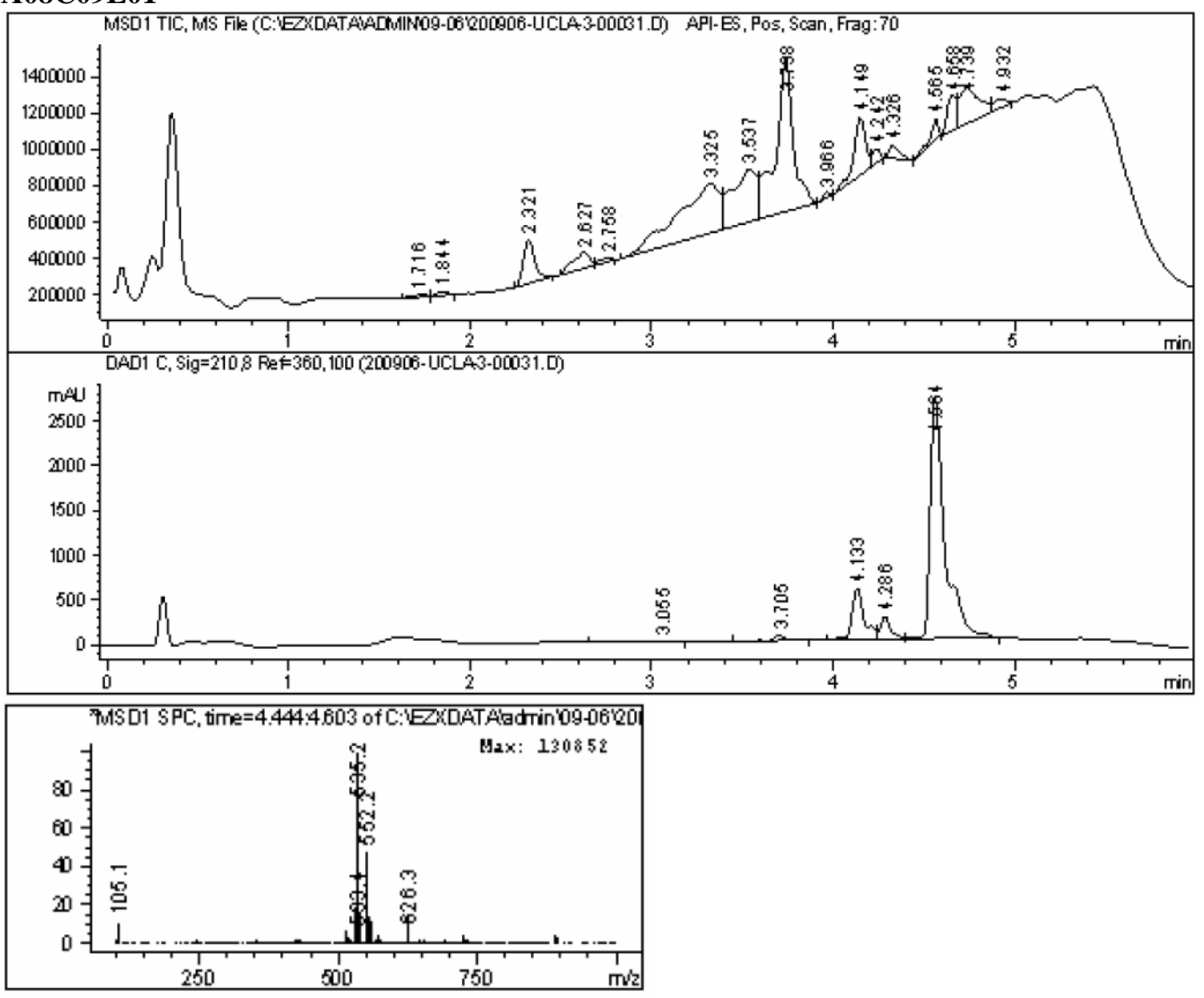




\section{A08C13E01}
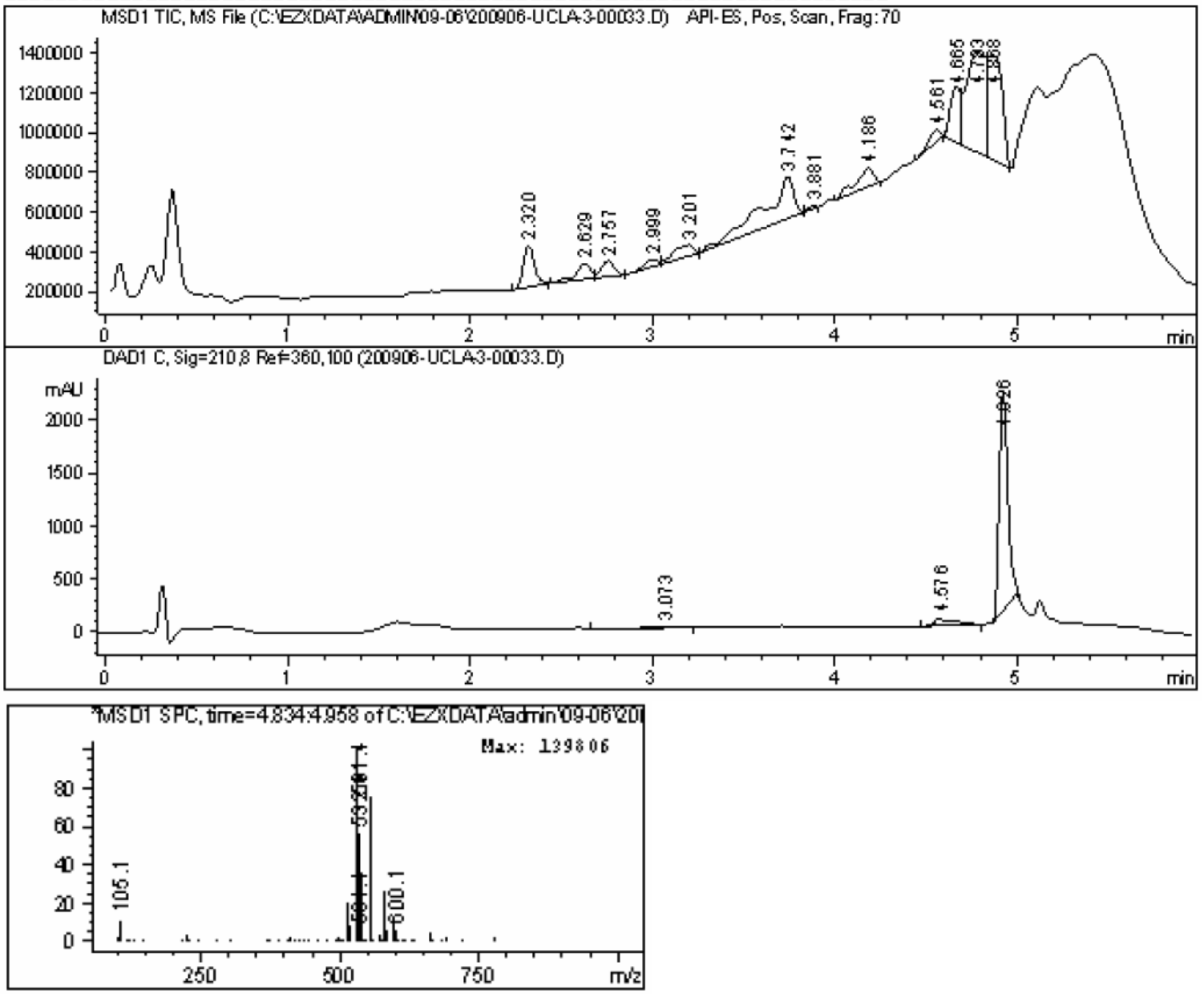


\section{A09C11E01}
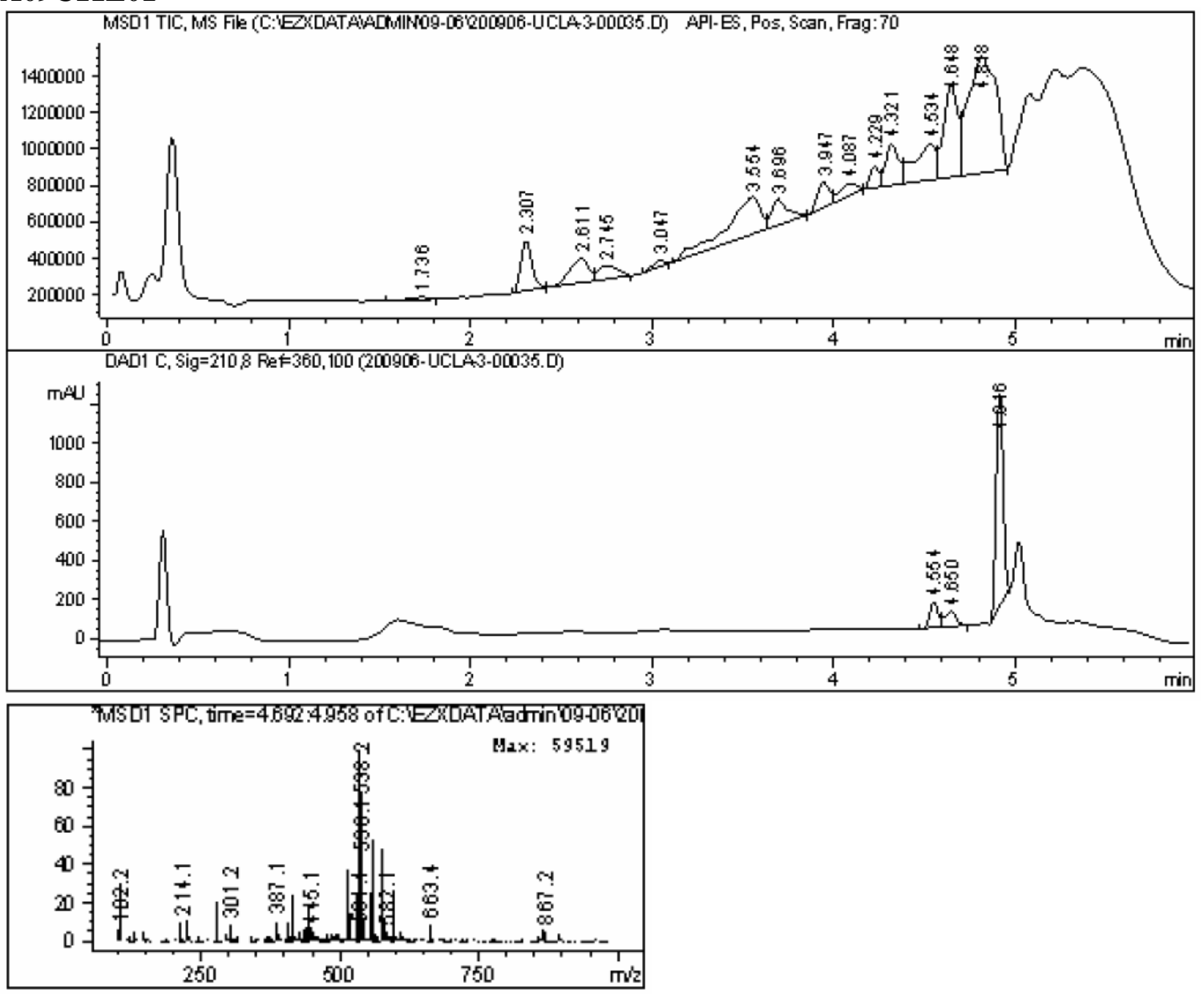


\section{A05C11E01}
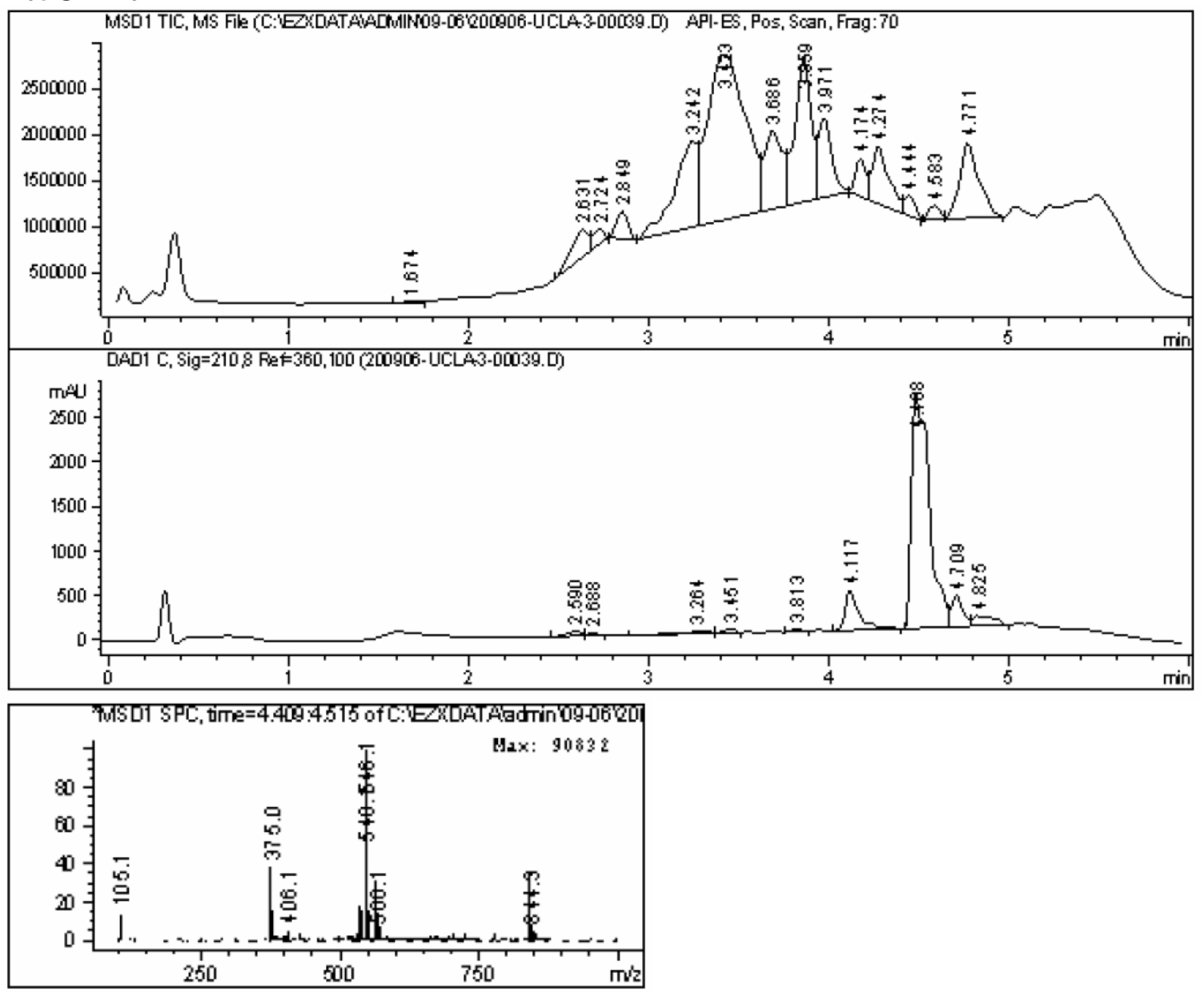


\section{A06C09E04}
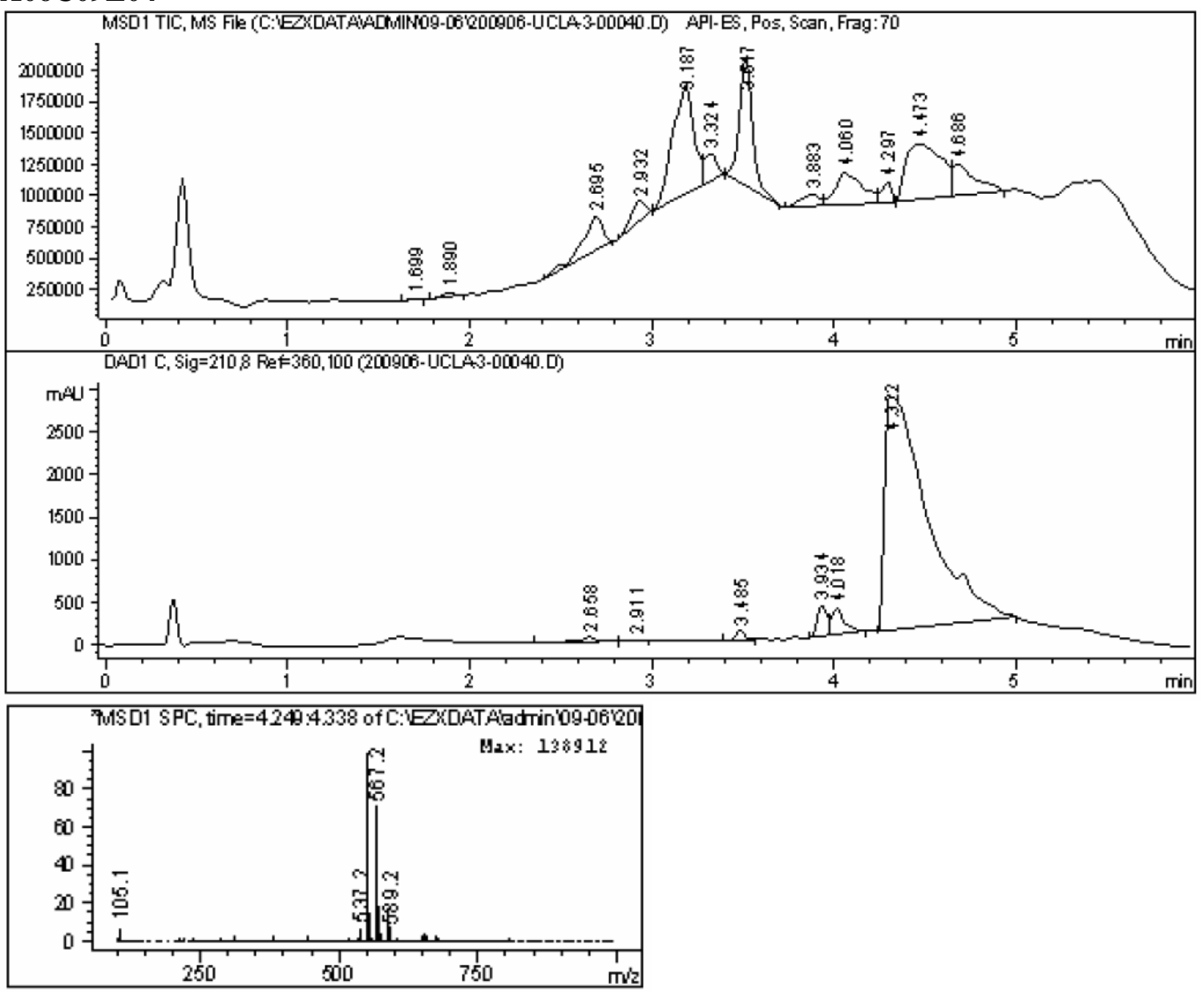


\section{A06C11E04}
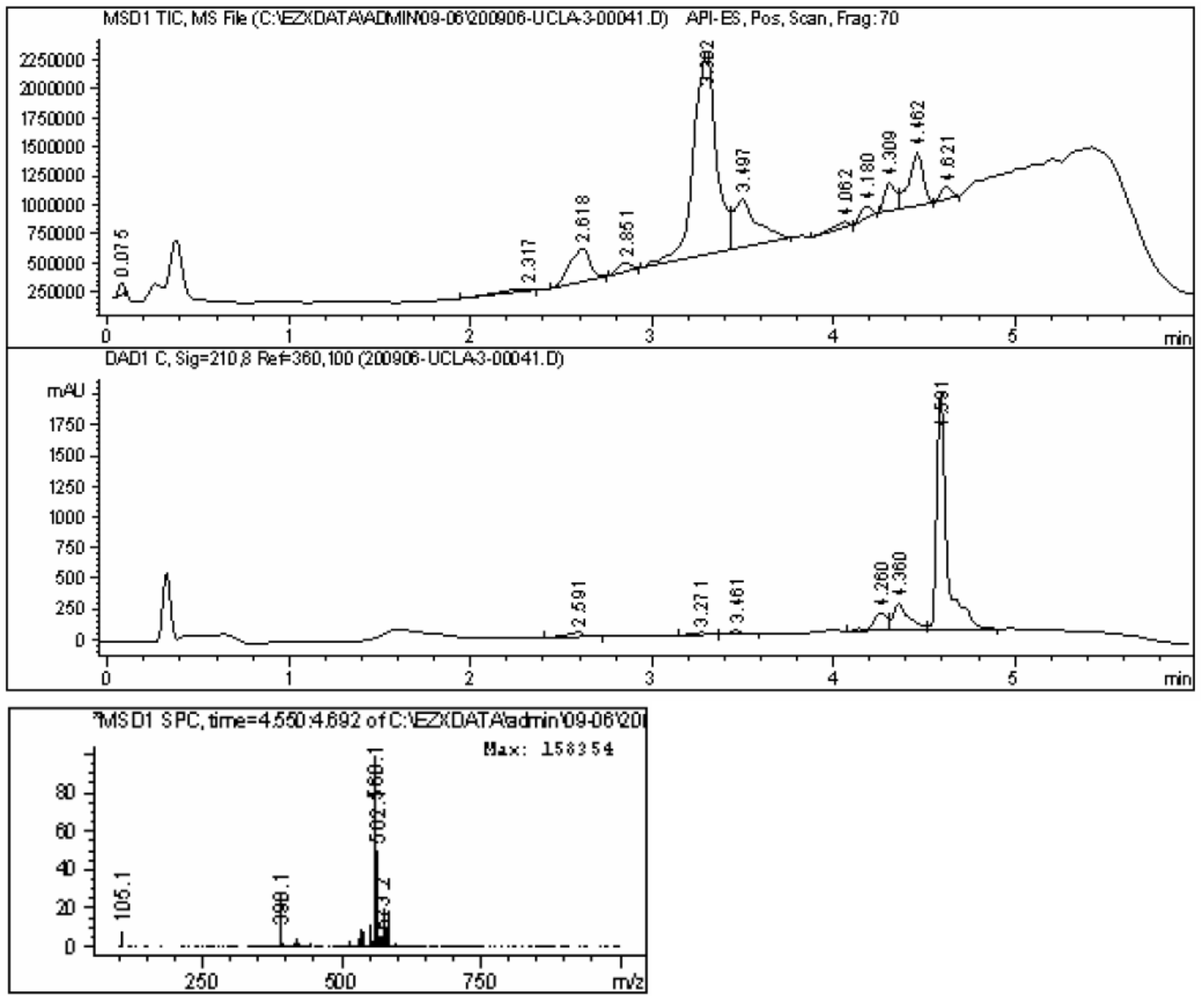


\section{A06C14E04}
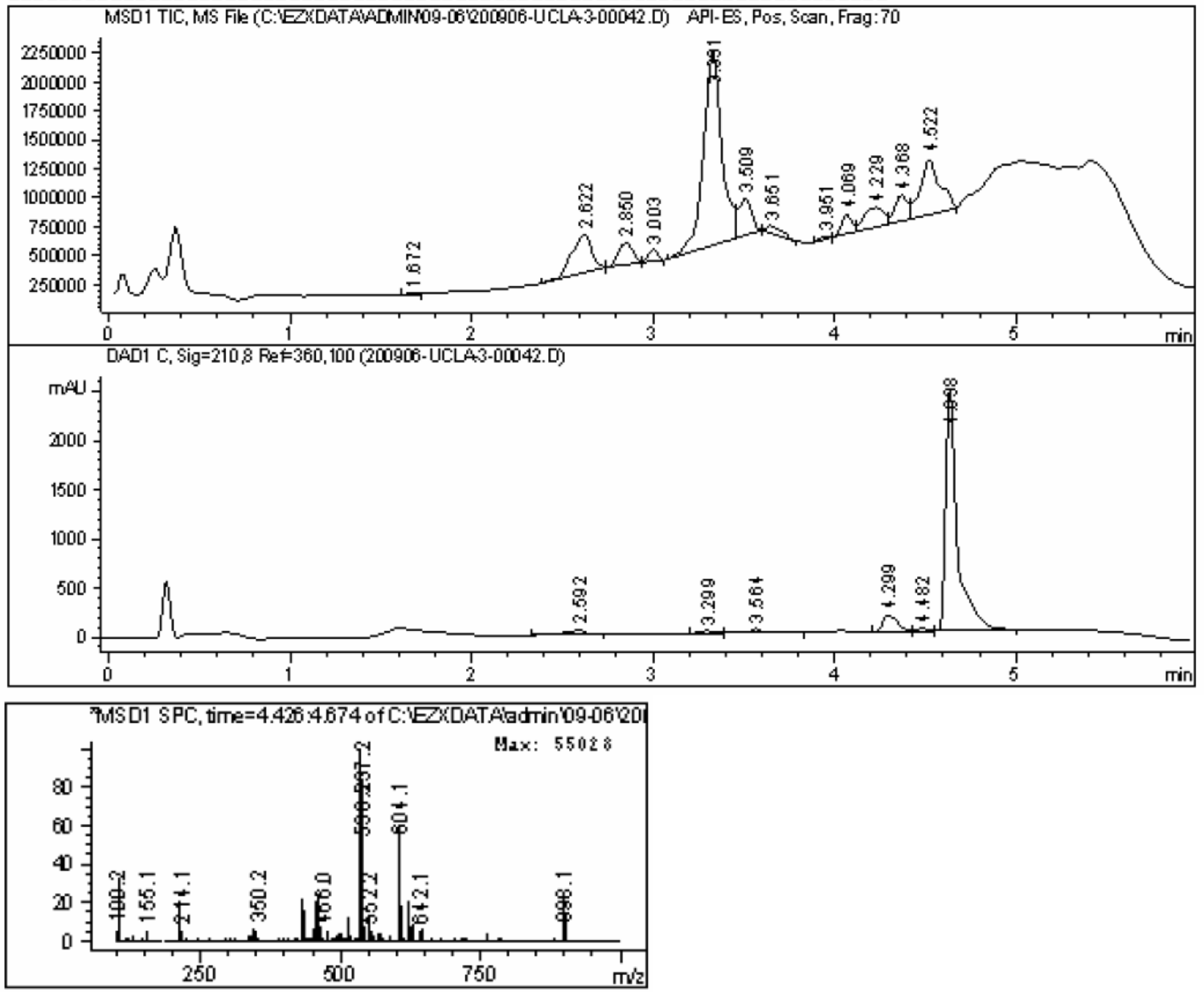


\section{A06C23E04}
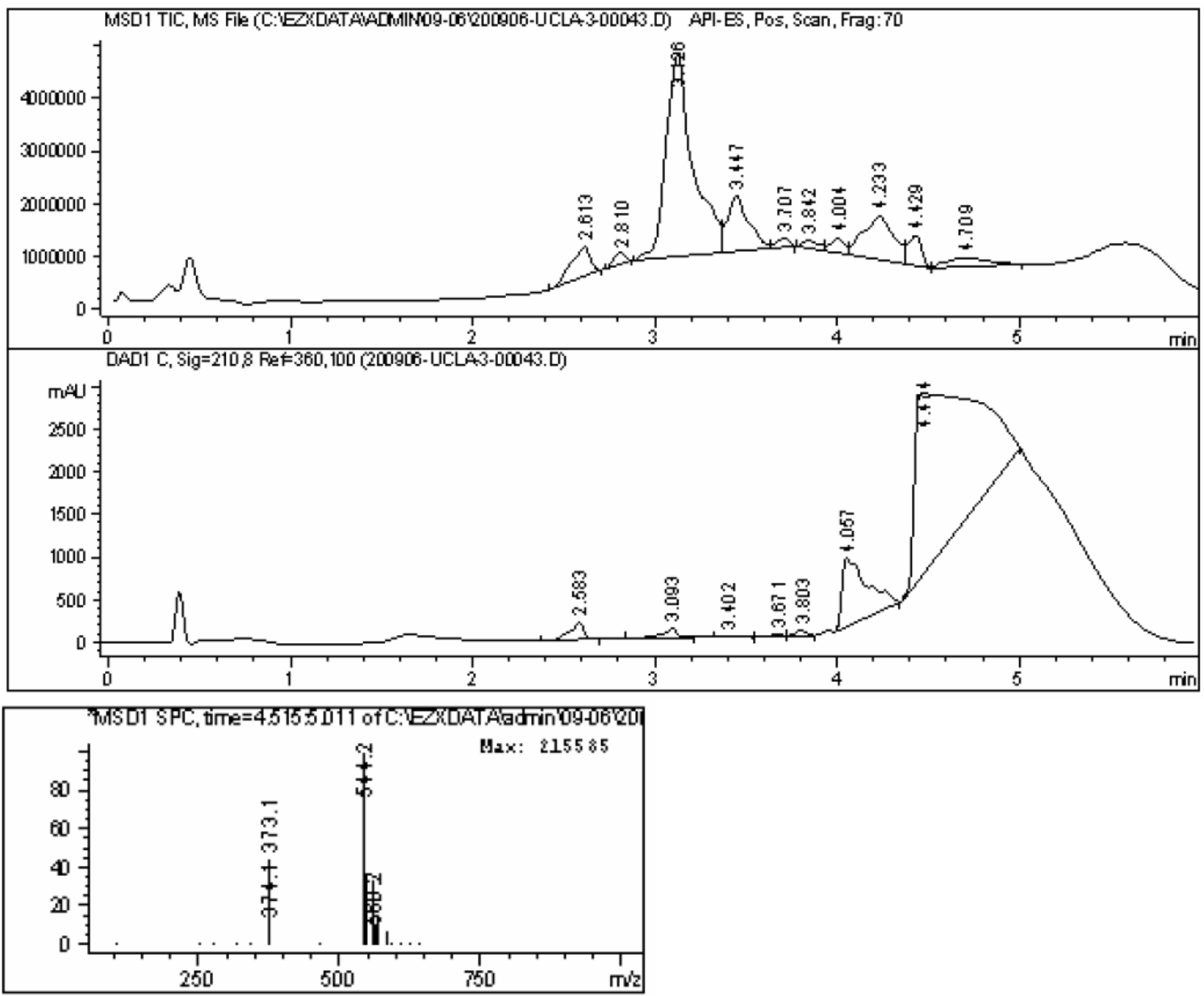


\section{A05C16E18}
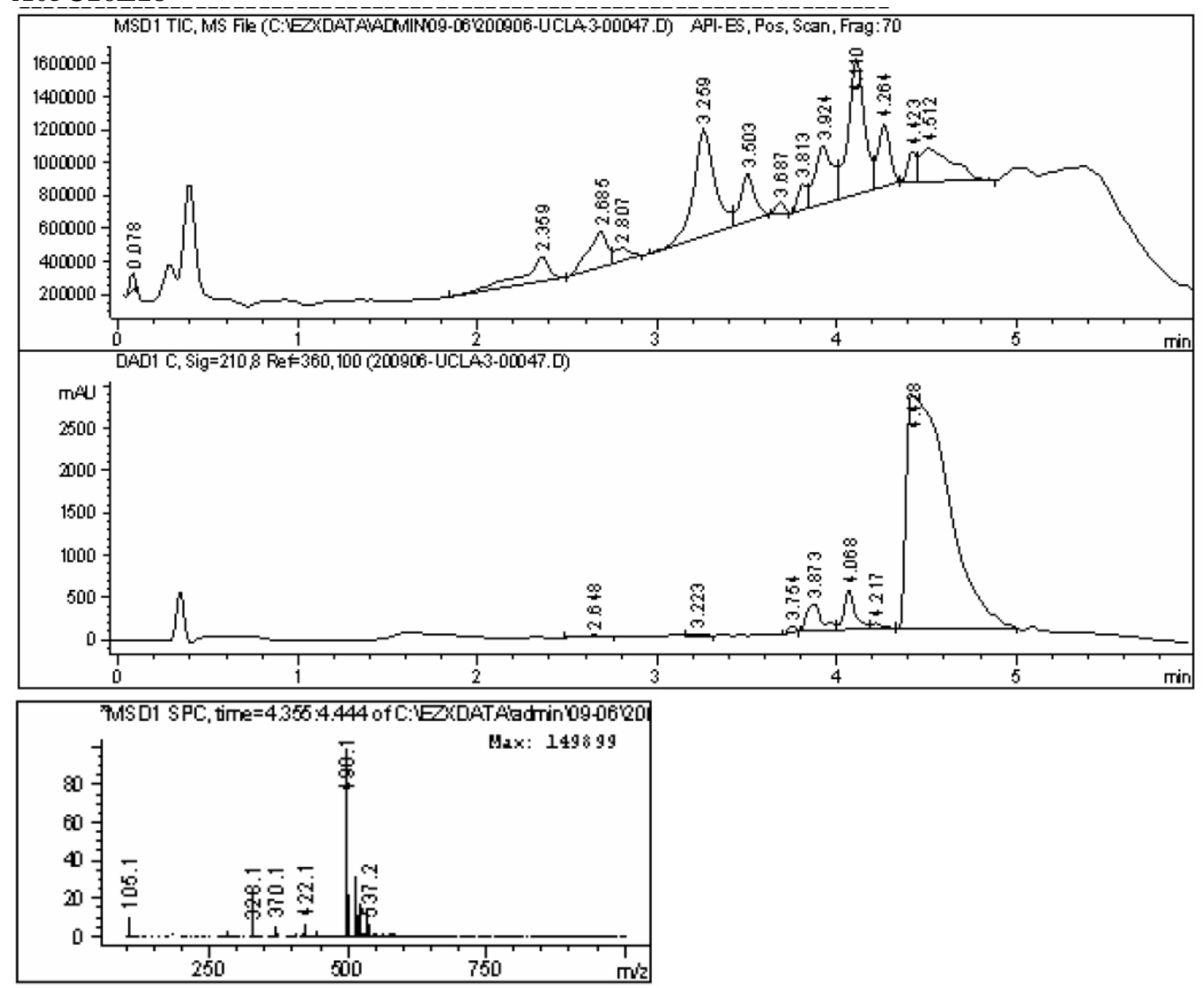


\section{A05C06E01}
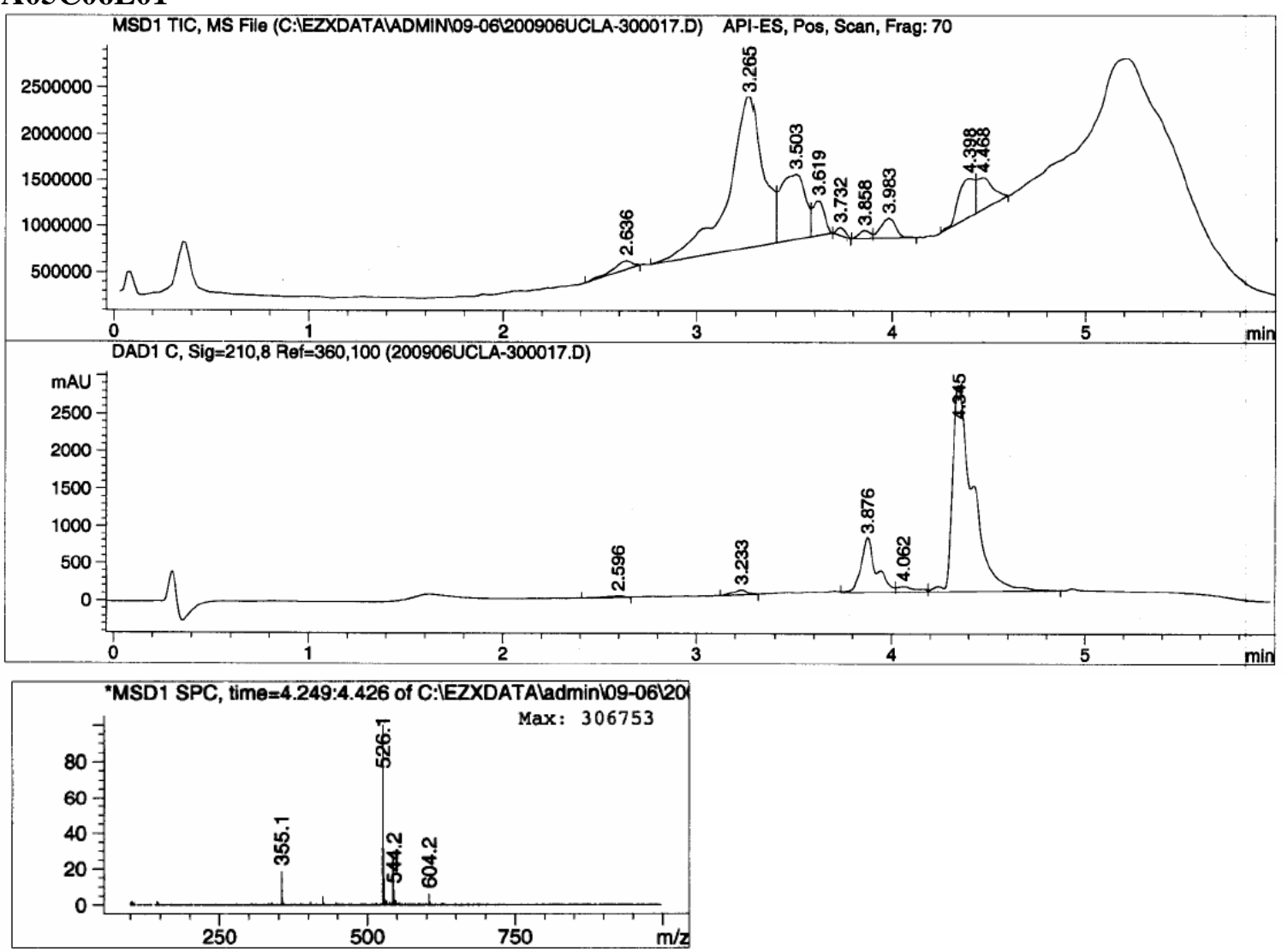


\section{A05C14E02}
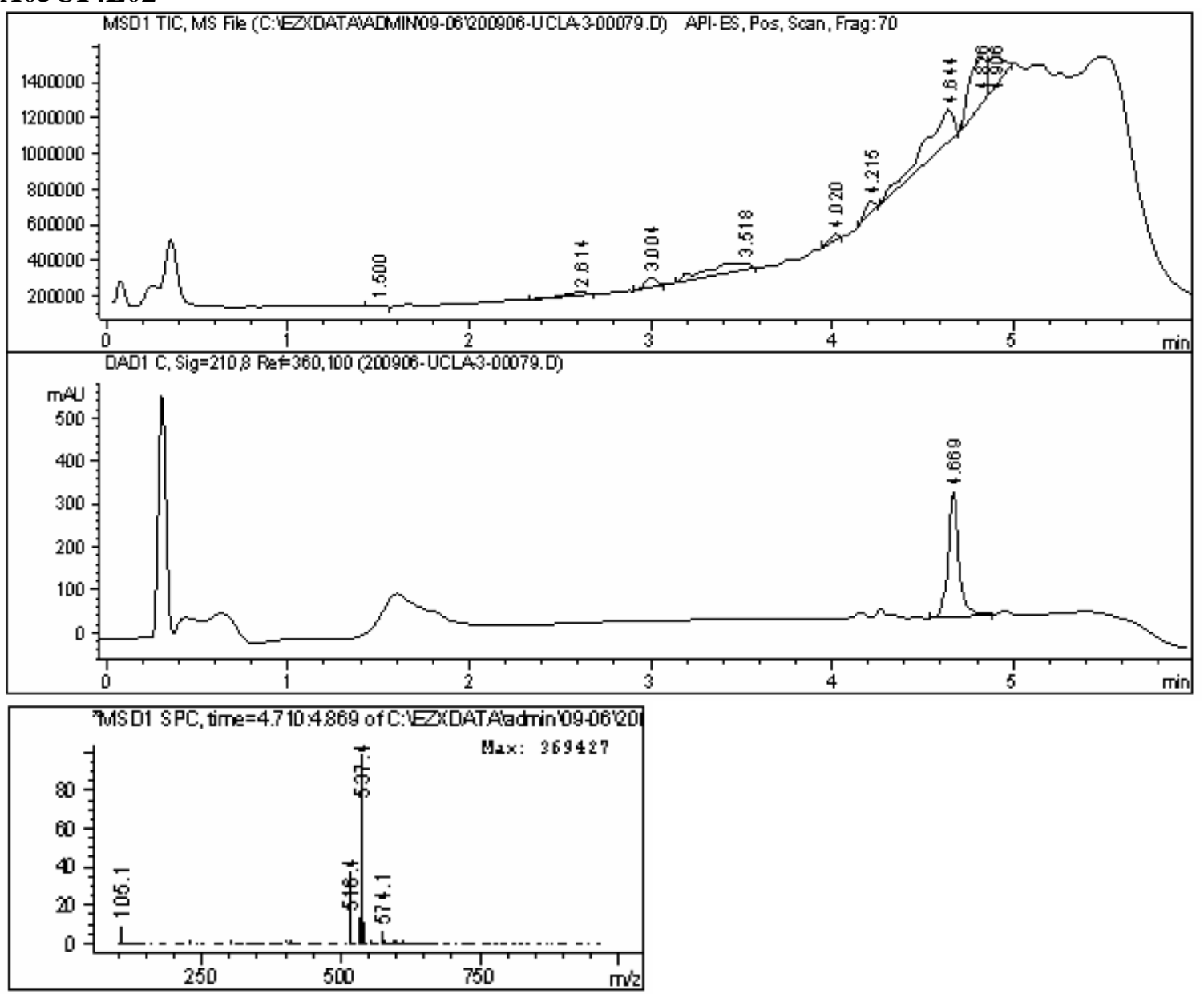


\section{A05C13E02}
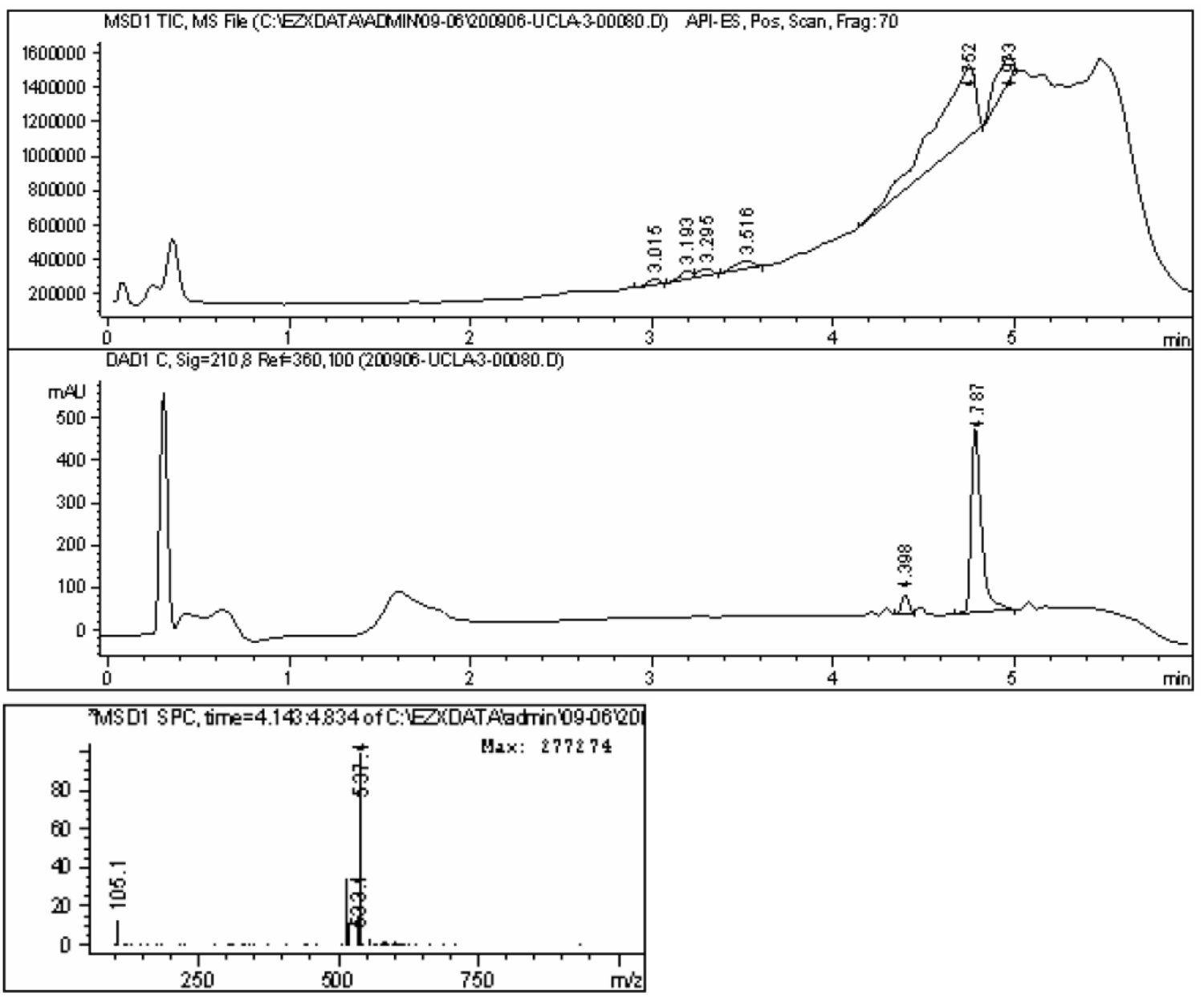


\section{A05C09E01}
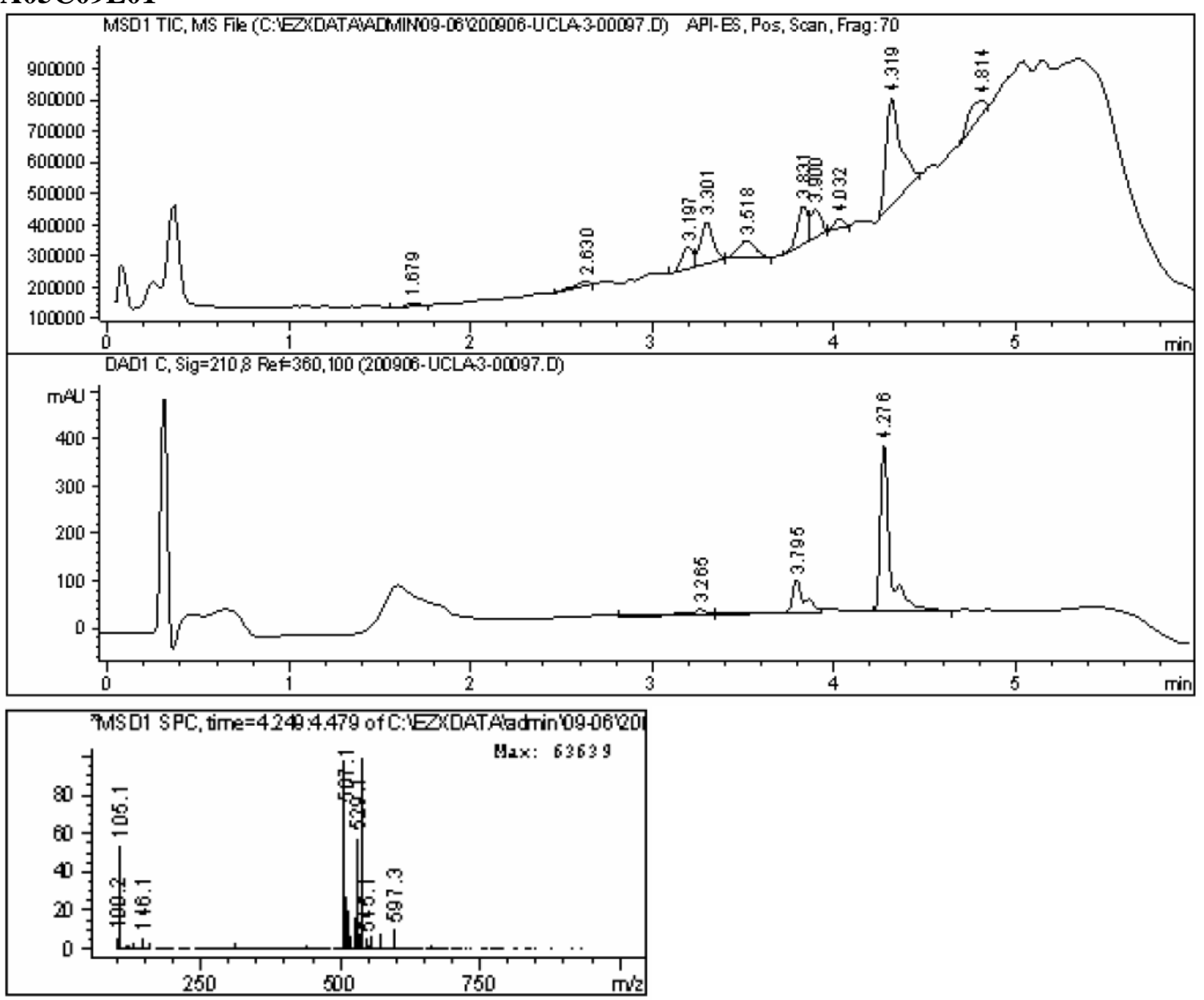


\section{A05C29E01}
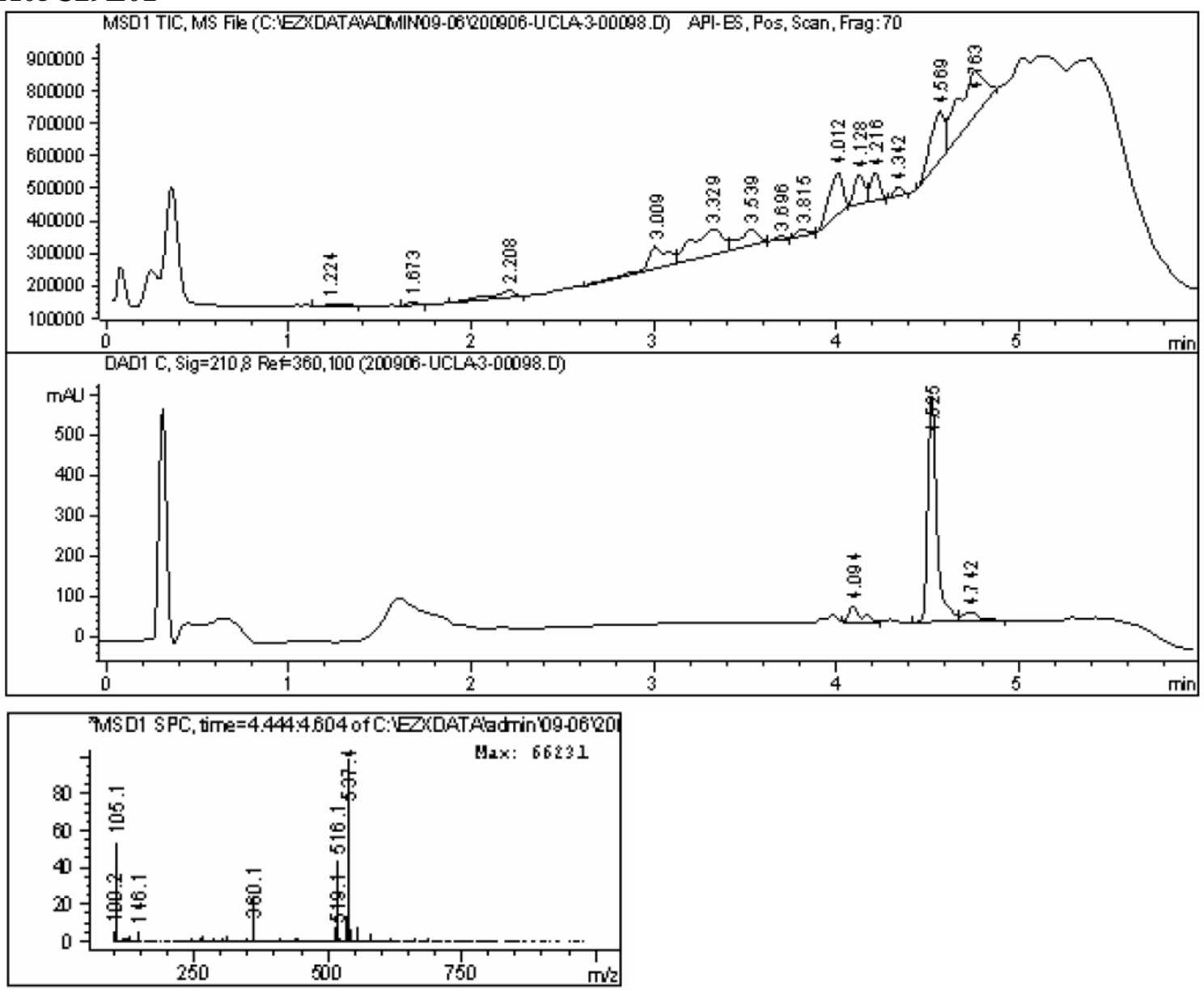


\section{A09C11E19}
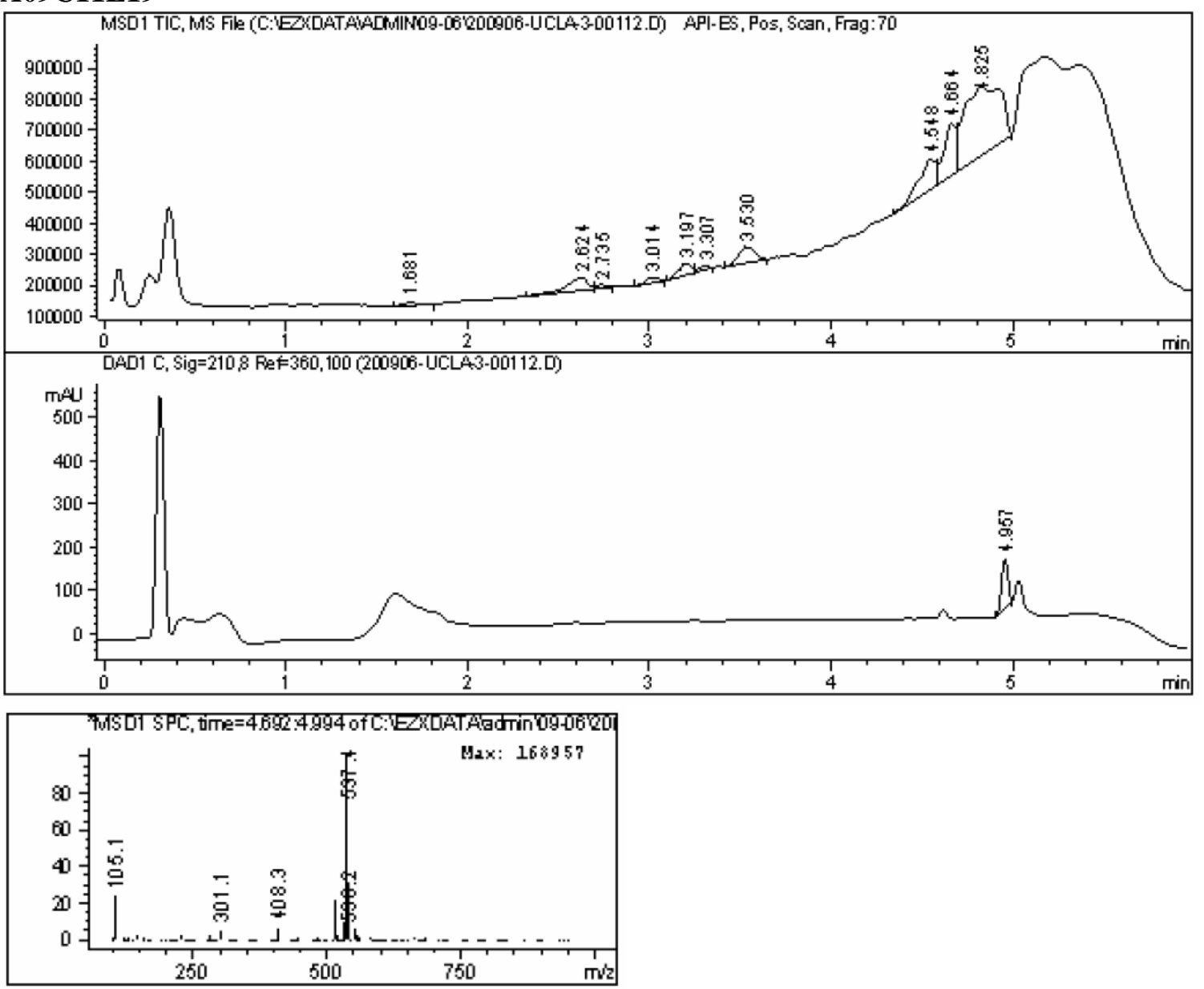


\section{A08C14E01}
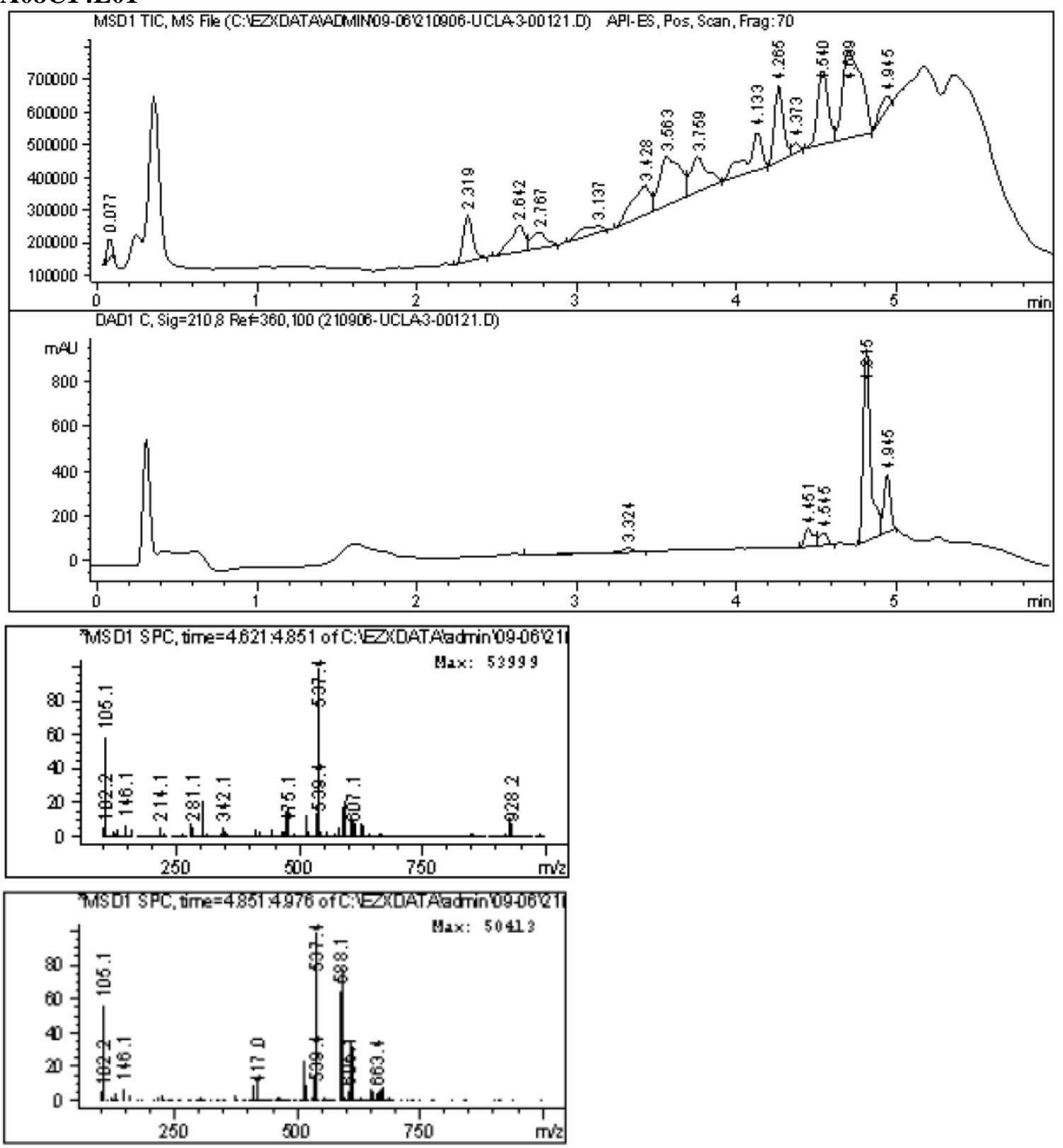


\section{A05C11E04}

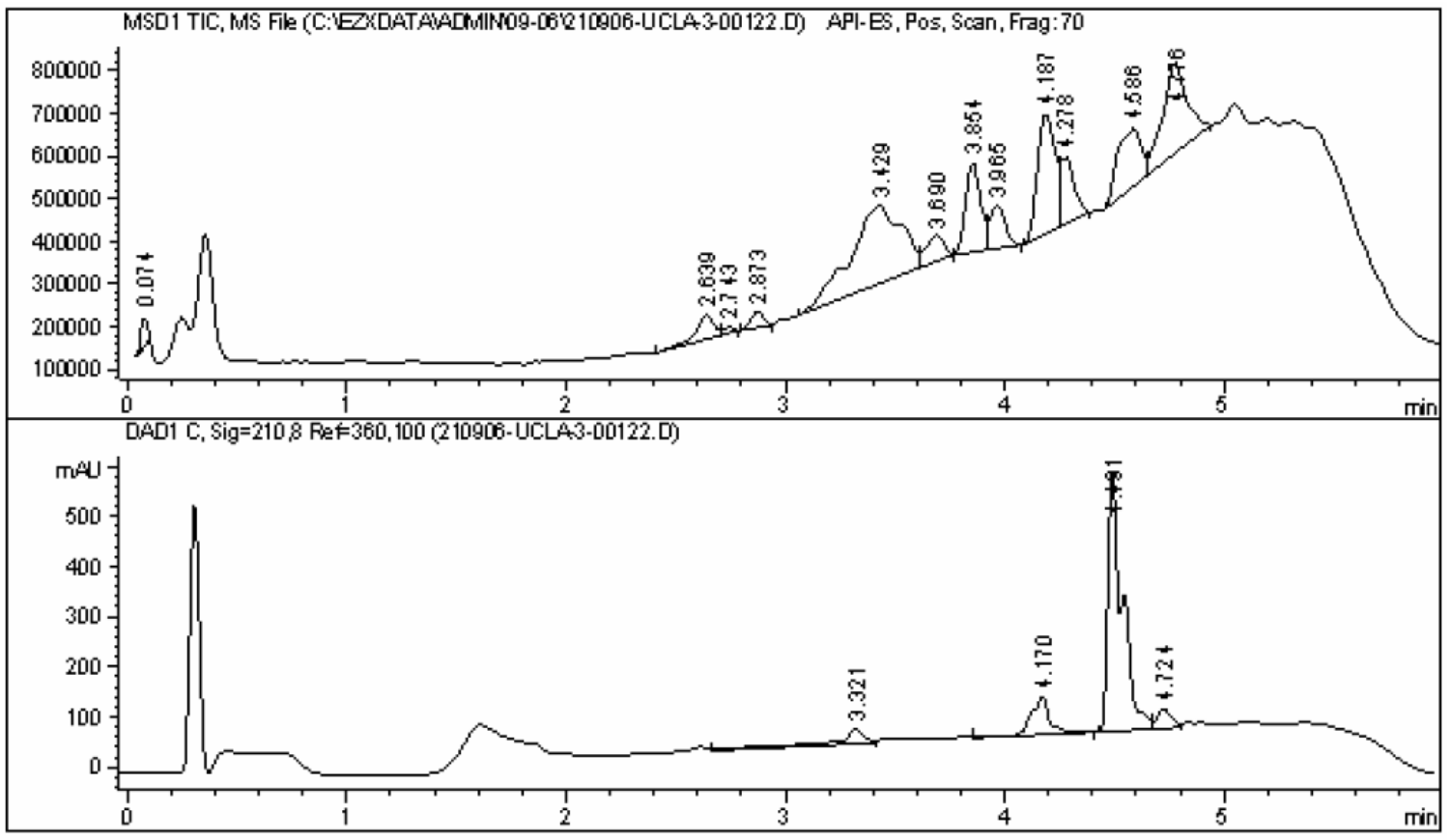

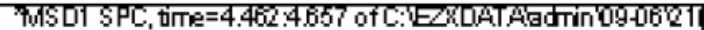

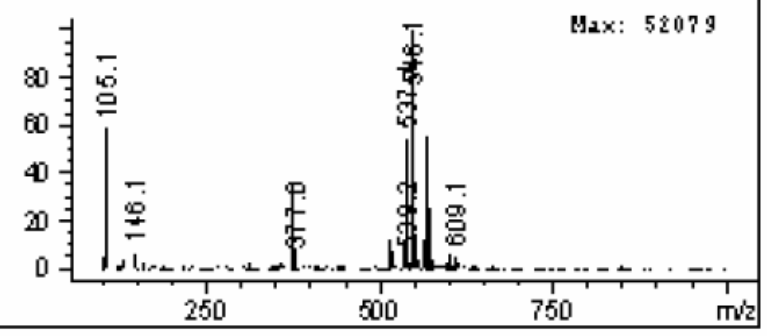




\section{A06C13E01}
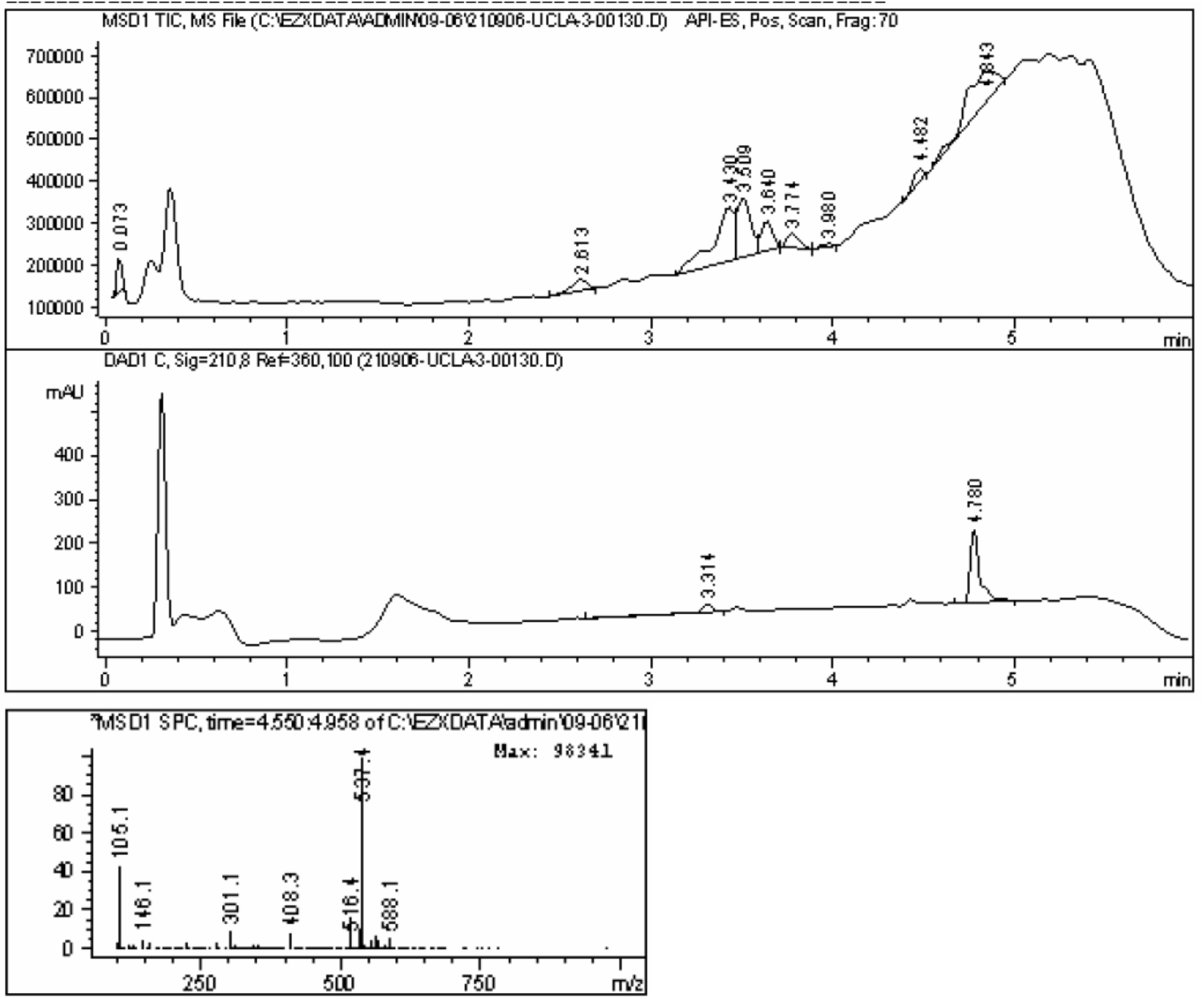

Combonent 2: Peak at Scan 271.2. Tov ions are 564586566 


\section{A06C11E18}
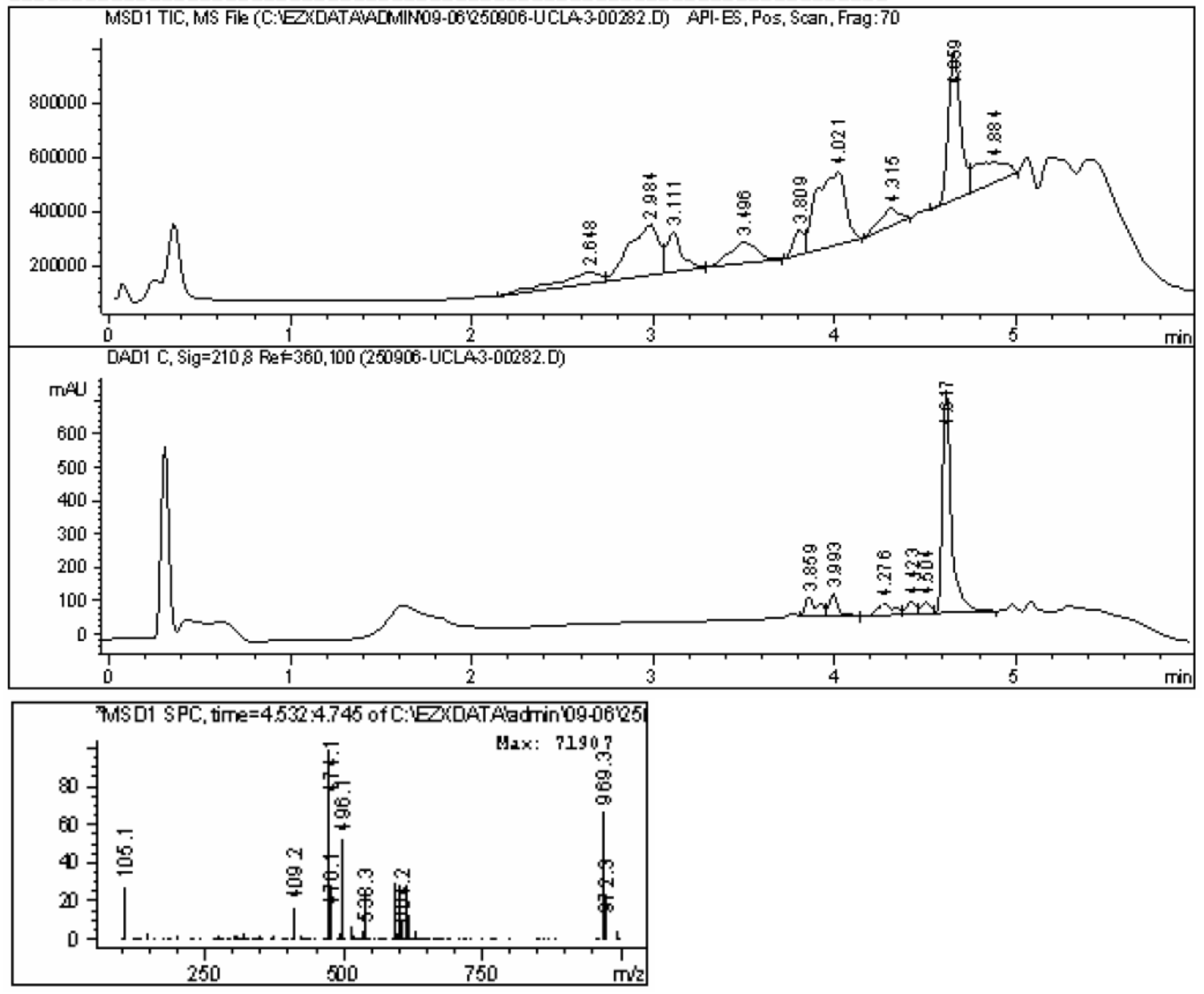


\section{A06C09E28}

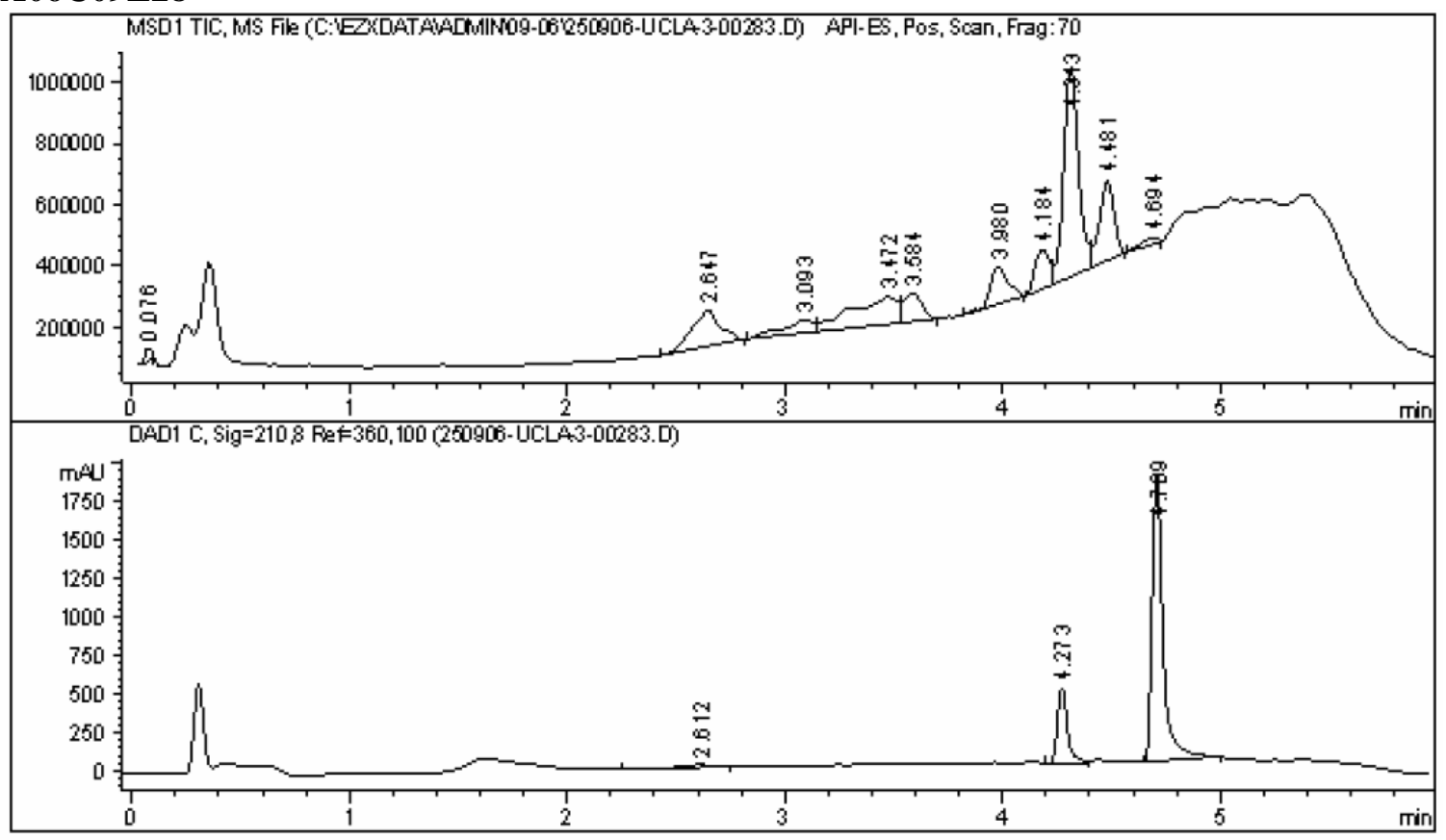

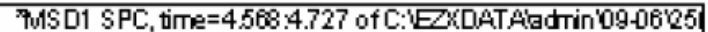

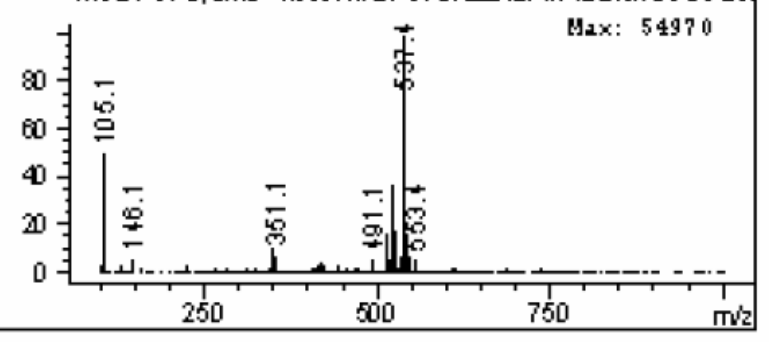




\section{A07C11E29}
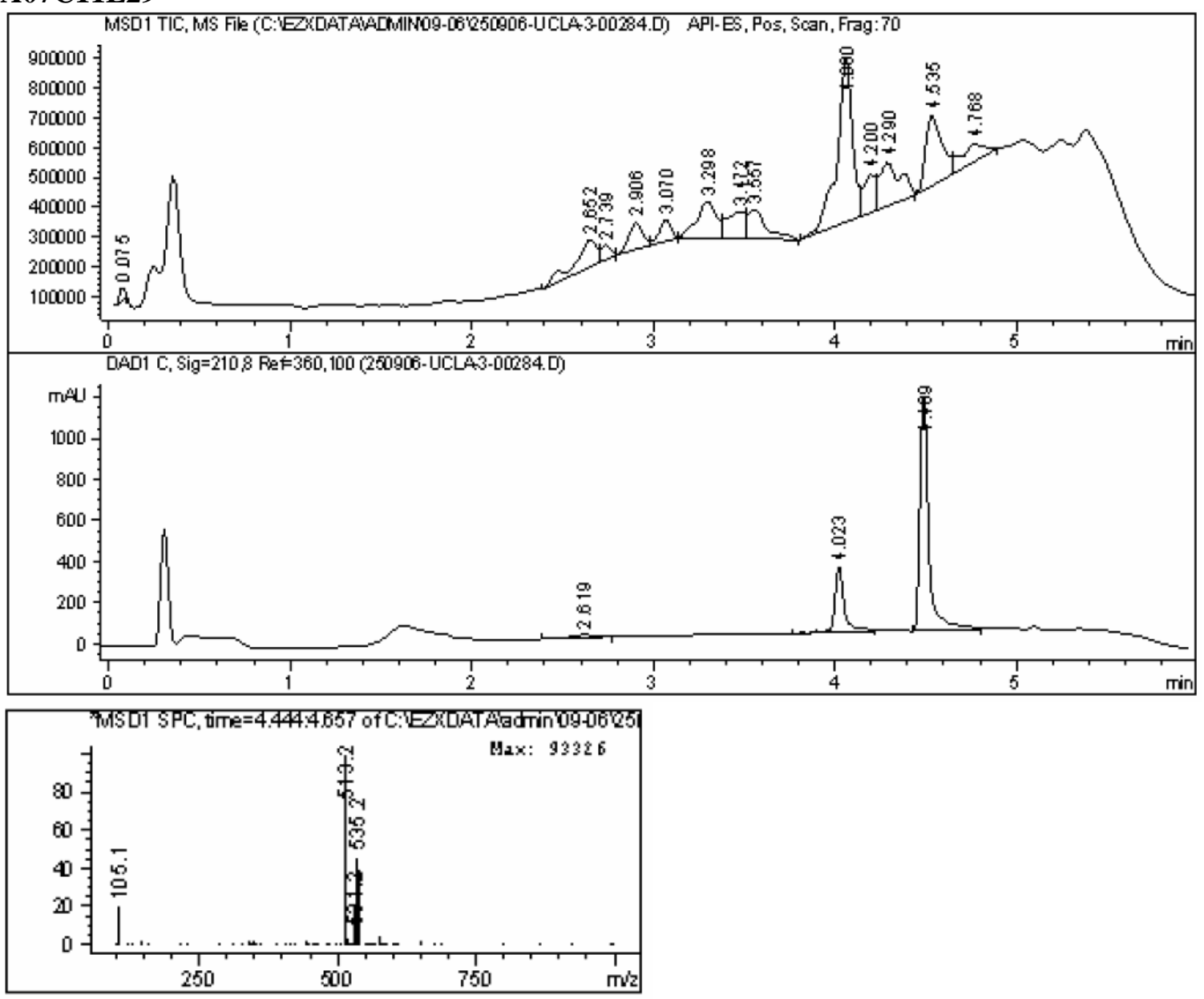


\section{A07C03E28}
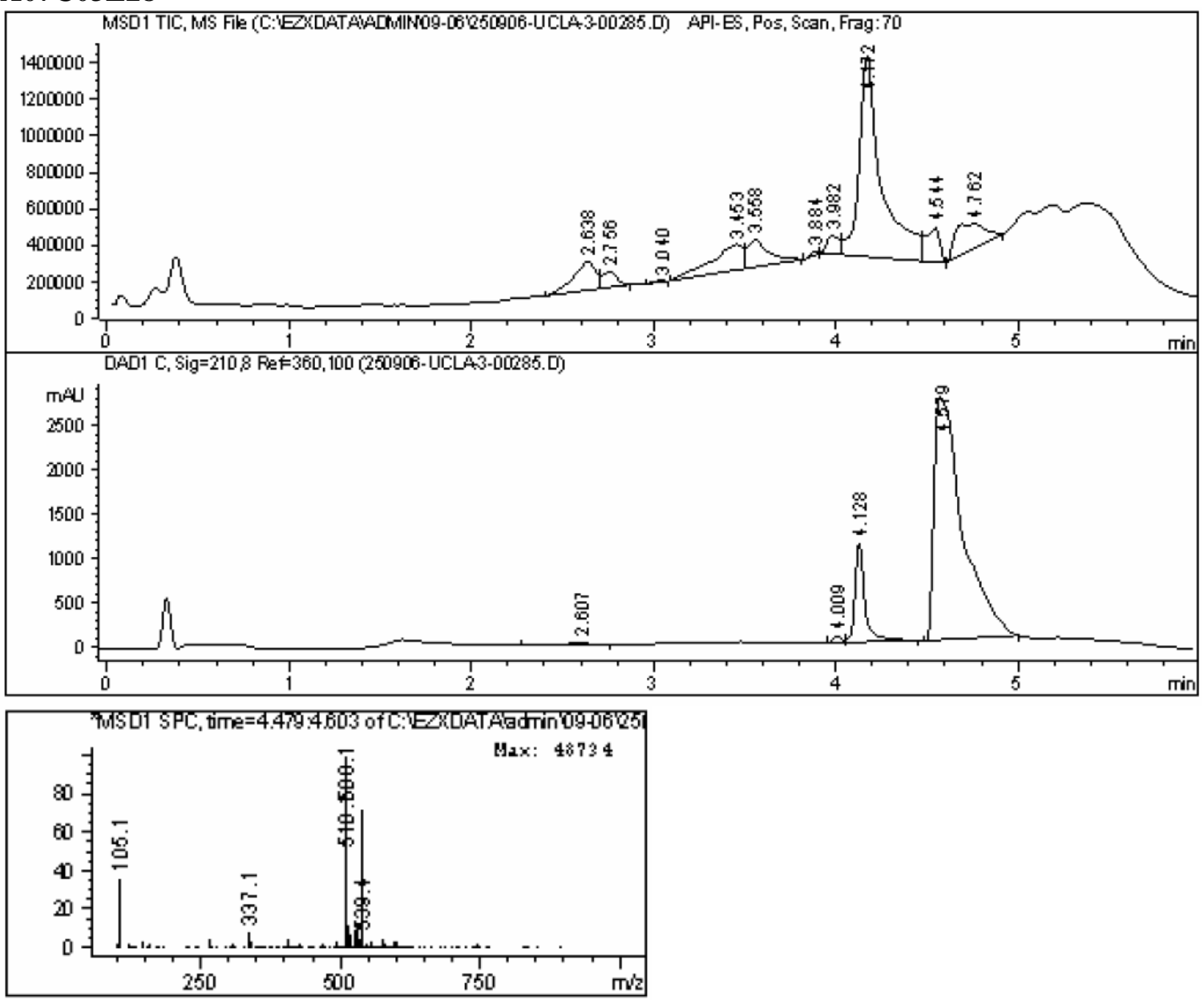

Combonent 2: Peak at Scan 254.2. Tov ions are 516 


\section{A05C23E29}
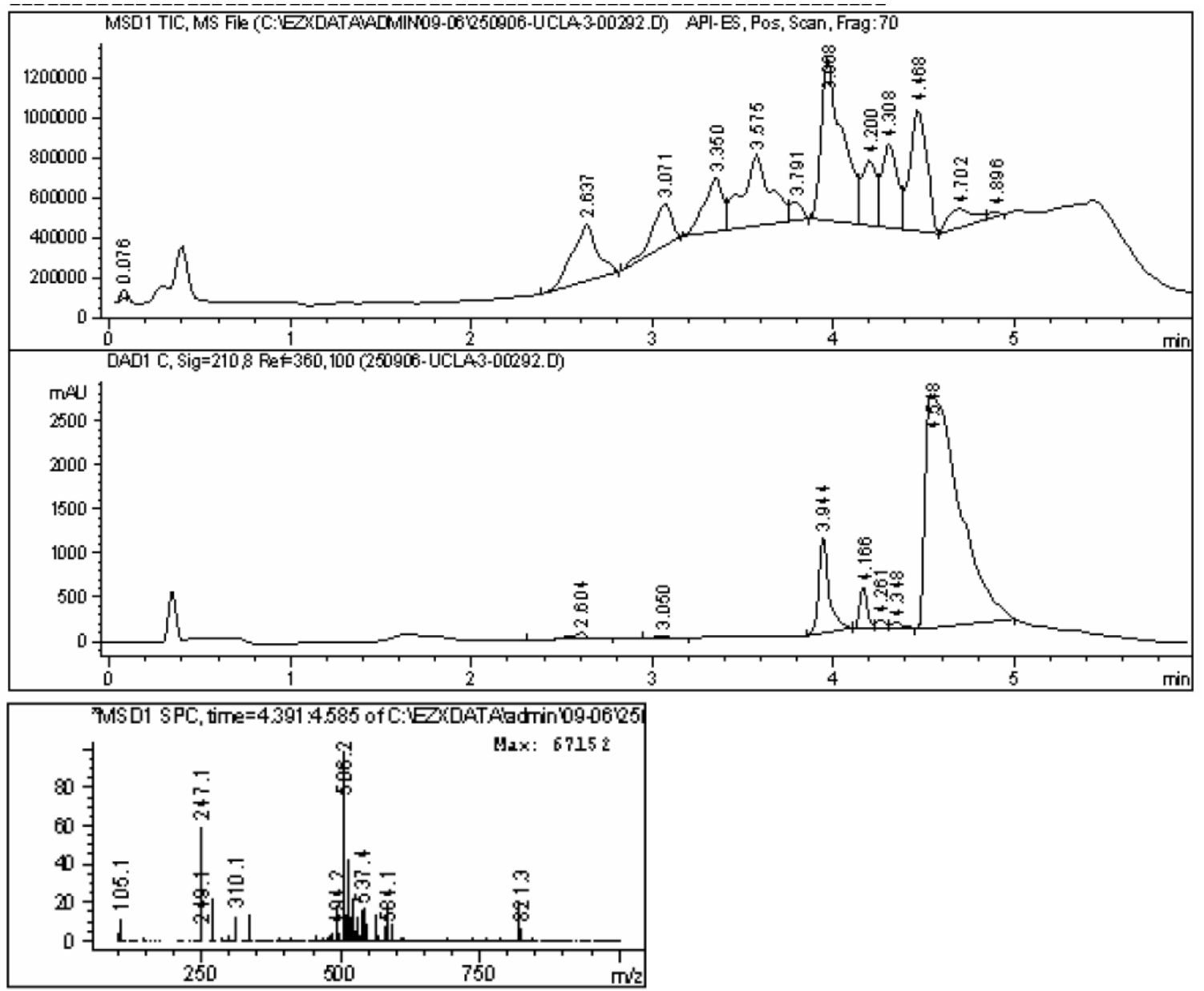


\section{A06C09E29}
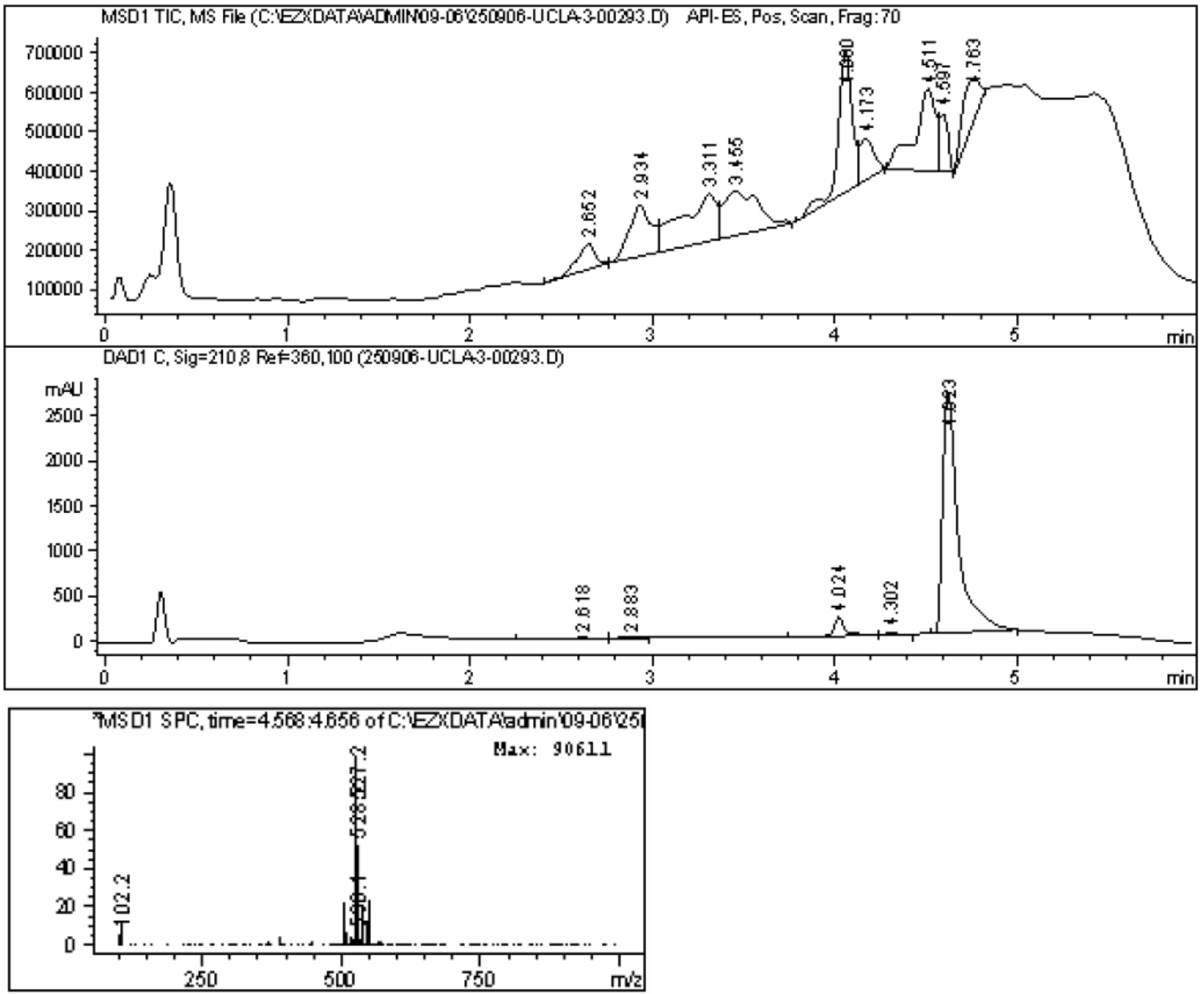


\section{A06C11E32}

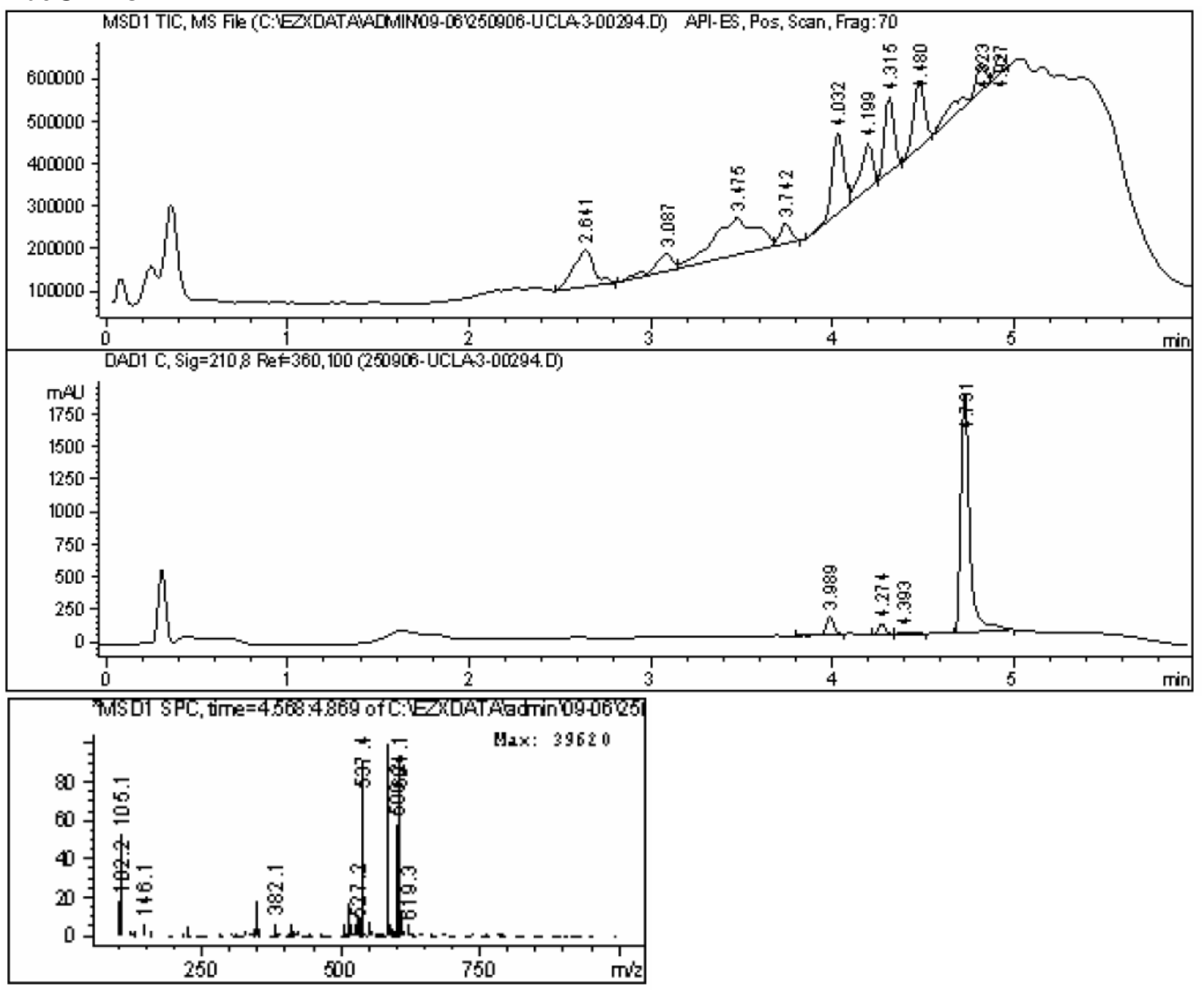




\section{A06C14E32}
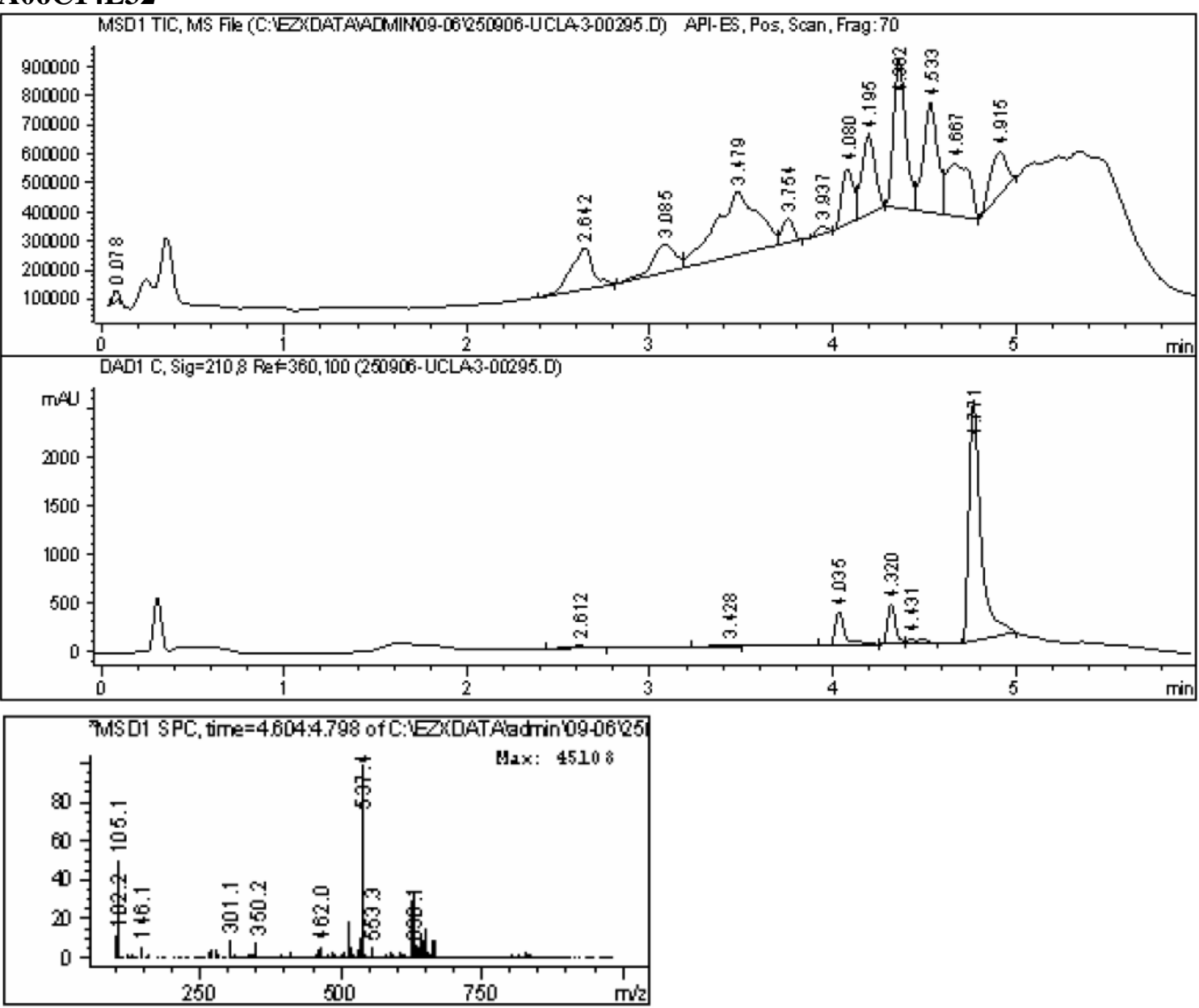

Combonent 4: Peak at Scan 269.5. Tov ions are 648 


\section{A06C16E16}
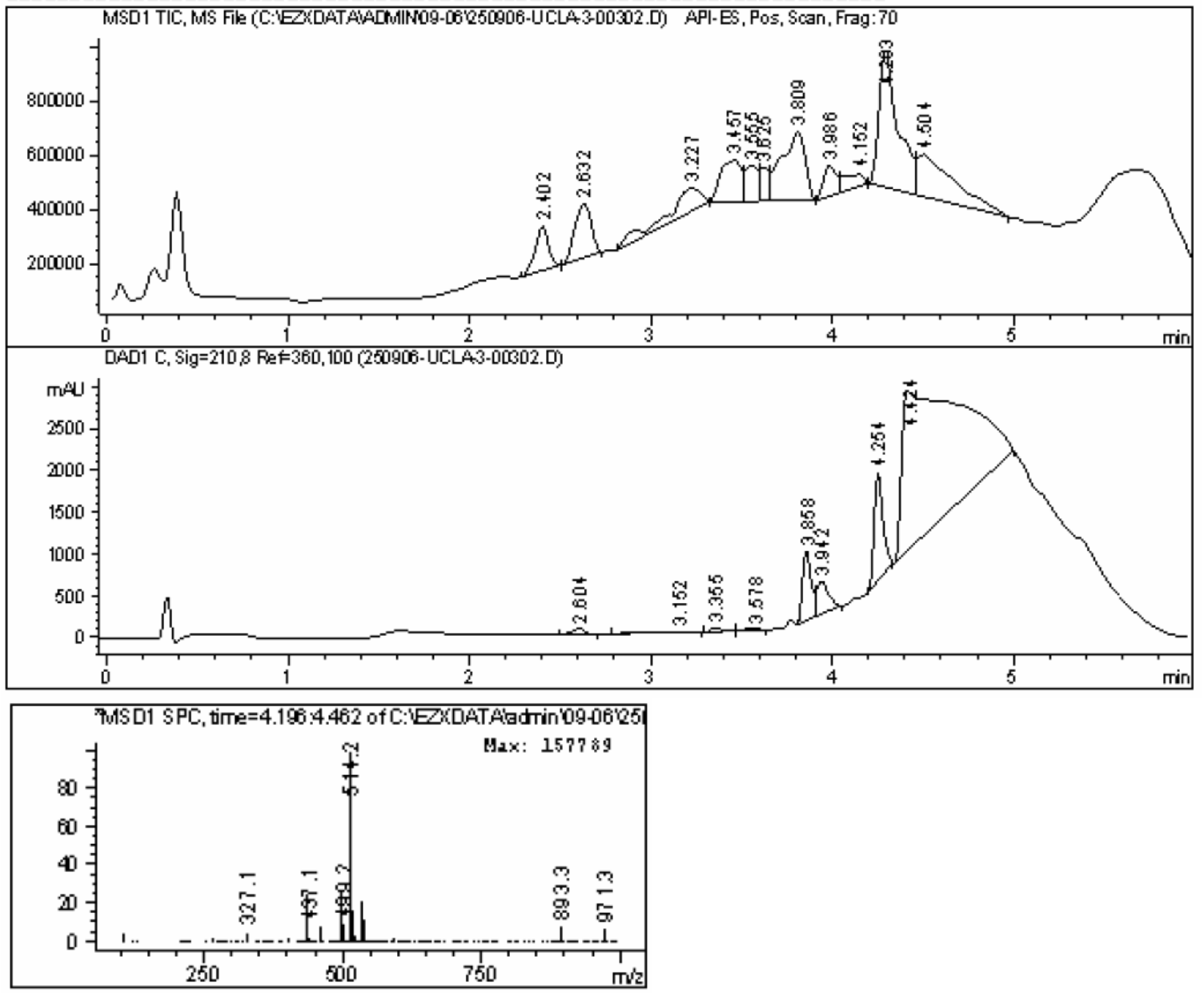


\section{A05C14E16}
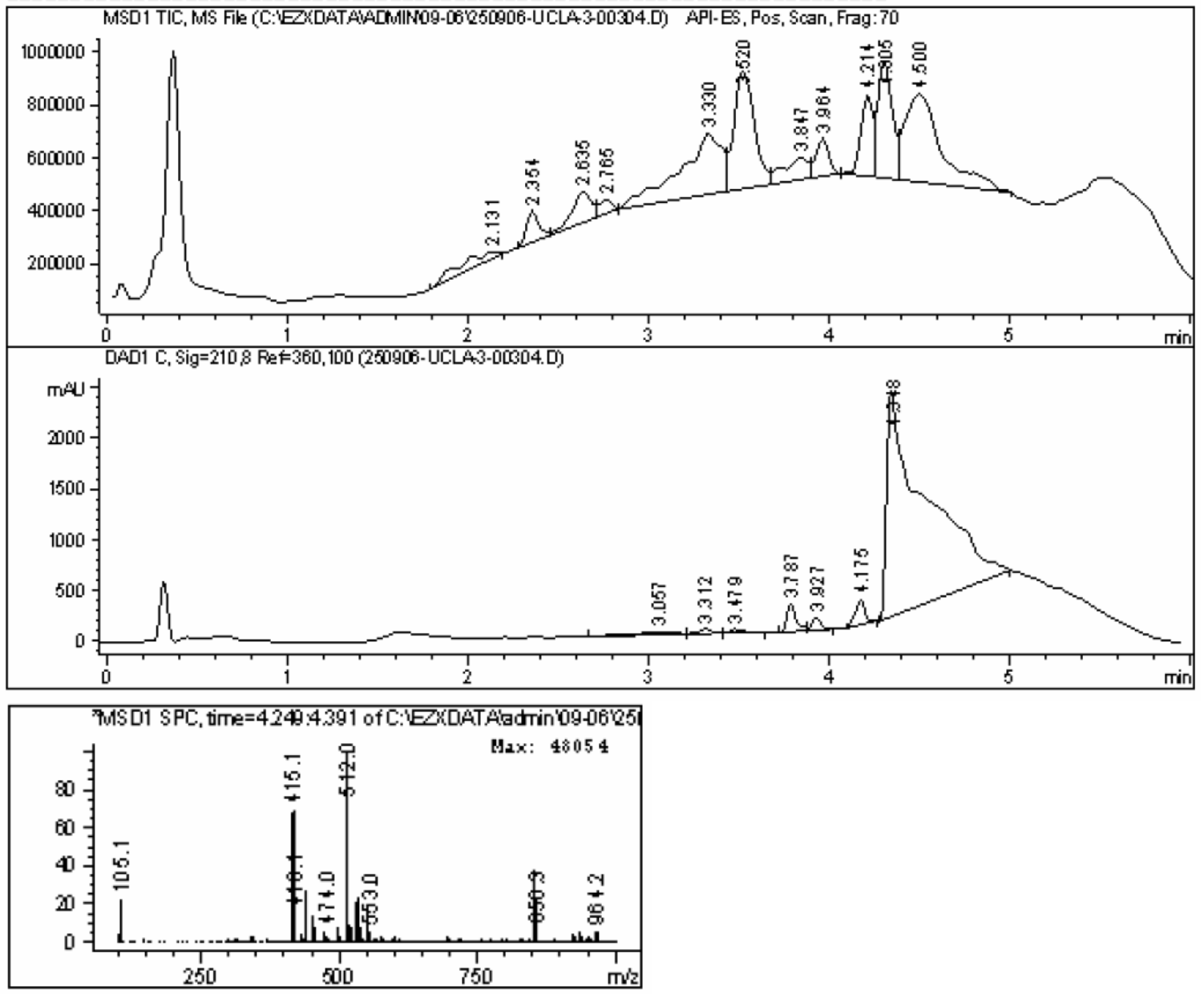


\section{A05C04E16}
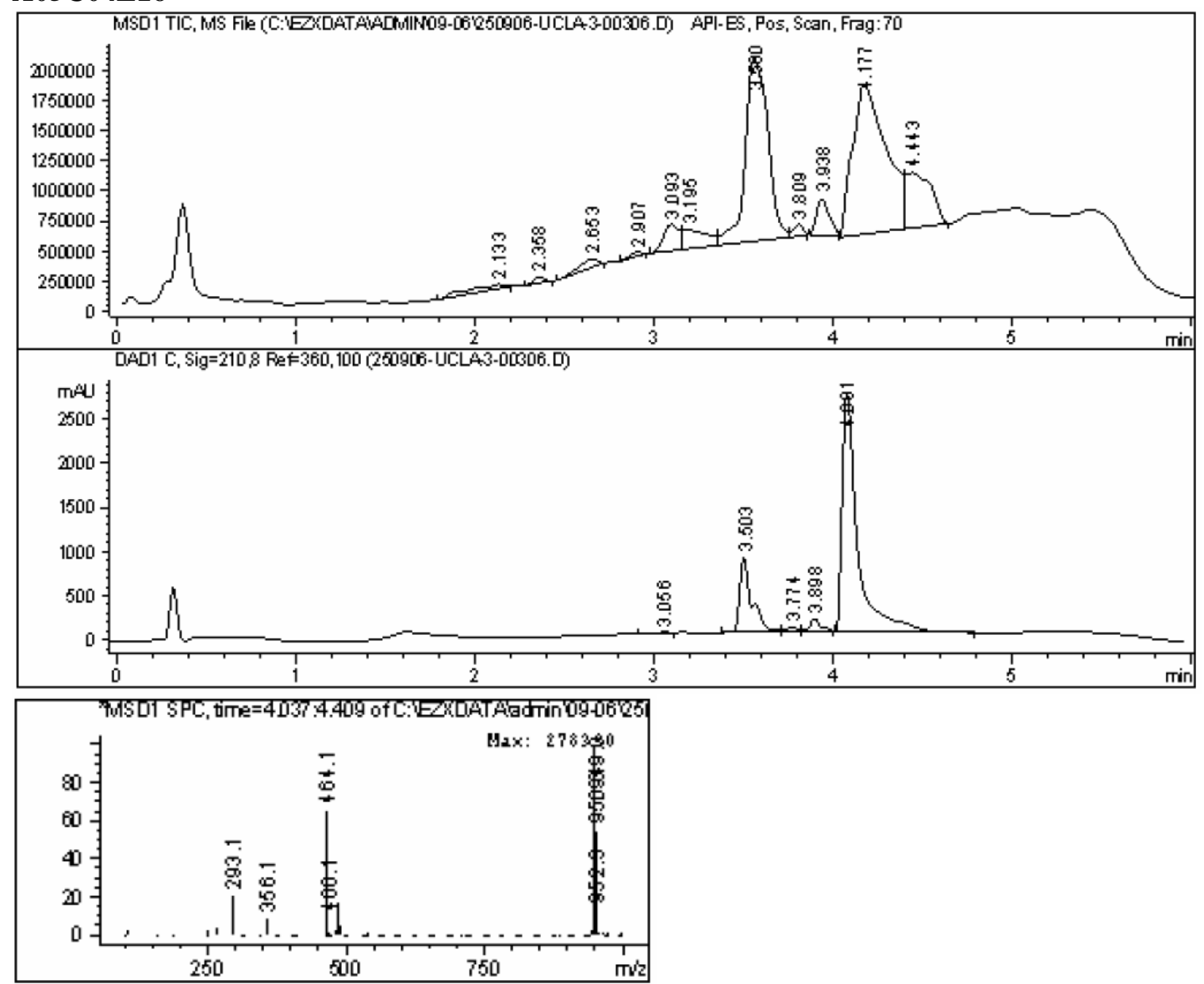


\section{A06C09E17}

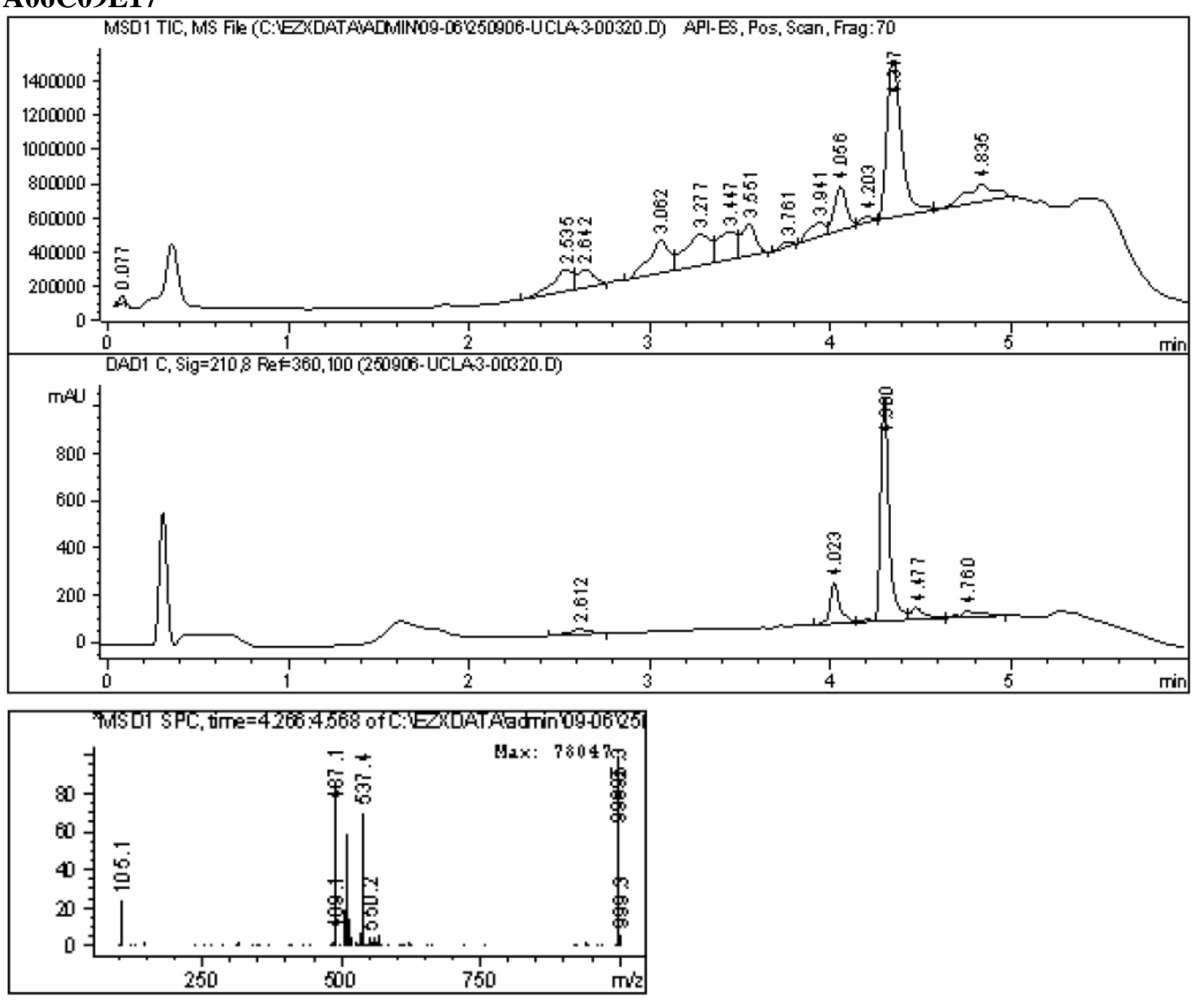




\section{A06C10E17}
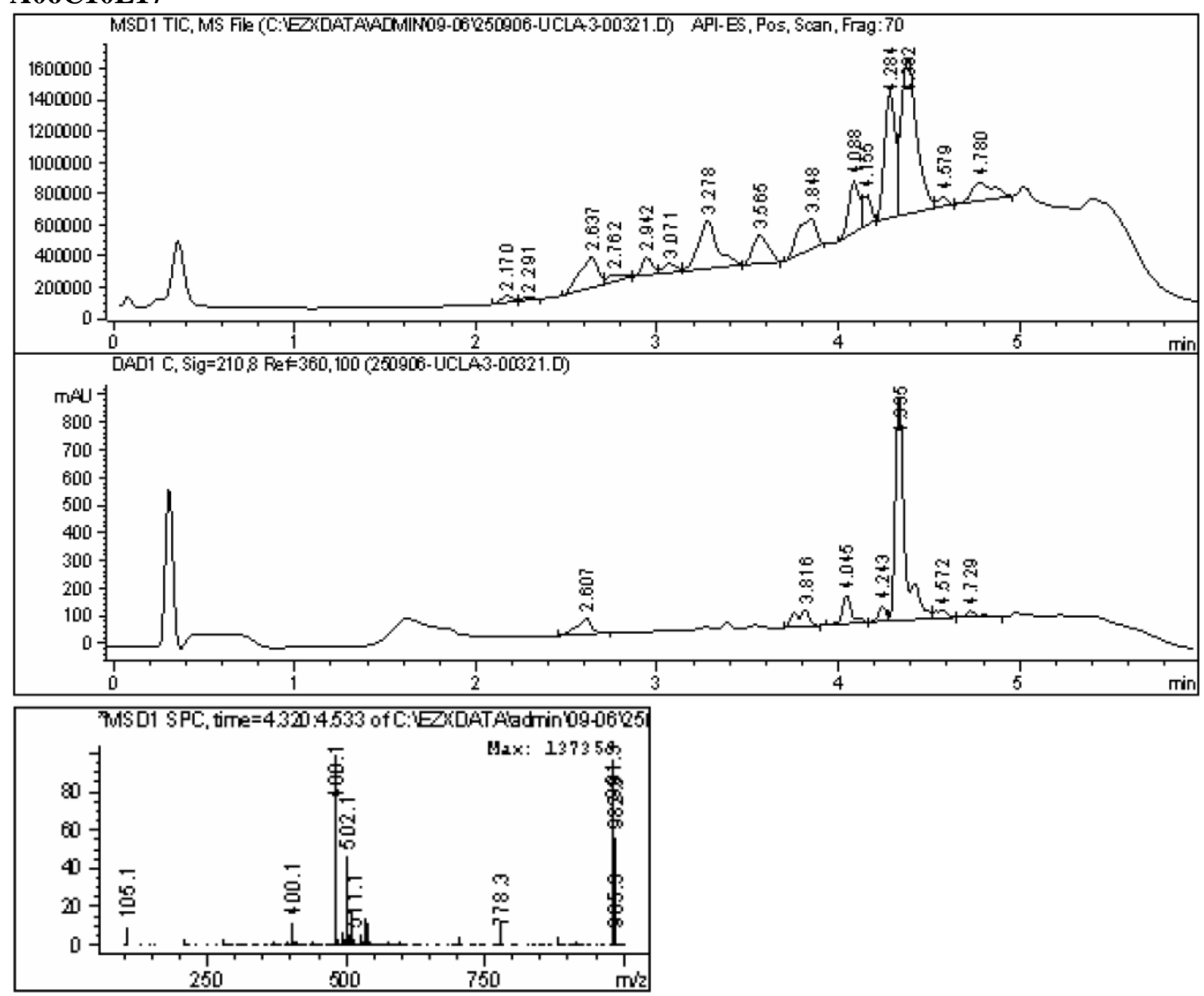


\section{A05C05E01}
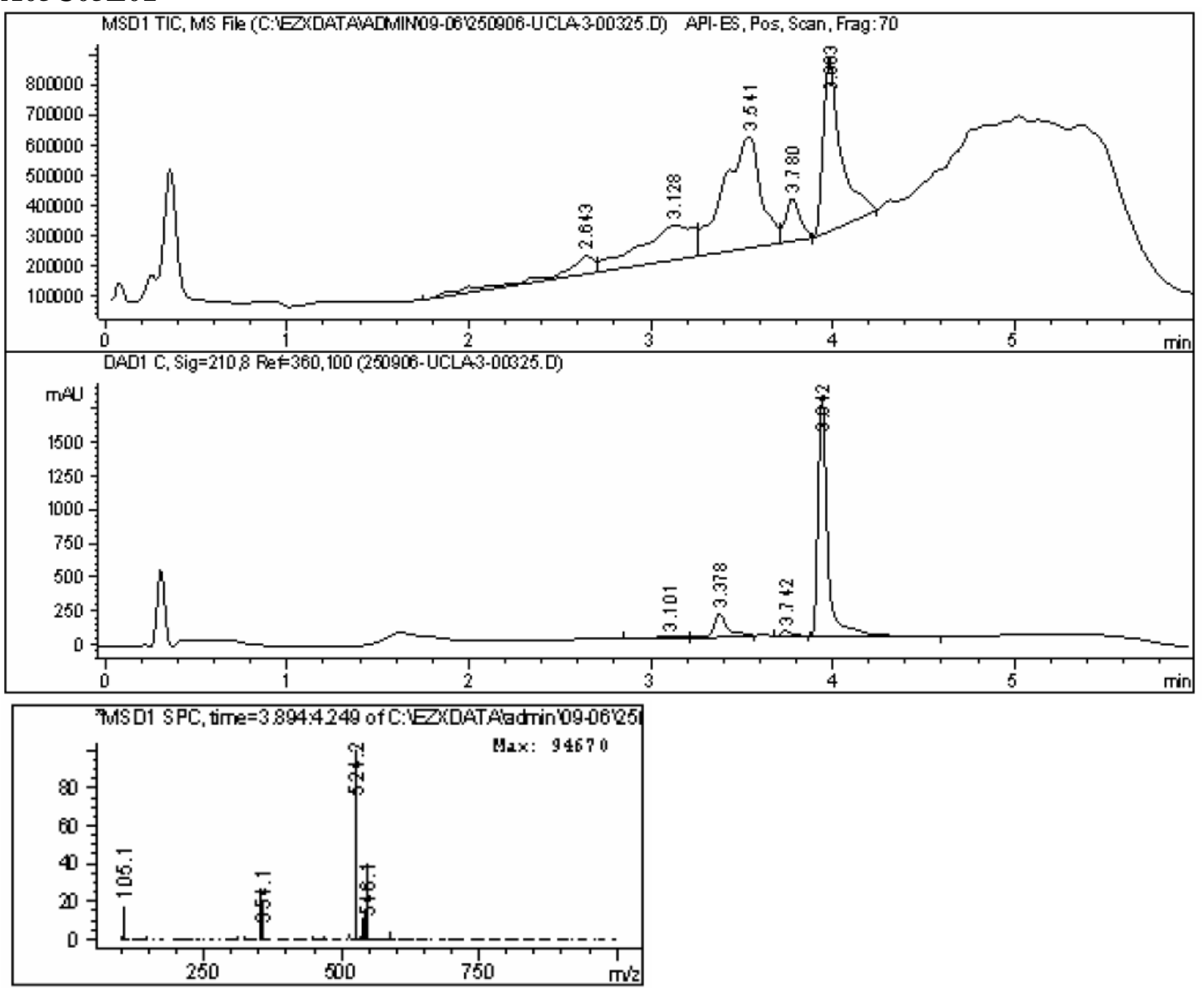


\section{A06C09E23}
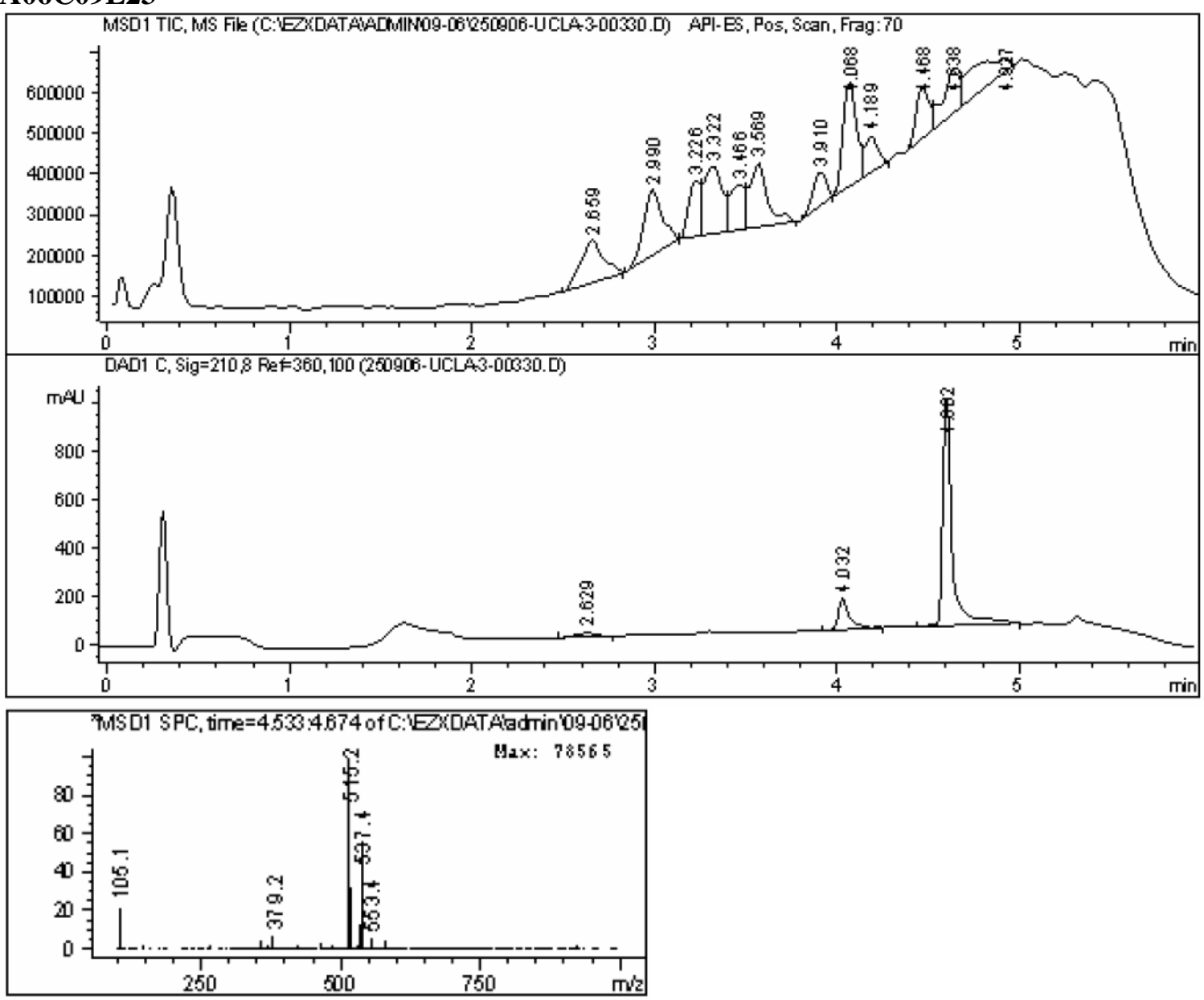


\section{A08C09E20}
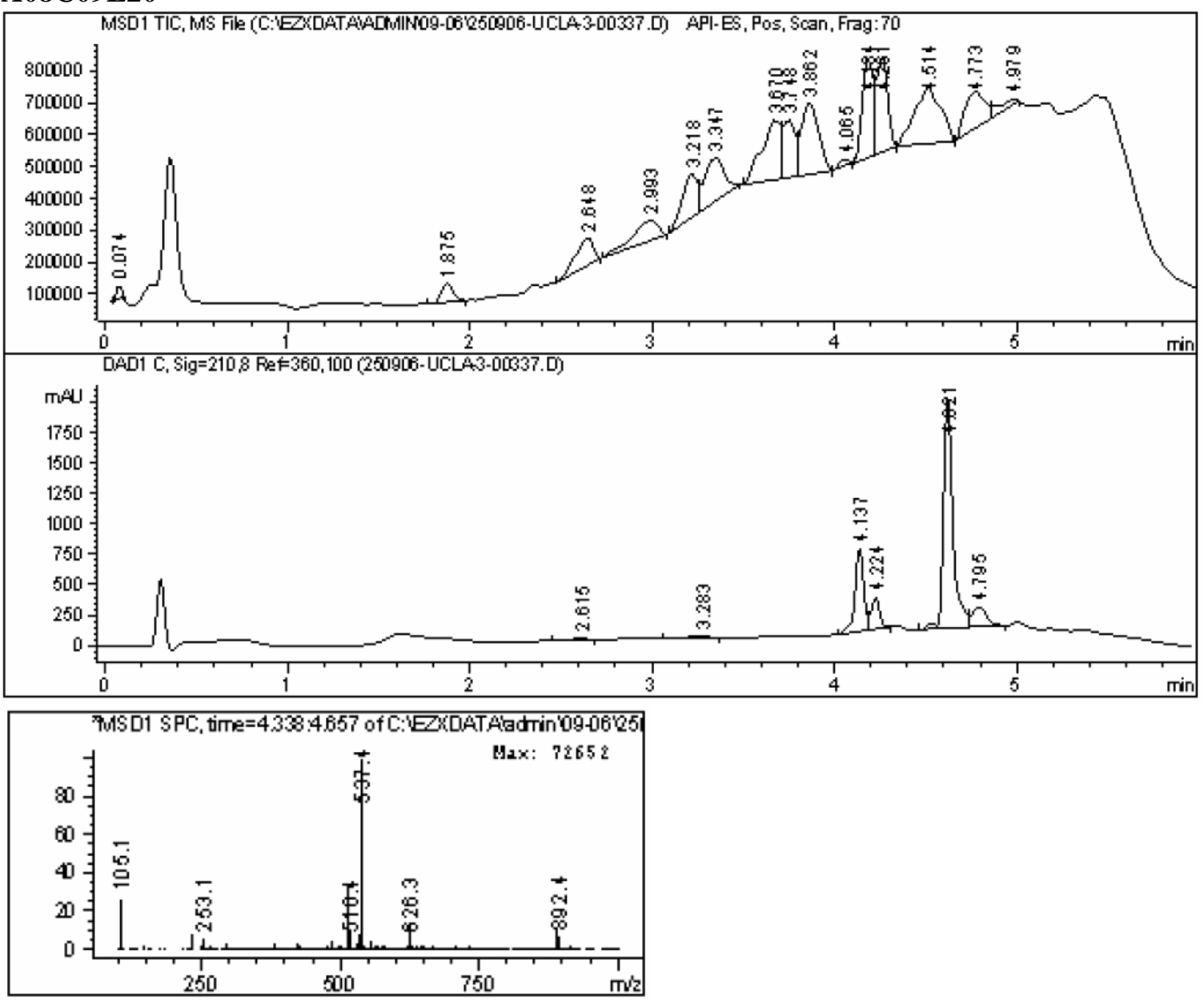


\section{A05C11E20}

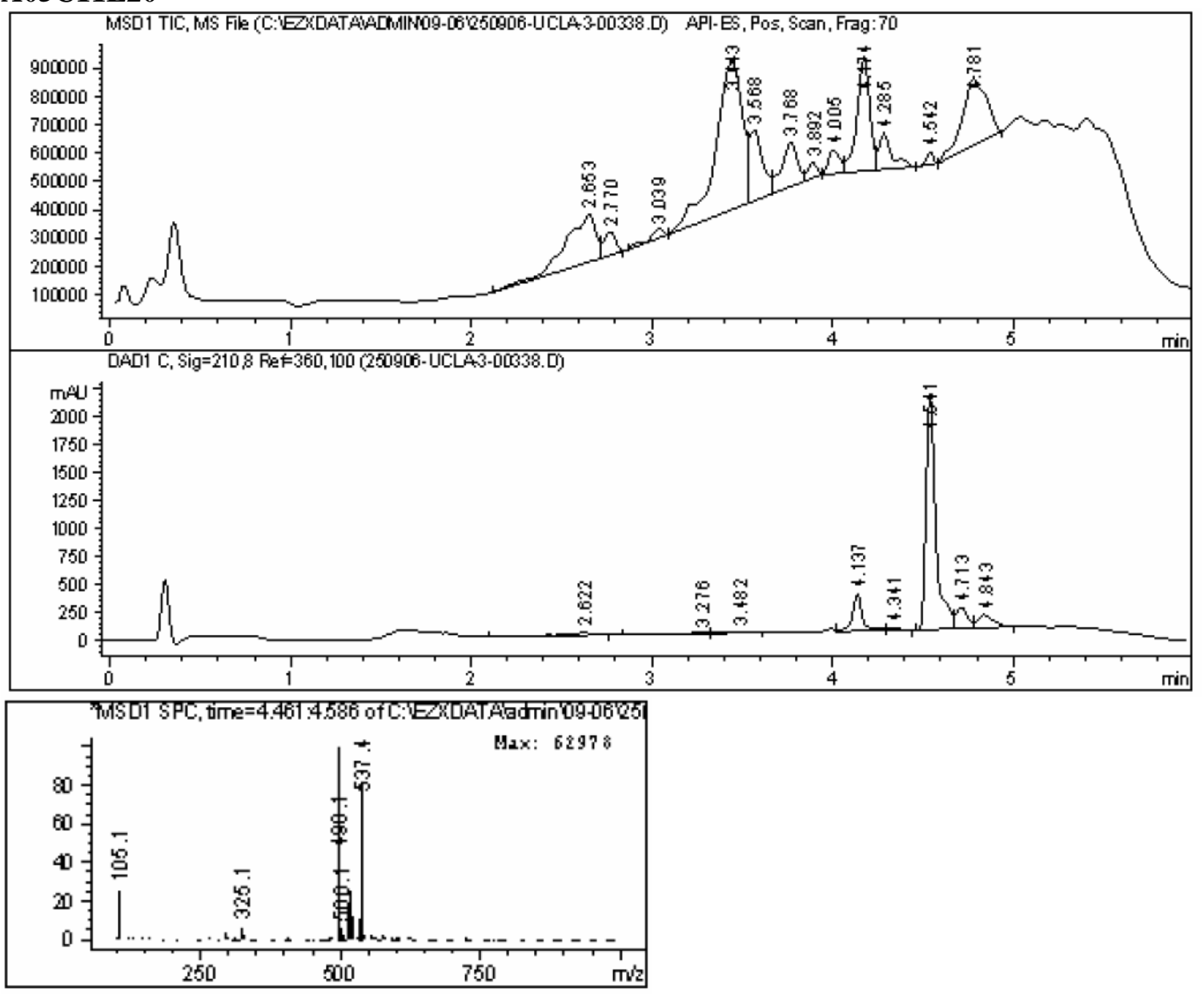




\section{A07C14E32}

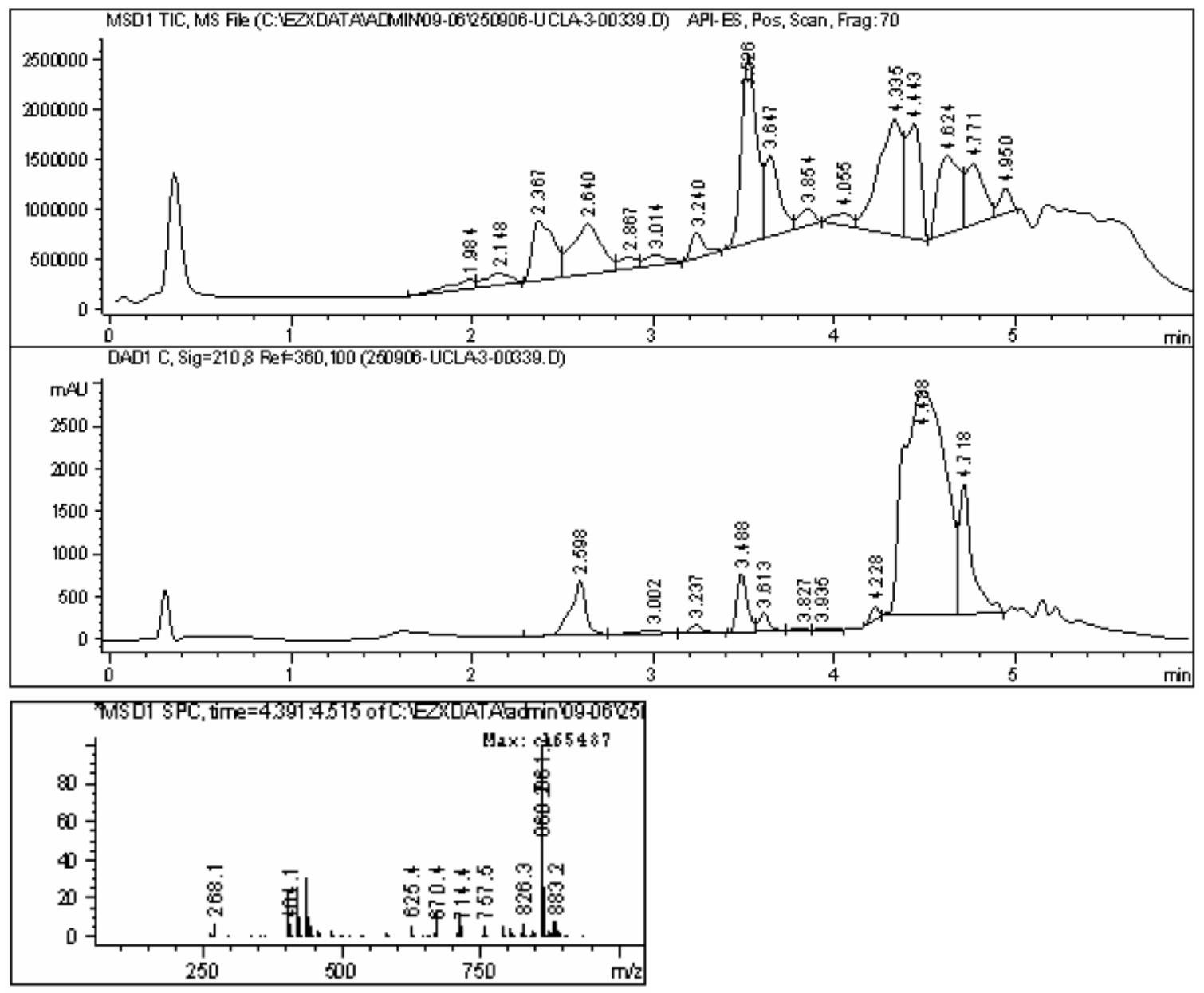



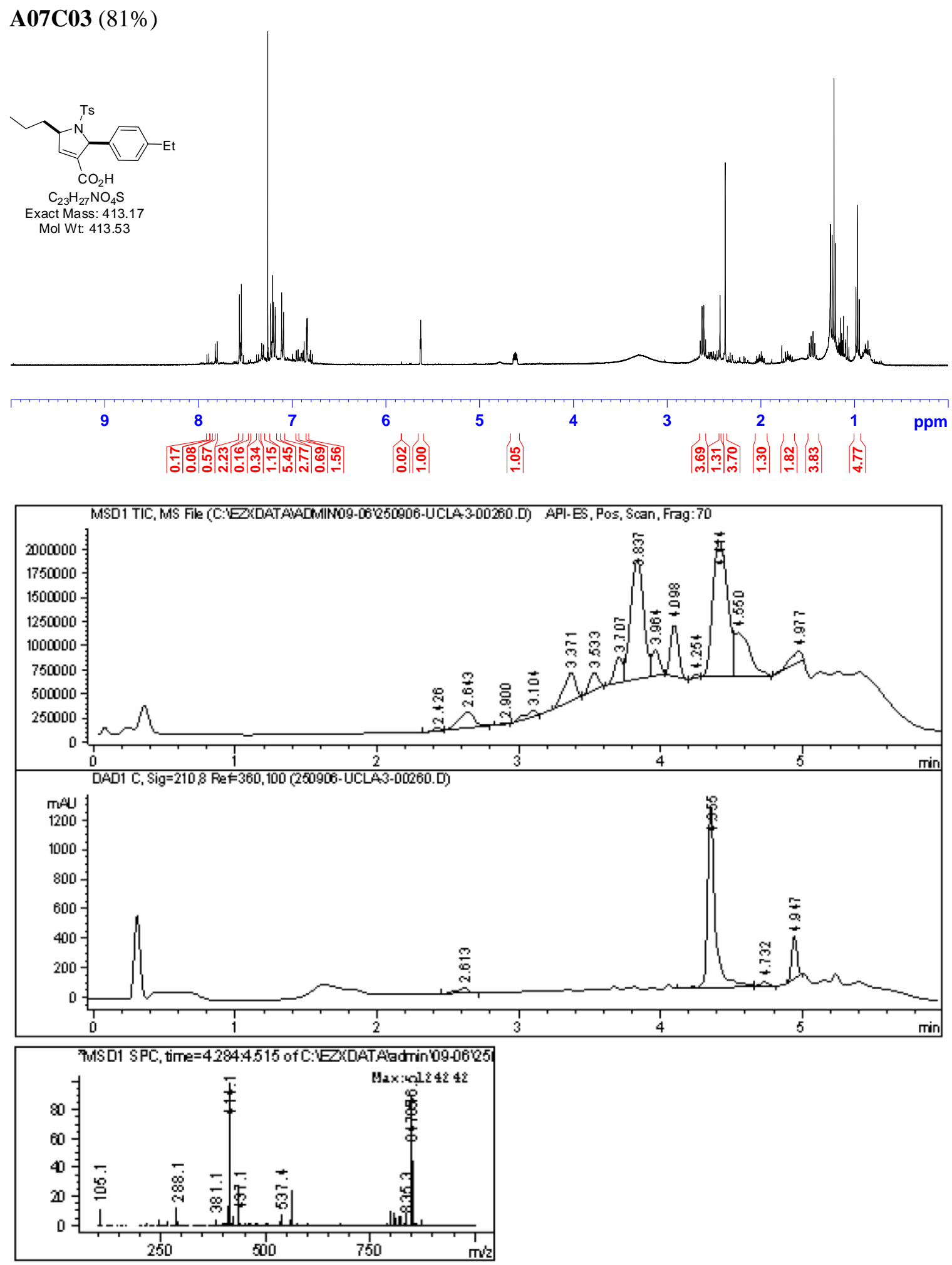
A09C03 (82\%)
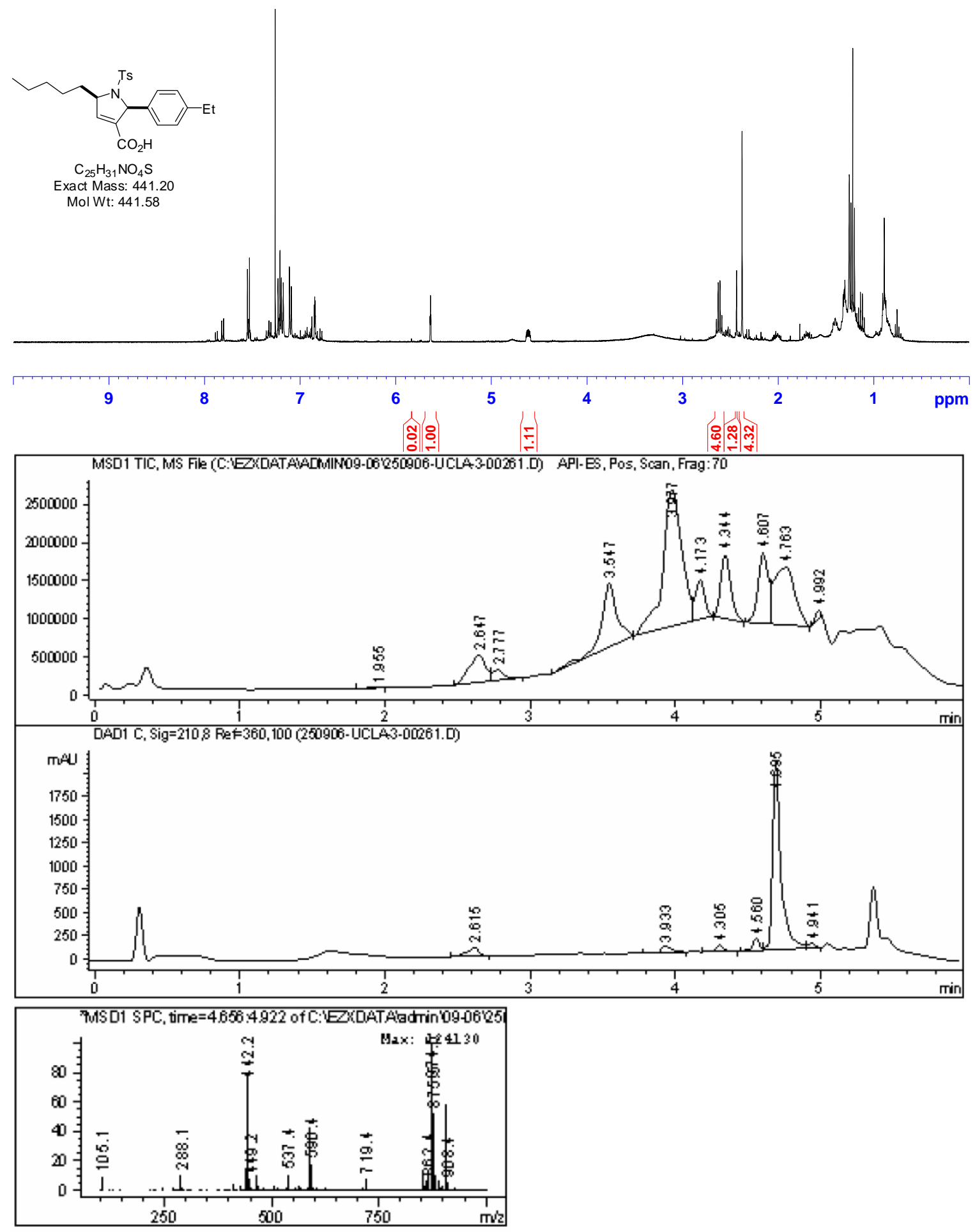
A10C03 (84\%)
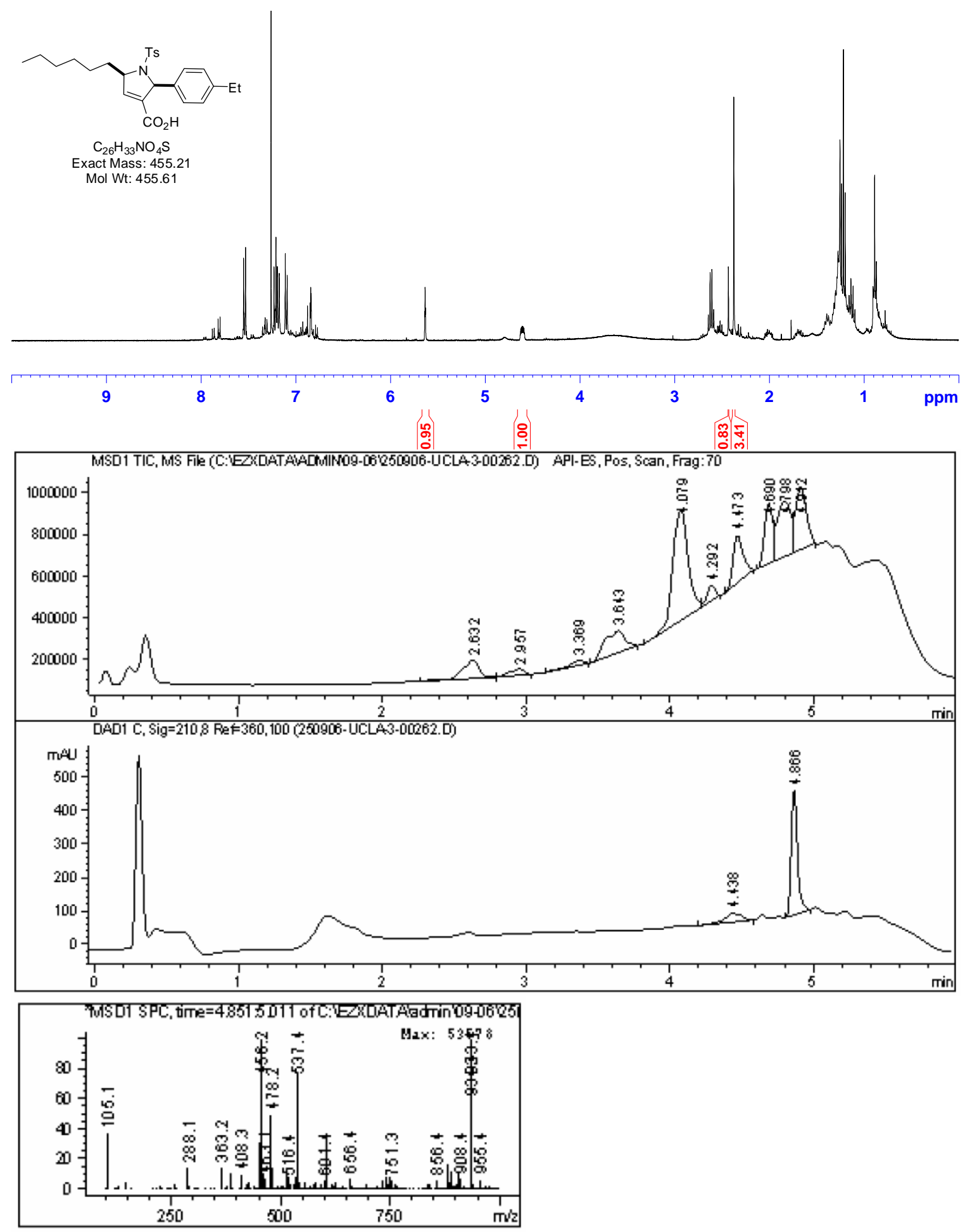


\section{A03C01}
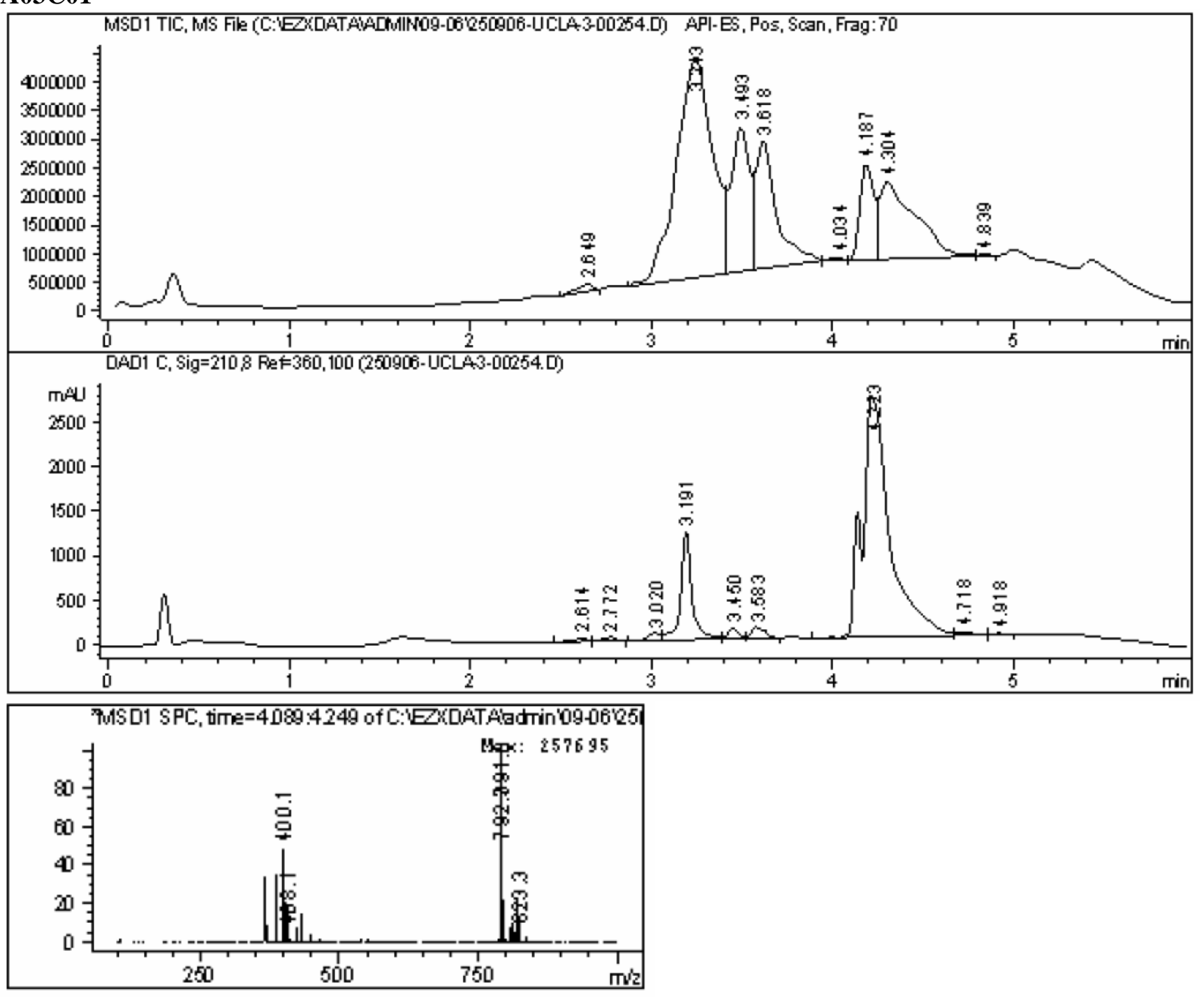


\section{A03C10}
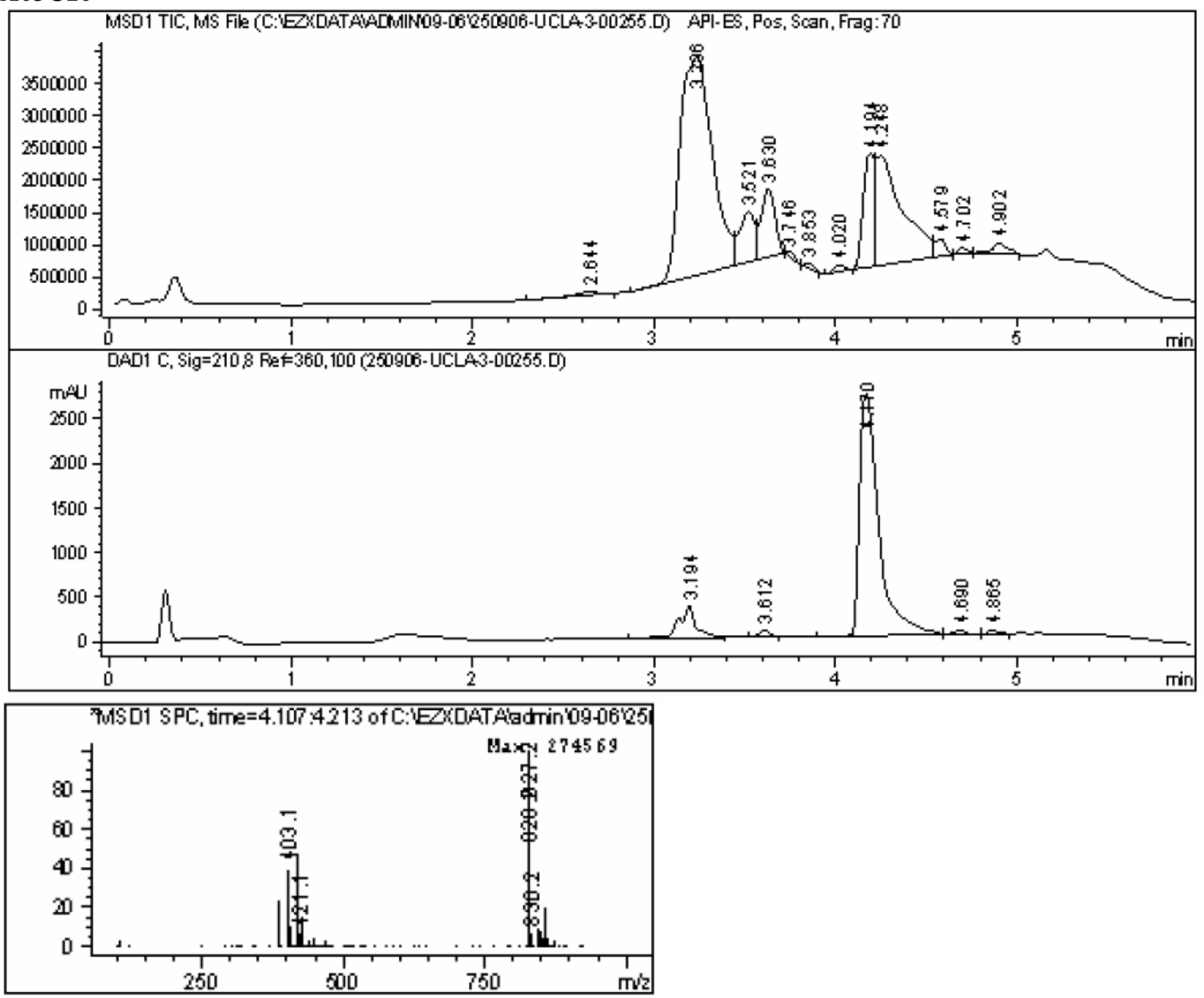

Comoonent 1: Peak at Scan 237.9. Ton ions are 418857842 


\section{A03C12}
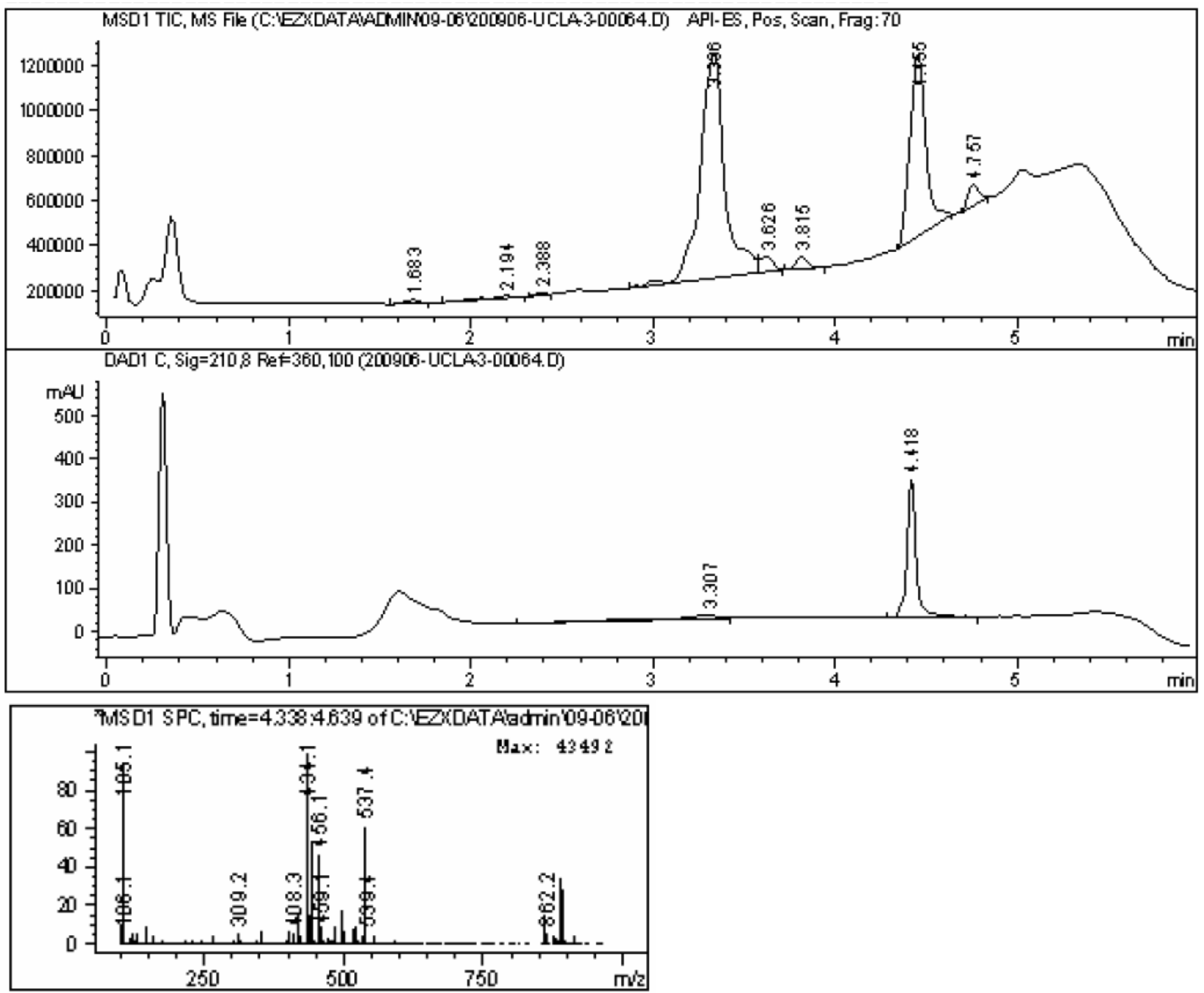


\section{A03C26}
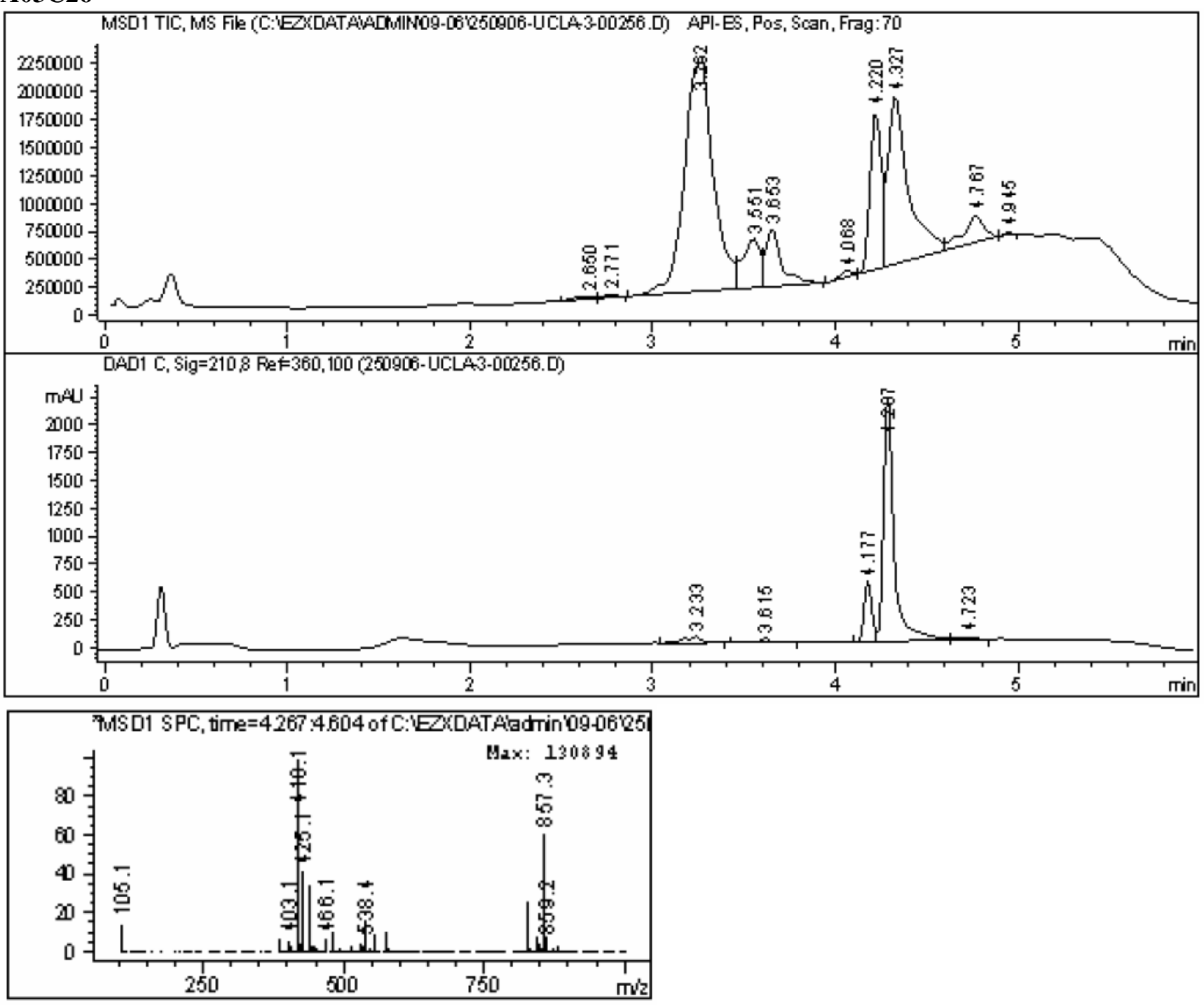

Component 2: Peak at Scan 243.8. Top ions are 418857858 


\section{A03C27}
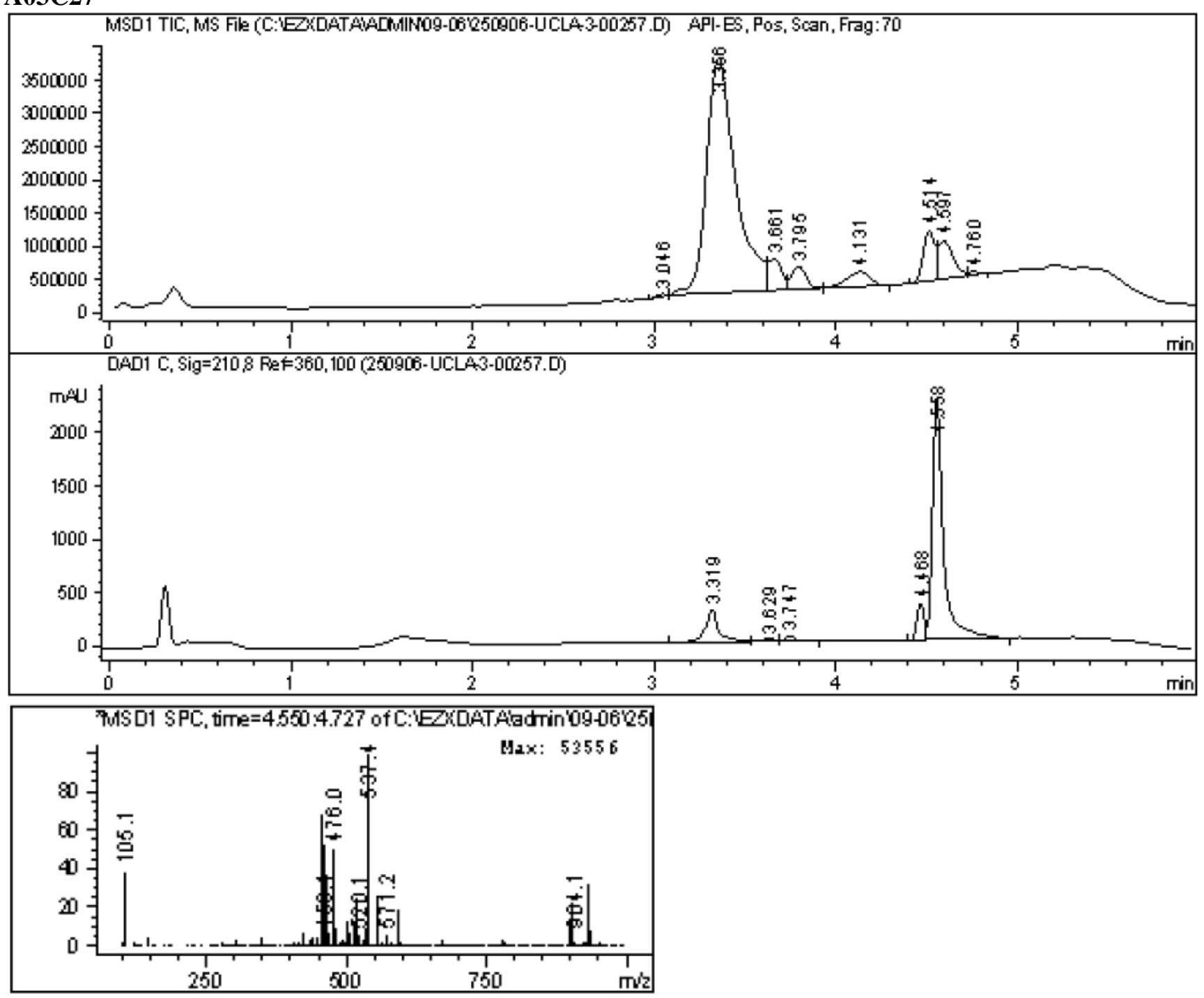

Comoonent 2: Peak at Scan 258.8. Tov ions are 454476931 


\section{A03C30}
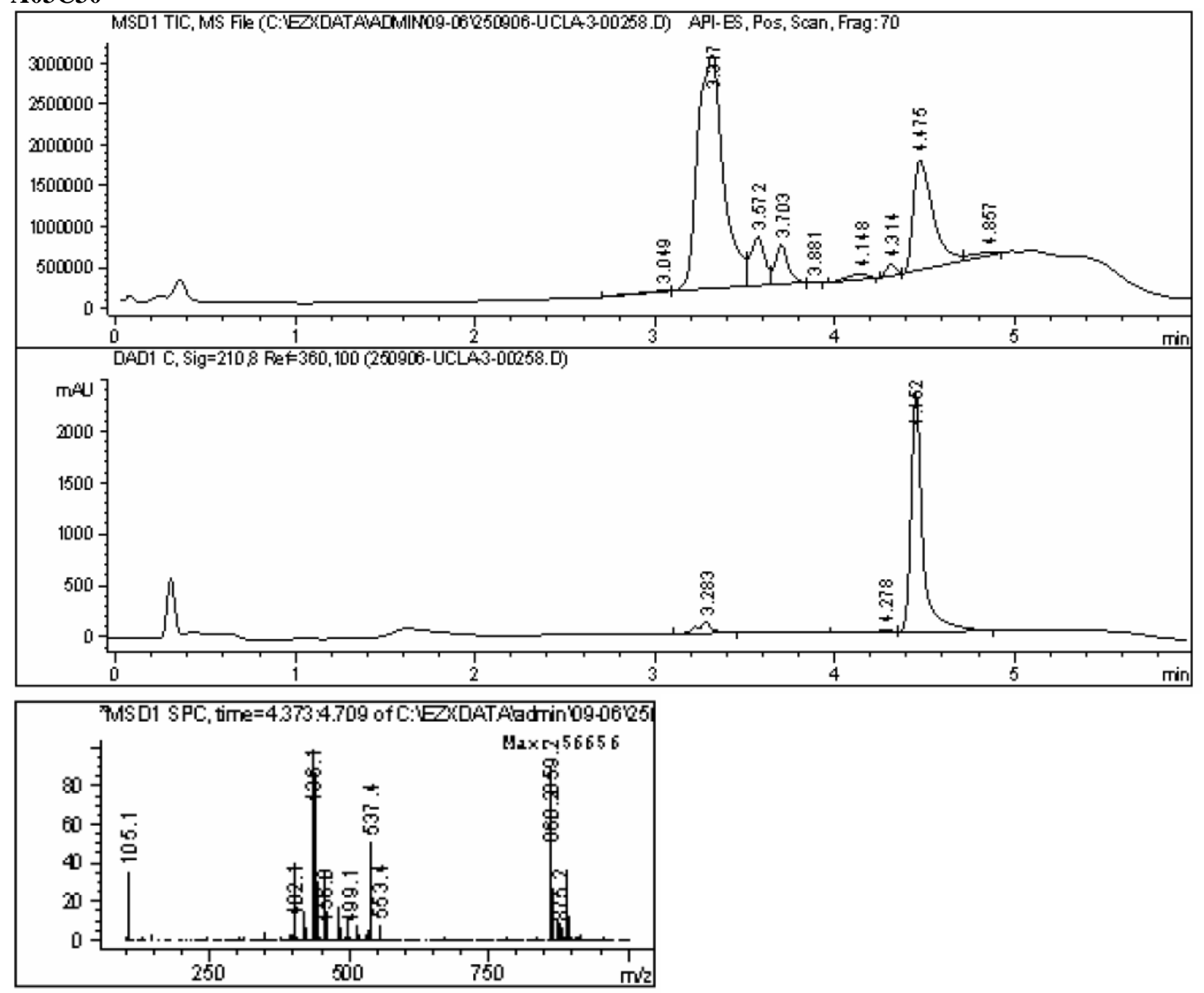

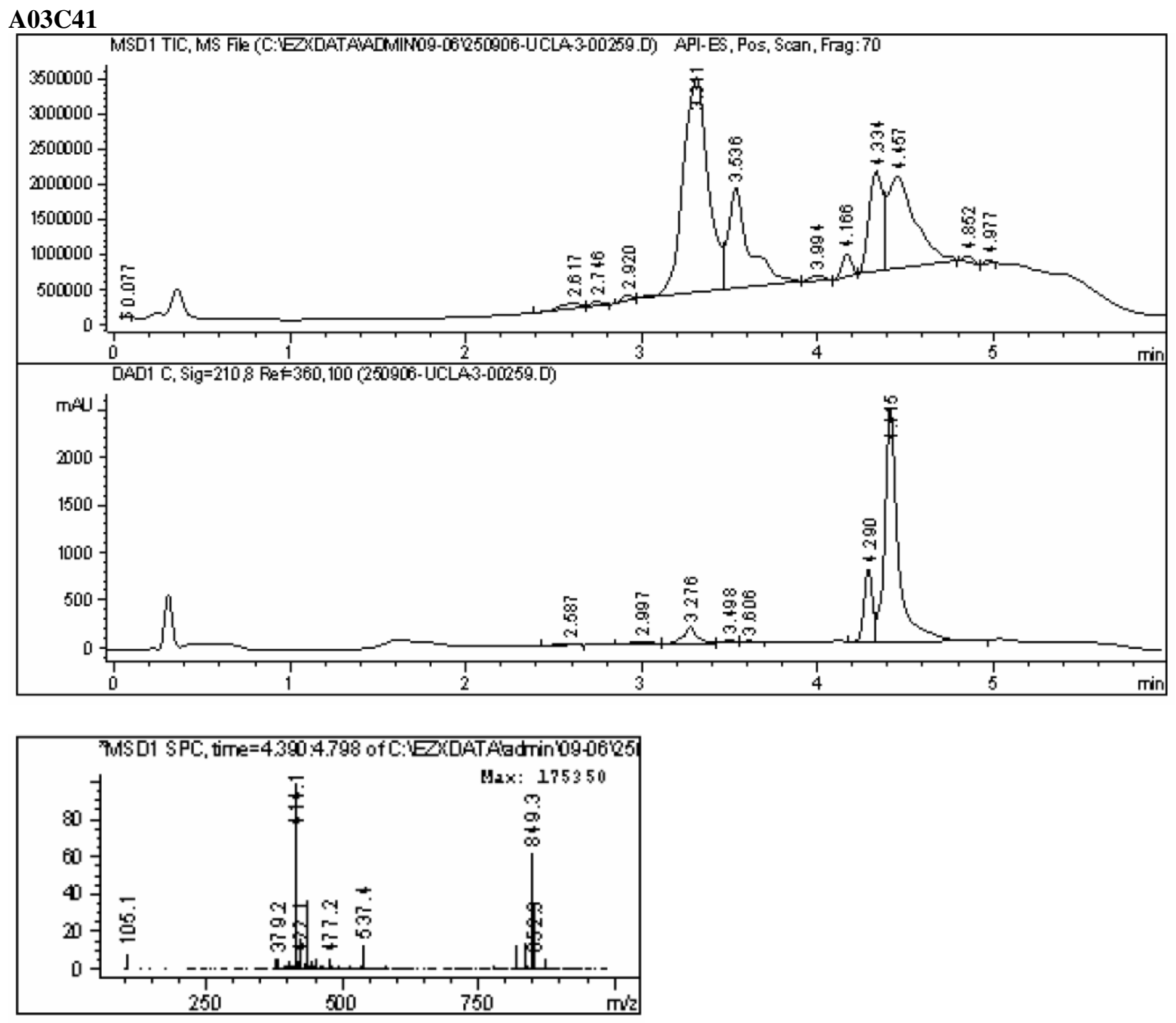
6-(4-Methoxy-phenyl)-1-(toluene-4-sulfonyl)-1,2,5,6-tetrahydro-pyridine-3-carboxylic acid (B01C04)
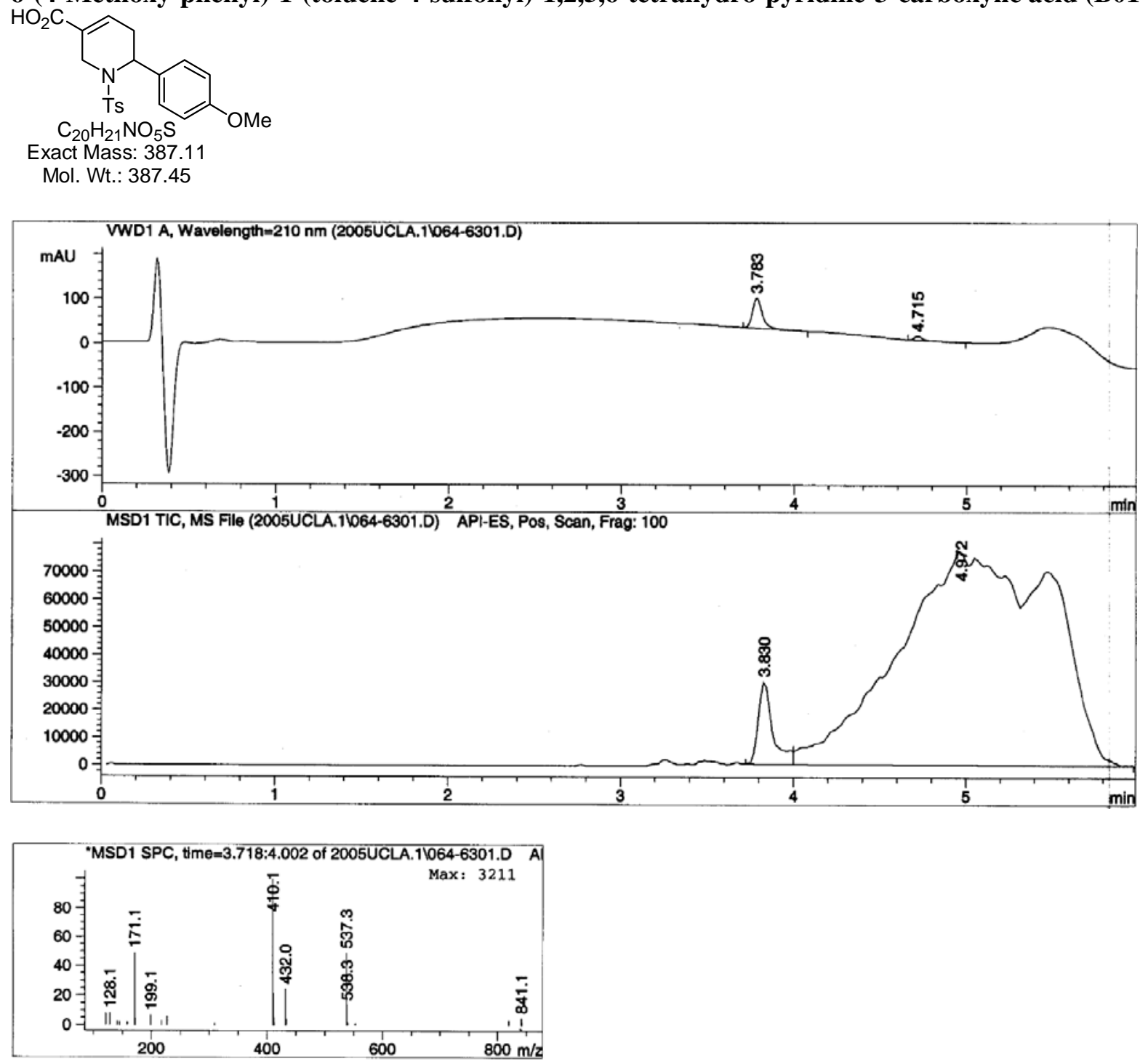
6-(4-Cyanophenyl)-2-phenyl-1-(toluene-4-sulfonyl)-1,2,5,6-tetrahydropyridine-3-carboxylic acid (B02C09)<smiles>[13CH3]N1C(c2ccc(C#N)cc2)CC=C(C(=O)O)C1c1ccccc1</smiles>

$\mathrm{C}_{26} \mathrm{H}_{22} \mathrm{~N}_{2} \mathrm{O}_{4} \mathrm{~S}$

Exact Mass: 458.13

Mol. Wt.: 458.53
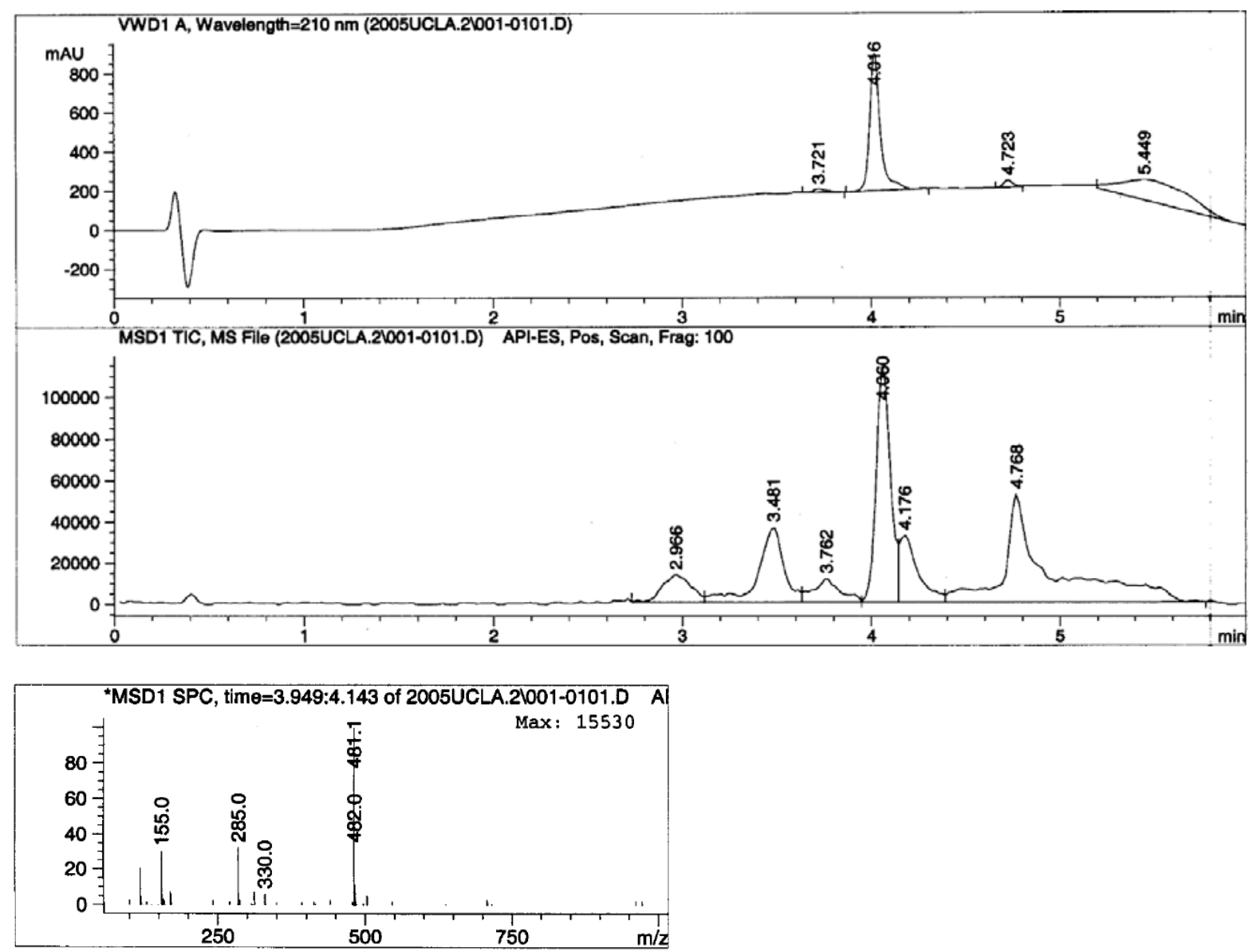
2-(3-Fluorophenyl)-6-(3-methoxyphenyl)-1-(toluene-4-sulfonyl)-1,2,5,6-tetrahydropyridine-3-carboxylic acid (B04C39)
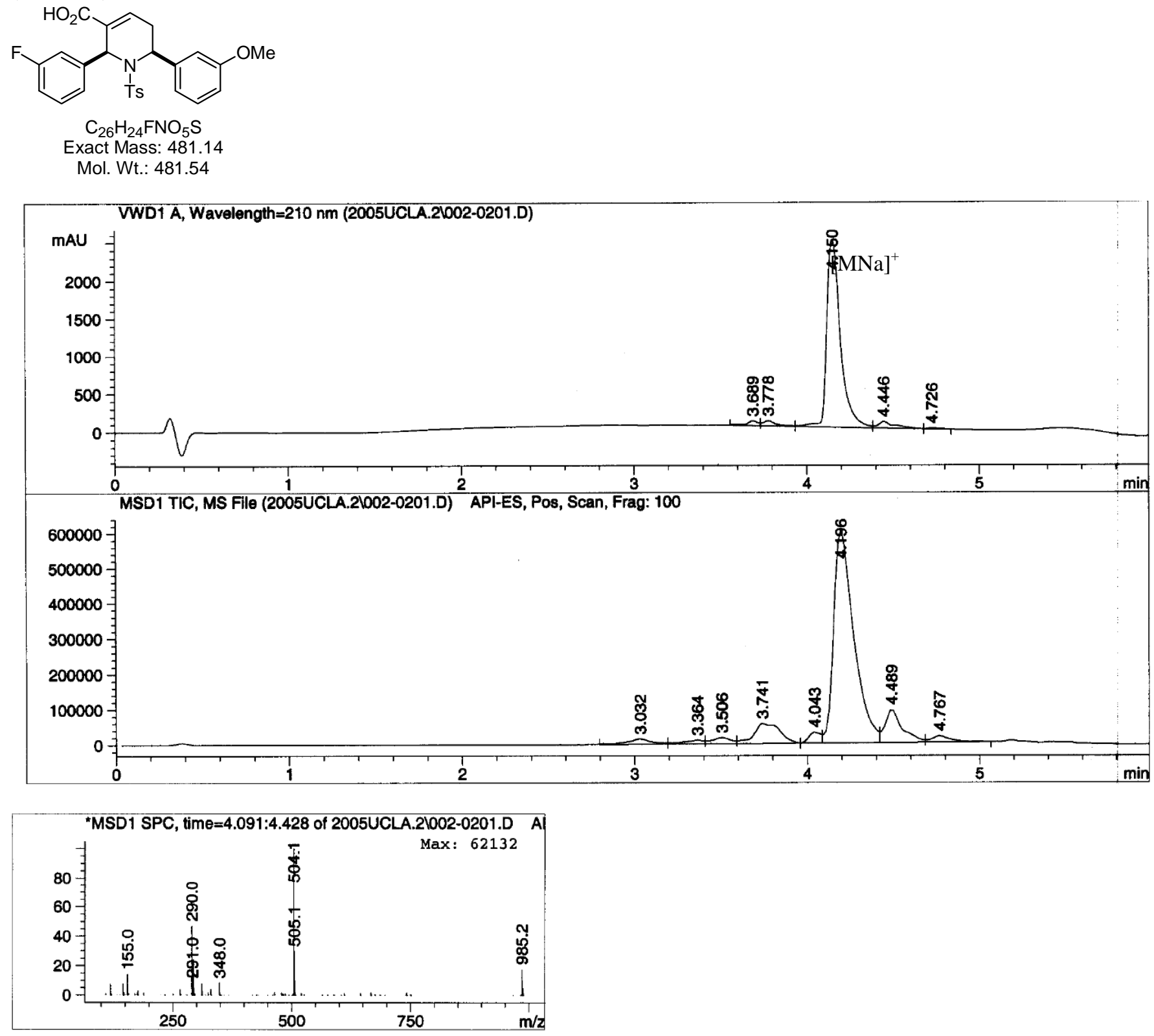
2-(3-Bromophenyl)-6-(4-ethoxyphenyl)-1-(toluene-4-sulfonyl)-1,2,5,6-tetrahydropyridine-3-carboxylic acid (B06C05)
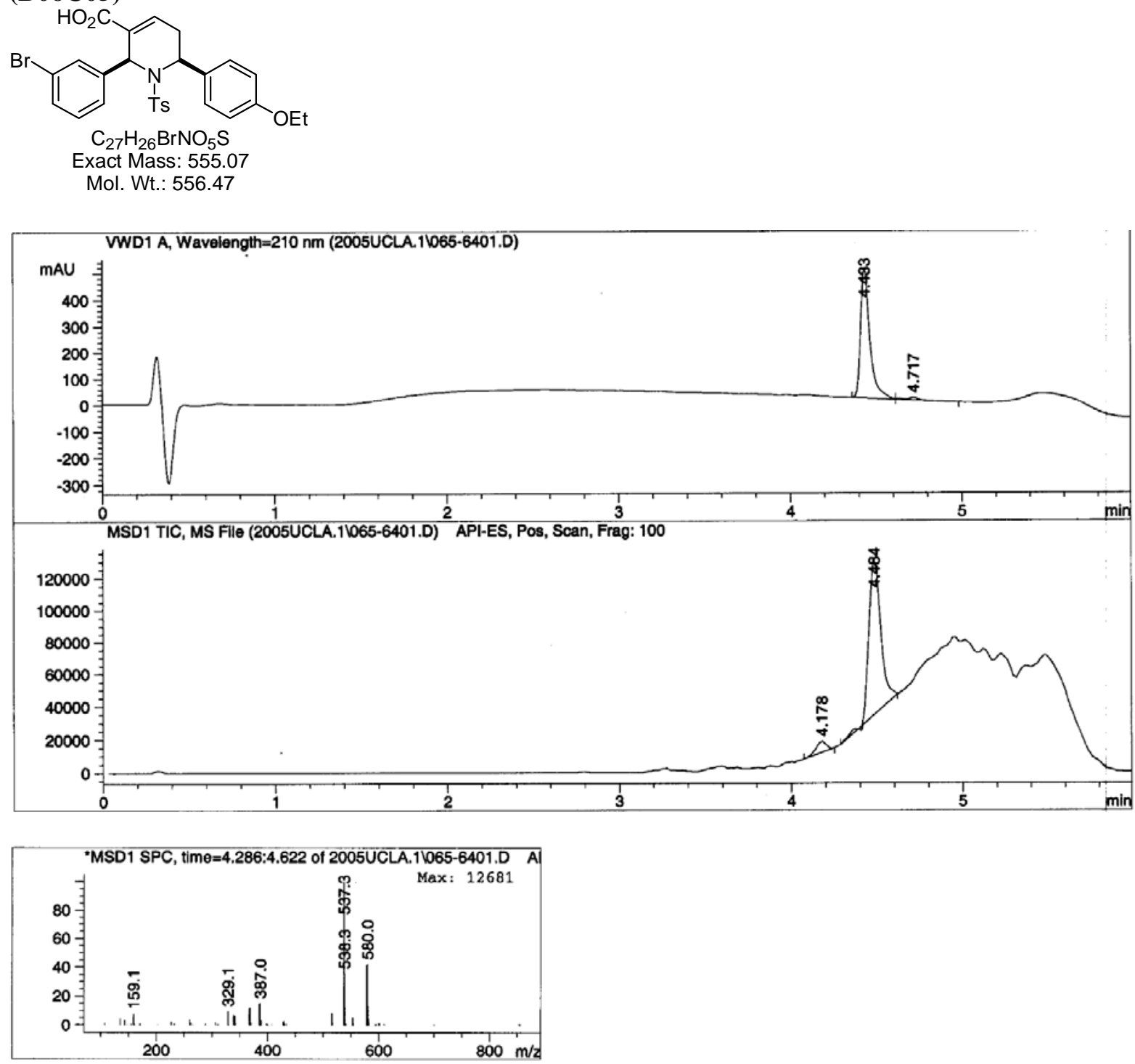
6-(2-Fluorophenyl)-1-(toluene-4-sulfonyl)-2-m-tolyl-1,2,5,6-tetrahydropyridine-3-carboxylic acid (B07C10)<smiles>Cc1cccc(C2C(C(=O)O)=CCC(c3ccccc3F)N2C)c1</smiles>

$\mathrm{C}_{26} \mathrm{H}_{24} \mathrm{FNO}_{4} \mathrm{~S}$

Exact Mass: 465.14

Mol. Wt.: 465.54
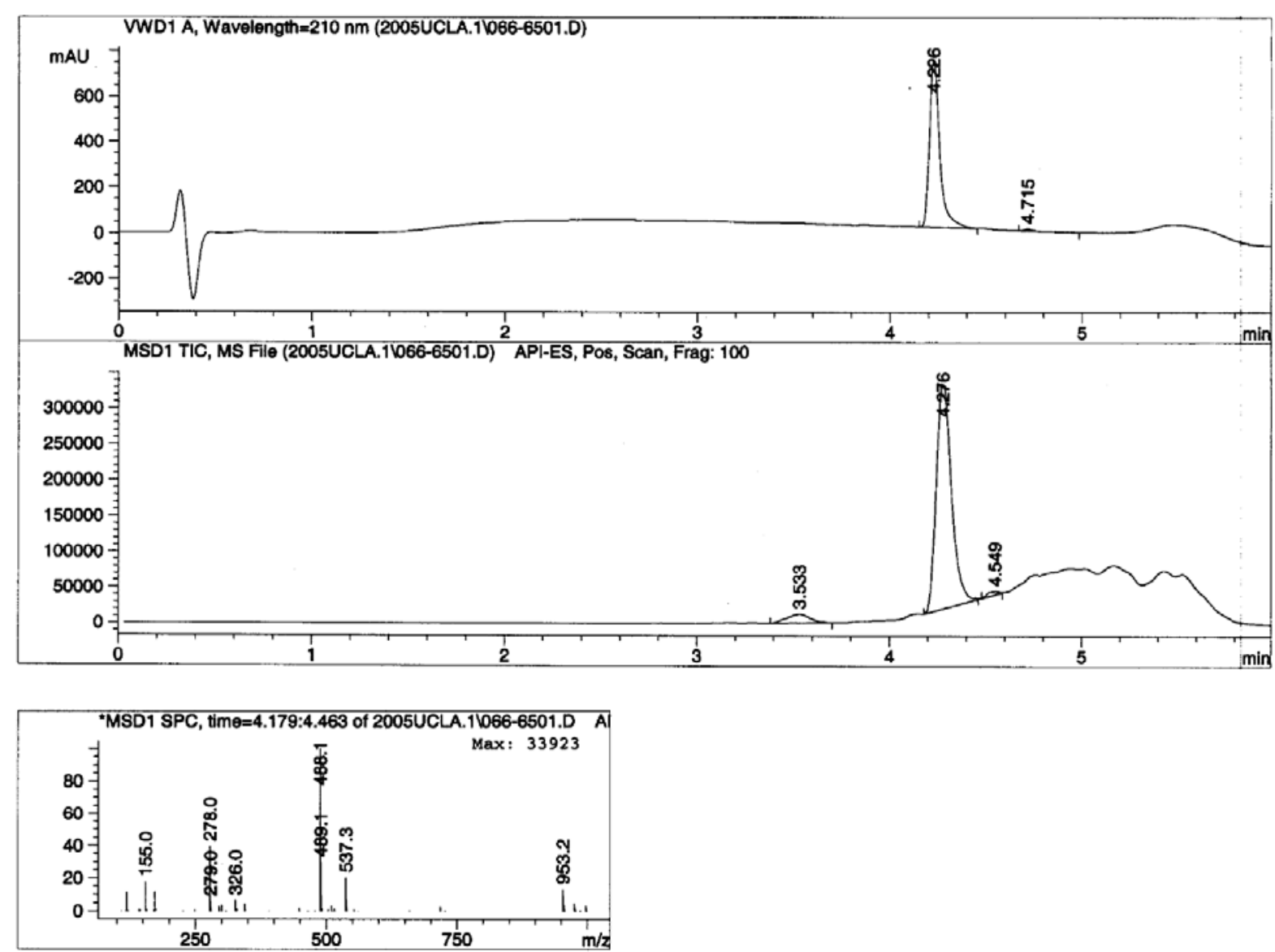
Benzenesulfonyl-2-(4-fluorophenyl)-6-p-tolyl-1,2,5,6-tetrahydropyridine-3-carboxylic acid (B08C43)
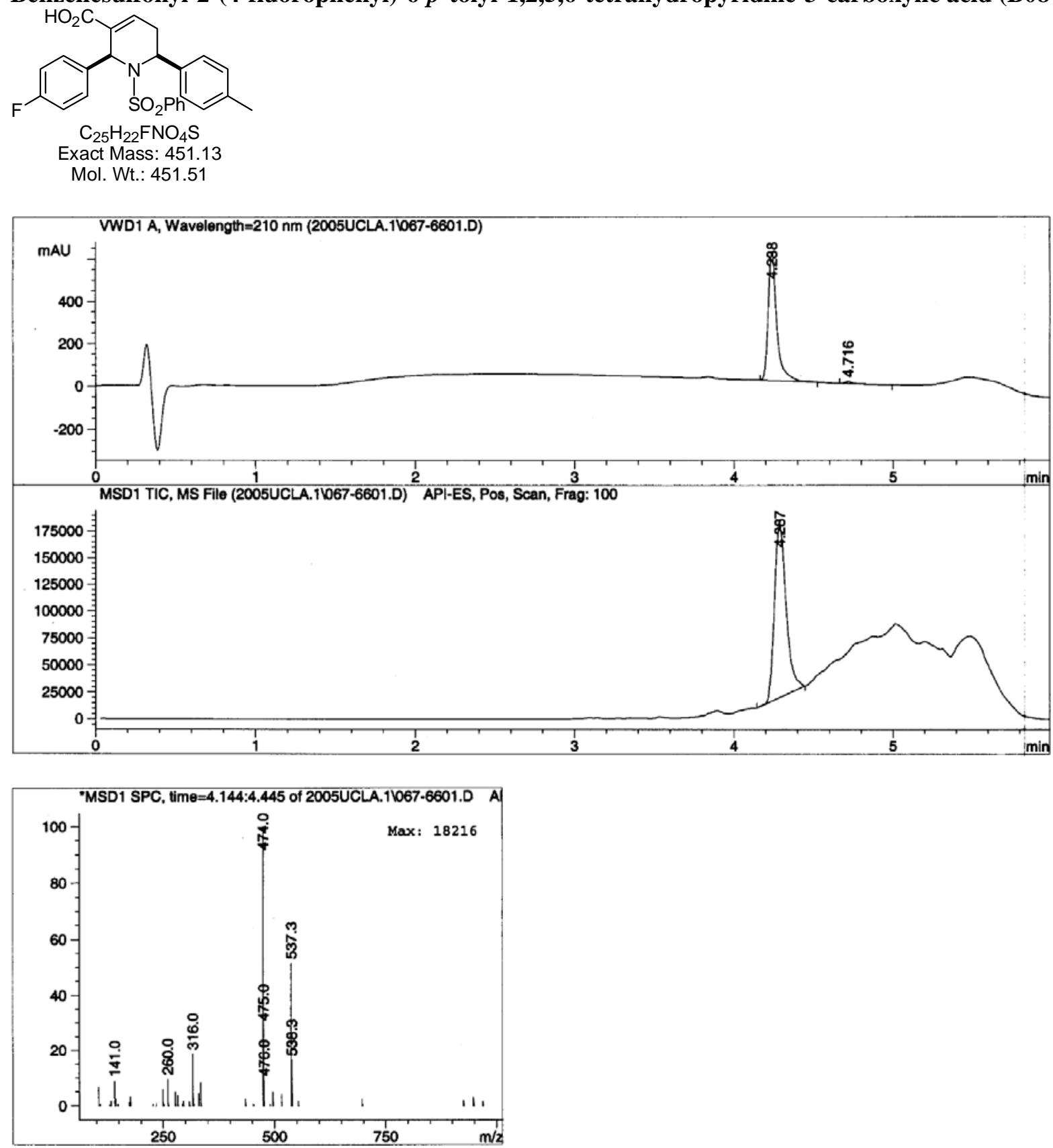
2-(4-Bromophenyl)-6-(3-fluorophenyl)-1-(toluene-4-sulfonyl)-1,2,5,6-tetrahydropyridine-3-carboxylic acid (B10C26)
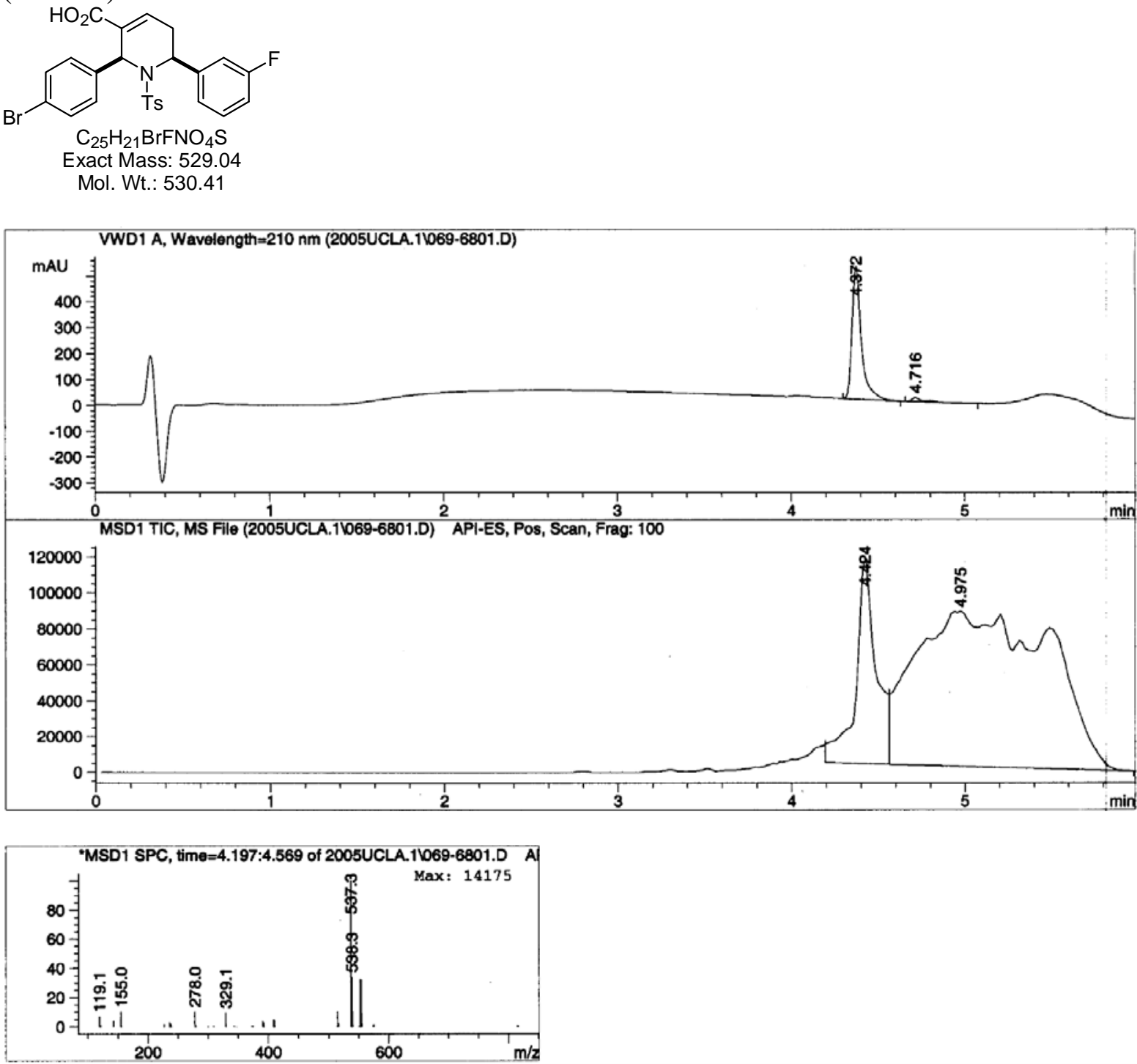

Component 3: Peak at Scan 248.4. Top ions are 552554278 
6-Thiophen-2-yl-1-(toluene-4-sulfonyl)-2-p-tolyl-1,2,5,6-tetrahydropyridine-3-carboxylic acid (B11C21)<smiles>Cc1ccc(C2C(C(=O)O)=CCC(c3cccs3)N2[13CH3])cc1</smiles>

$\mathrm{C}_{24} \mathrm{H}_{23} \mathrm{NO}_{4} \mathrm{~S}_{2}$

Exact Mass: 453.11

Mol. Wt.: 453.57
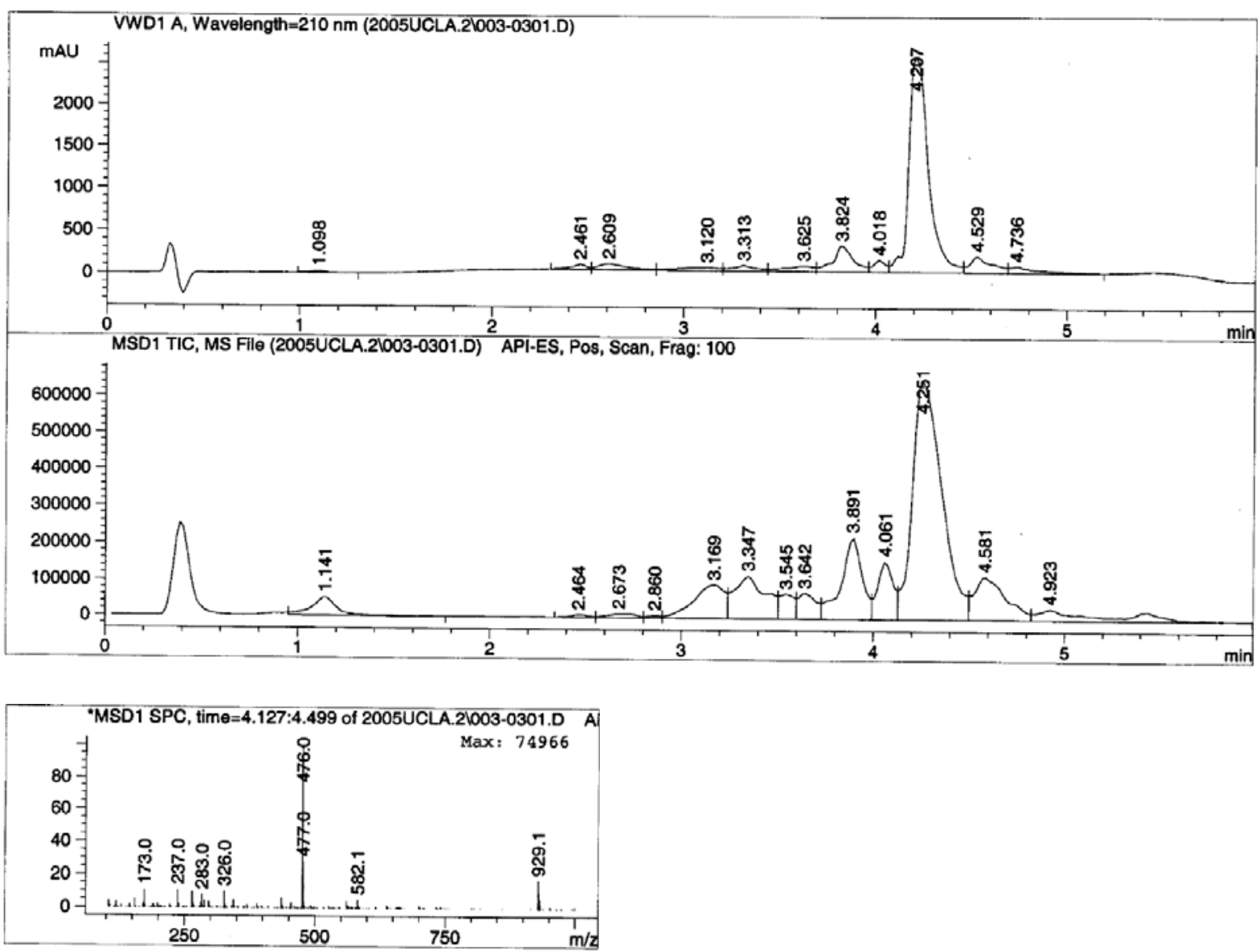
2-(4-tert-Butylphenyl)-6-(4-cyanophenyl)-1-(toluene-4-sulfonyl)-1,2,5,6-tetrahydropyridine-3-carboxylic acid (B12C09)
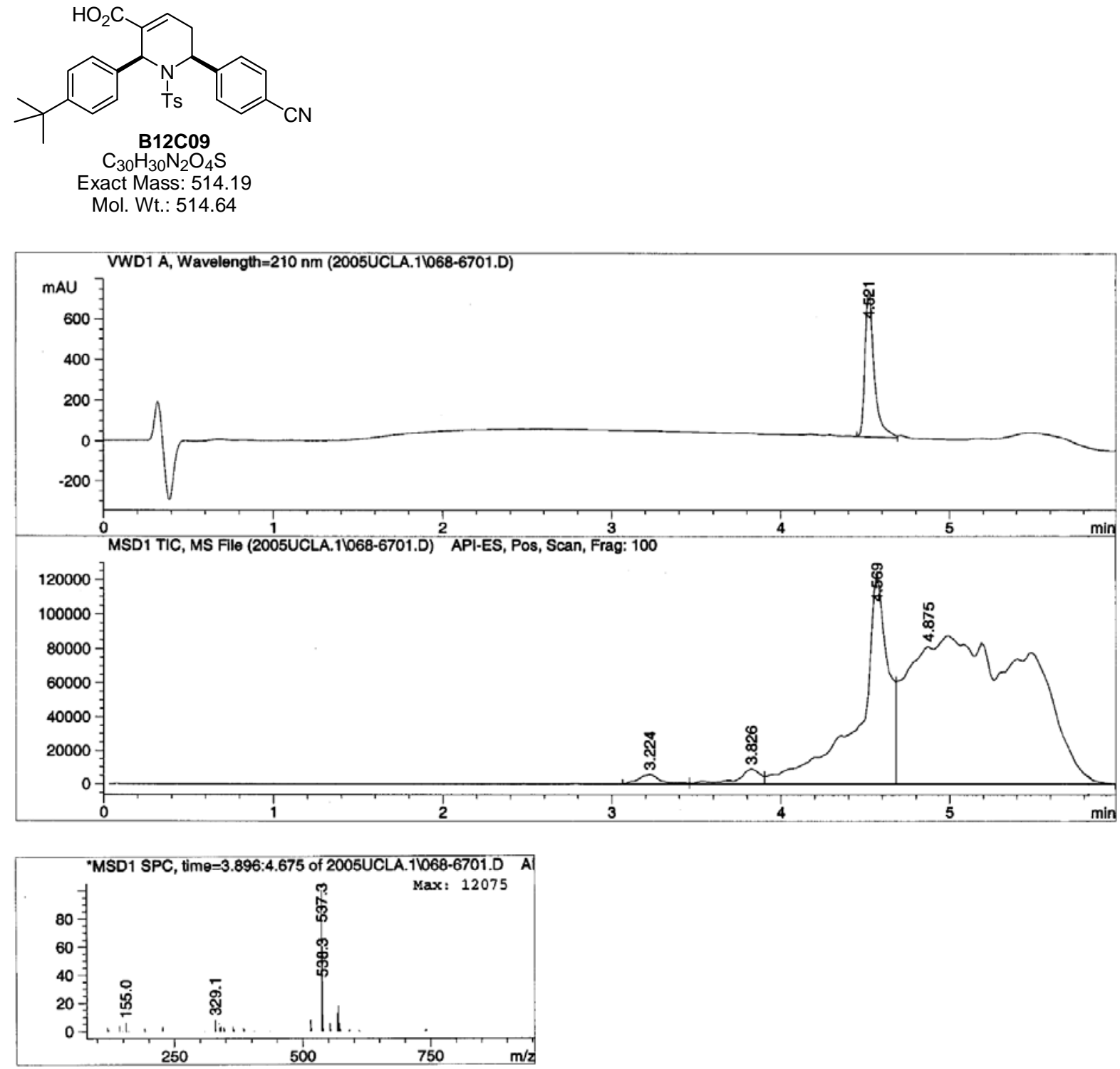
4-Benzylsulfanyl-6-phenyl-1-(toluene-4-sulfonyl)-piperidine-3-carboxylic acid (B01C01E06)<smiles>O=C(O)C1CN([As])C(c2ccccc2)C[C@H]1SCc1ccccc1</smiles>

$\mathrm{C}_{26} \mathrm{H}_{27} \mathrm{NO}_{4} \mathrm{~S}_{2}$

Exact Mass: 481.14

Mol. Wt.: 481.63
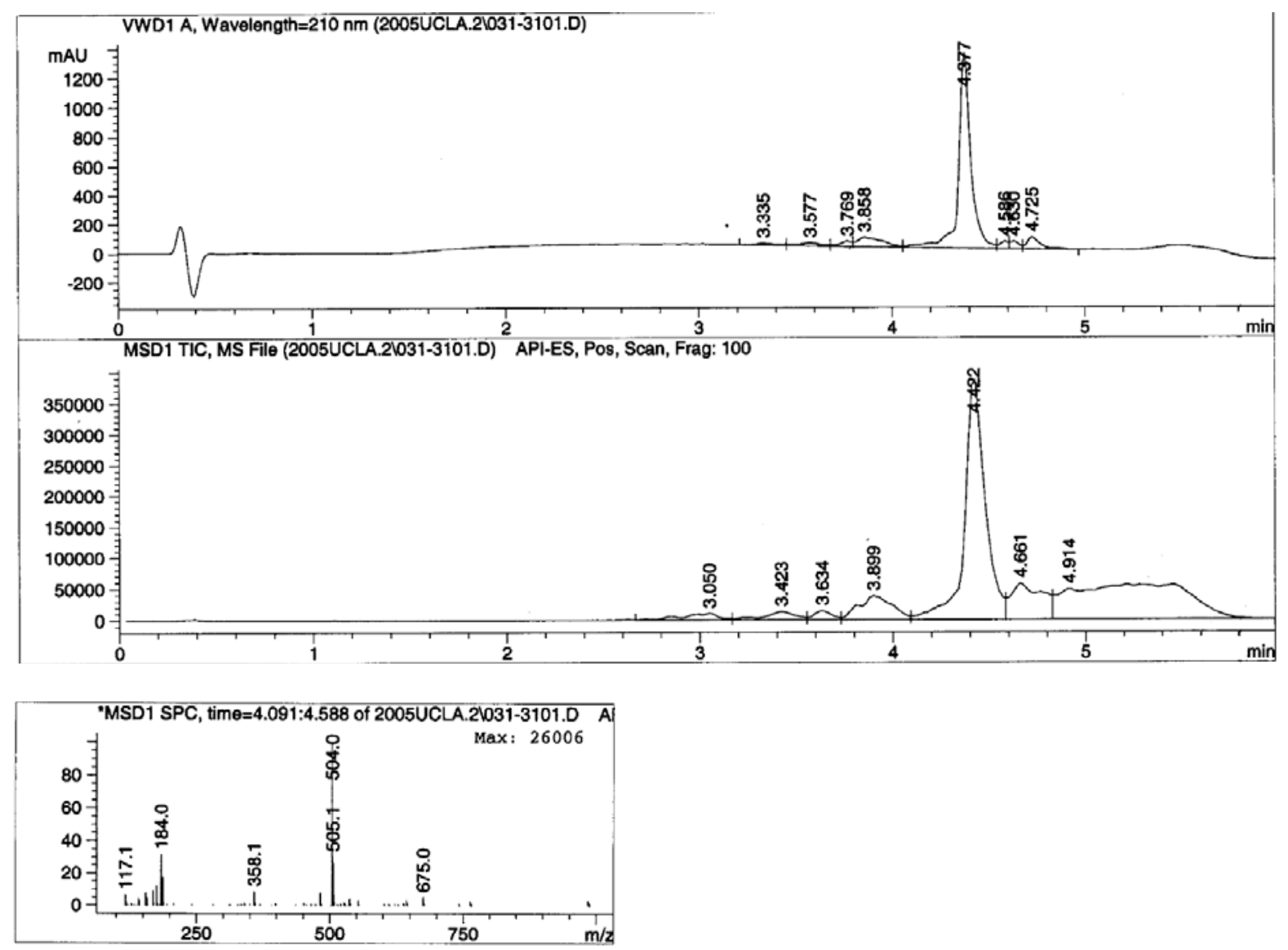
6-Phenyl-4-propylsulfanyl-1-(toluene-4-sulfonyl)-piperidine-3-carboxylic acid (B01C01E18)

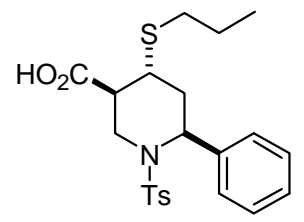

$\mathrm{C}_{22} \mathrm{H}_{27} \mathrm{NO}_{4} \mathrm{~S}_{2}$

Exact Mass: 433.14

Mol. Wt.: 433.58
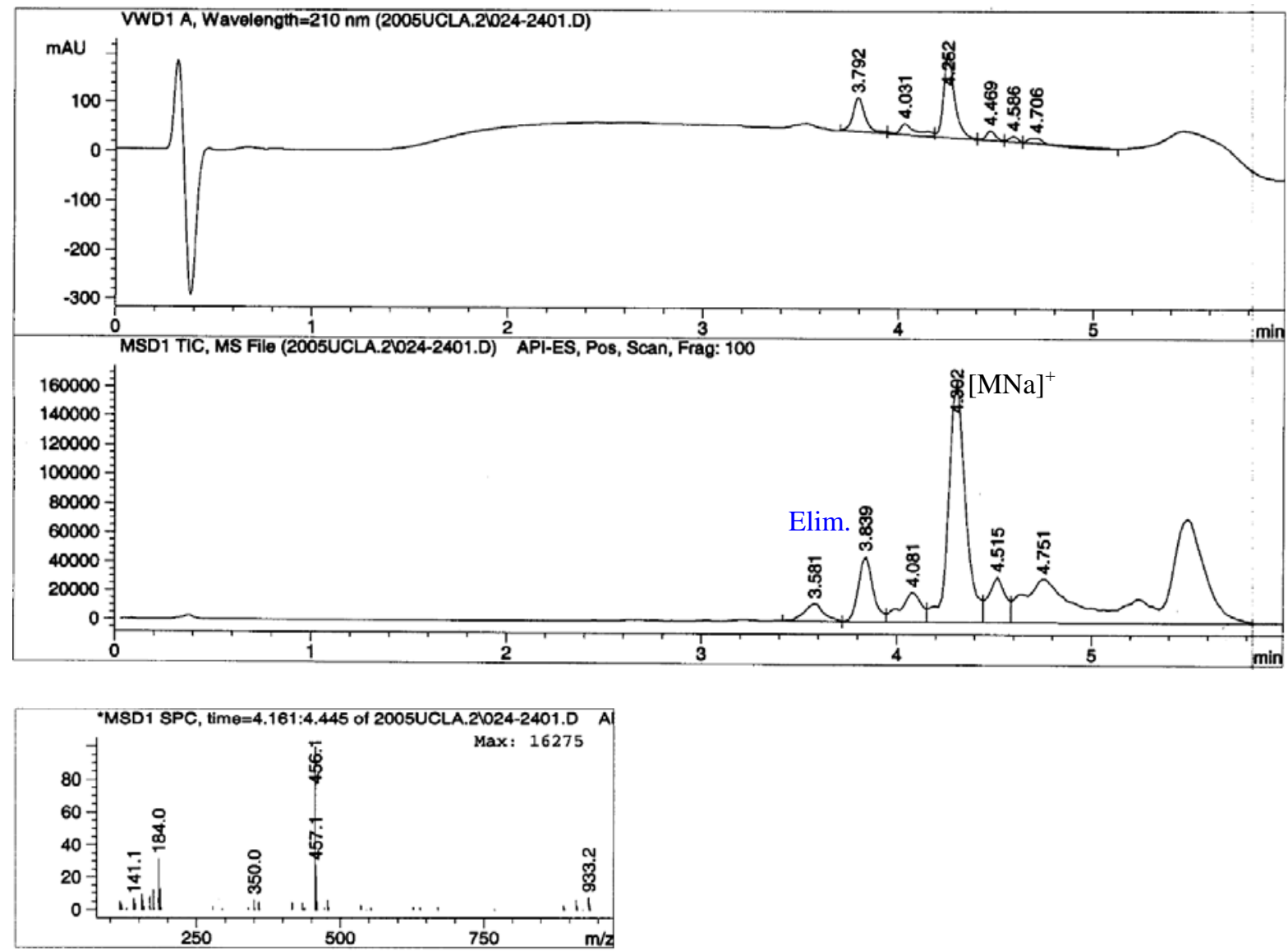
4-(4-Methoxyphenylsulfanyl)-1-(toluene-4-sulfonyl)-6-p-tolylpiperidine-3-carboxylic acid (B01C02E04)

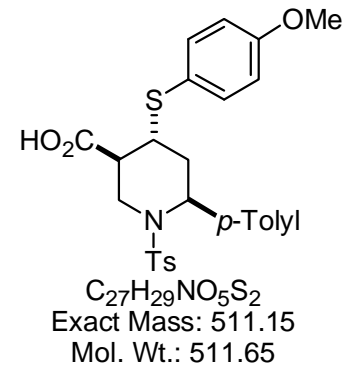
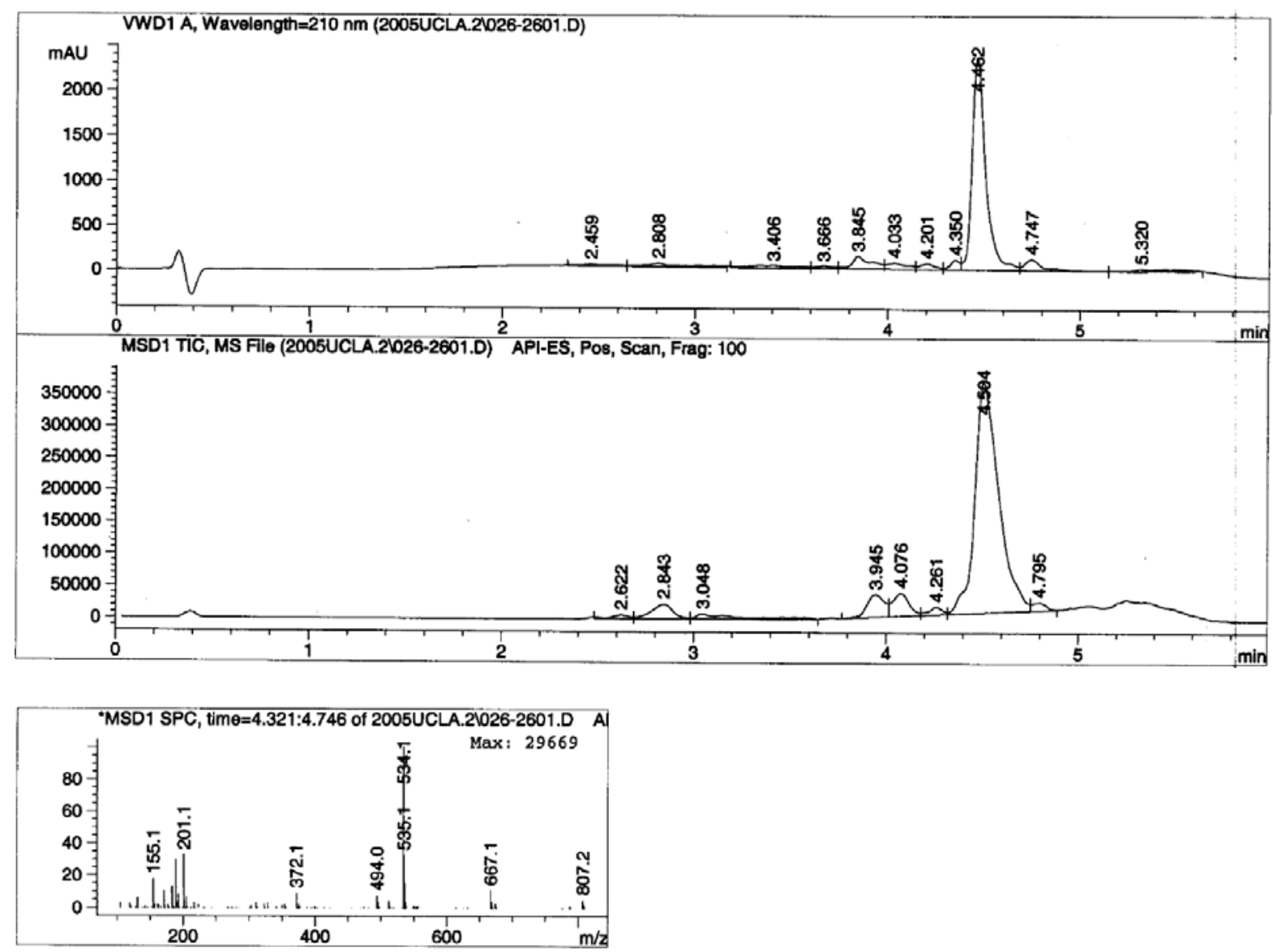
6-(4-Ethylphenyl)-4-phenylsulfanyl-1-(toluene-4-sulfonyl)-piperidine-3-carboxylic acid (B01C03E01)

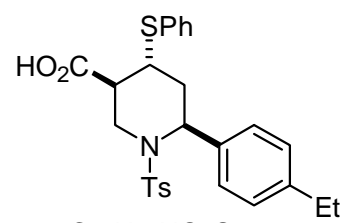

$\mathrm{C}_{27} \mathrm{H}_{29} \mathrm{NO}_{4} \mathrm{~S}_{2}$

Exact Mass: 495.15

Mol. Wt.: 495.65
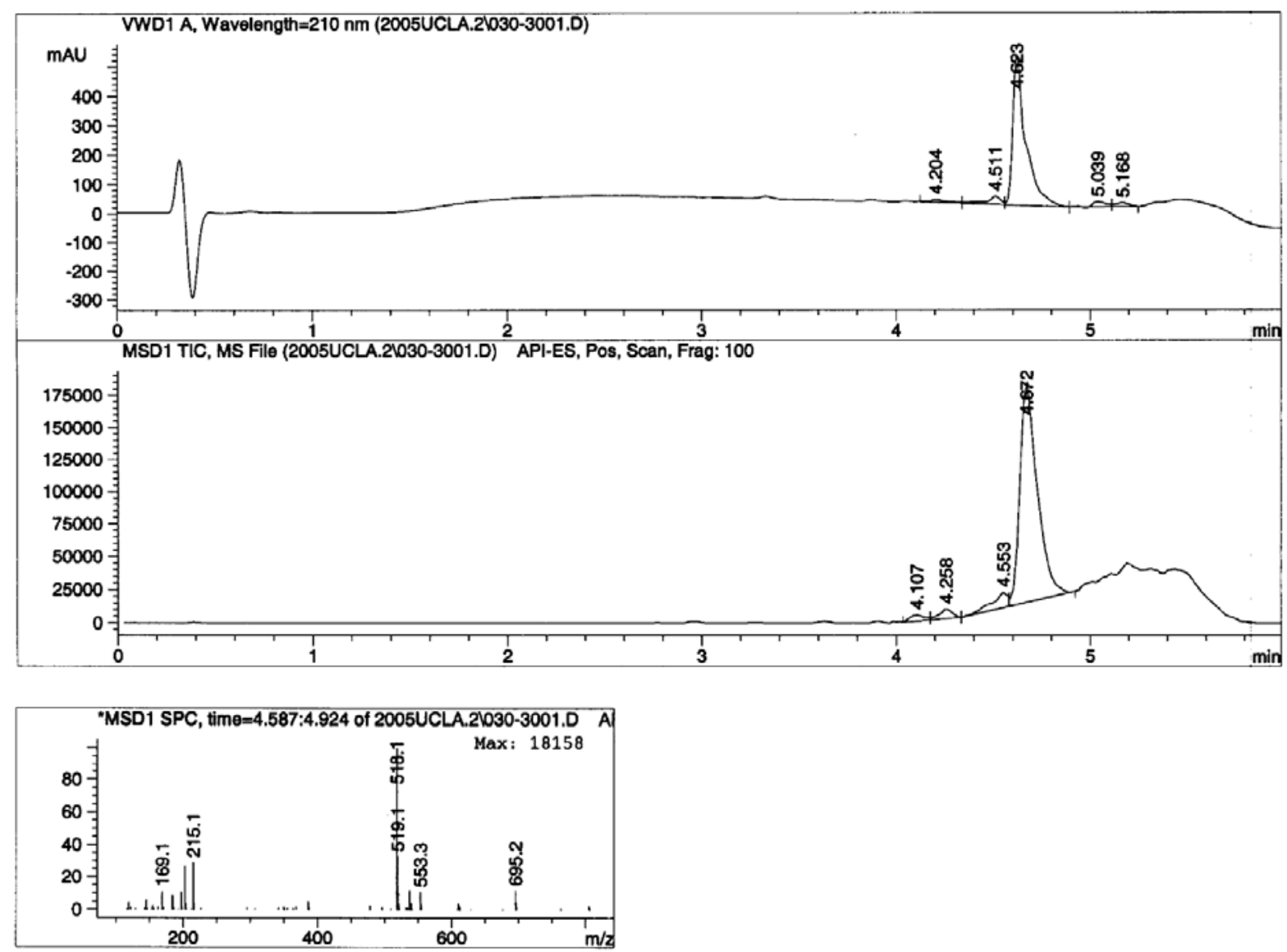
1-(4-Chlorobenzenesulfonyl)-4-(4-chlorobenzylsulfanyl)-6-p-tolyl-piperidine-3-carboxylic acid (B01C30E09)<smiles>Cc1ccc(C2C[C@H](SCc3ccc(Cl)cc3)[C@@H](C(=O)O)CN2S(=O)(=O)c2ccc(Cl)cc2)cc1</smiles>

$\mathrm{C}_{26} \mathrm{H}_{25} \mathrm{Cl}_{2} \mathrm{NO}_{4} \mathrm{~S}_{2}$

Exact Mass: 549.06

Mol. Wt.: 550.52
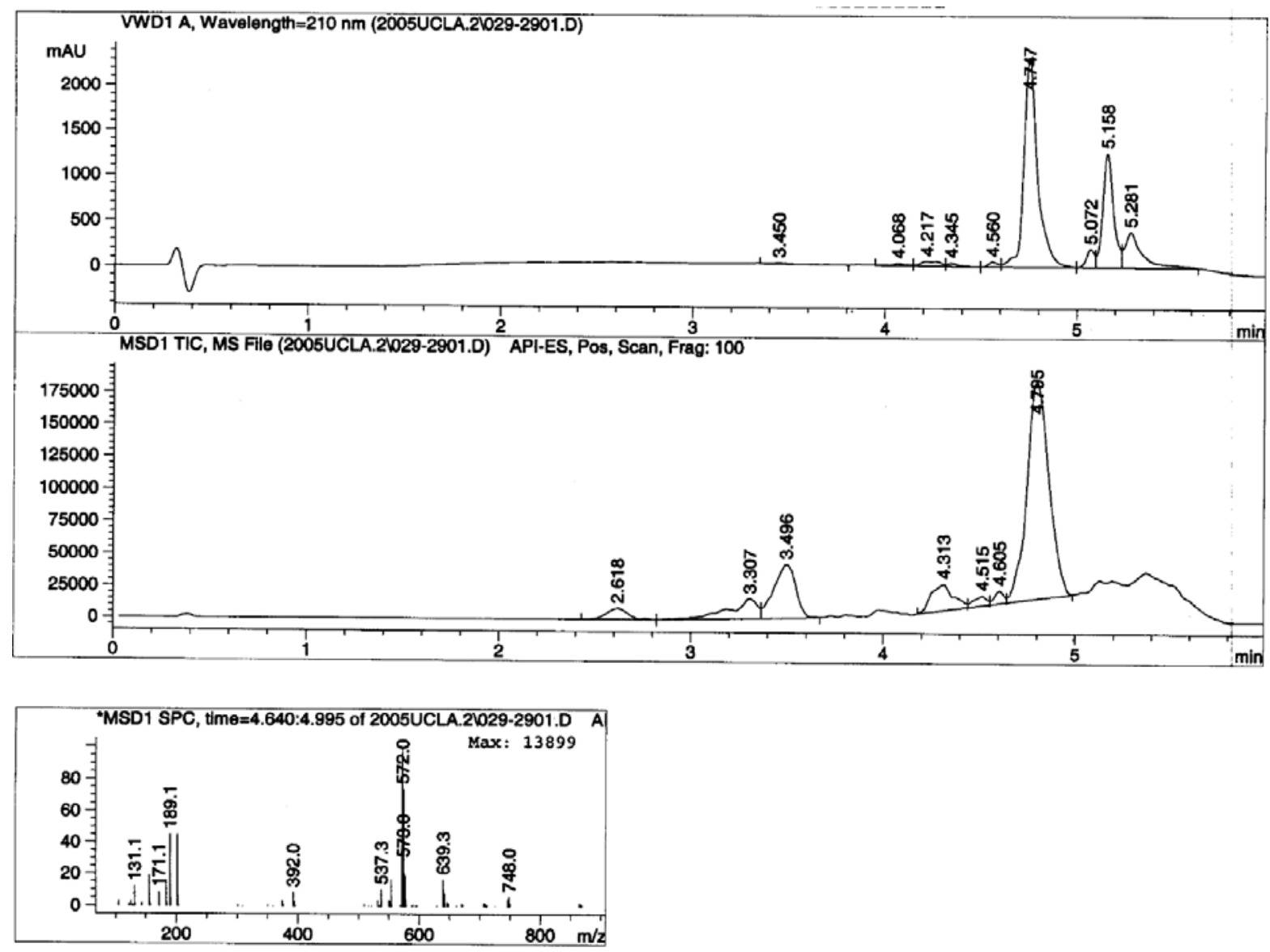
Benzenesulfonyl-6-(4-methoxyphenyl)-4-p-tolylsulfanyl-piperidine-3-carboxylic acid (B01C35E02)
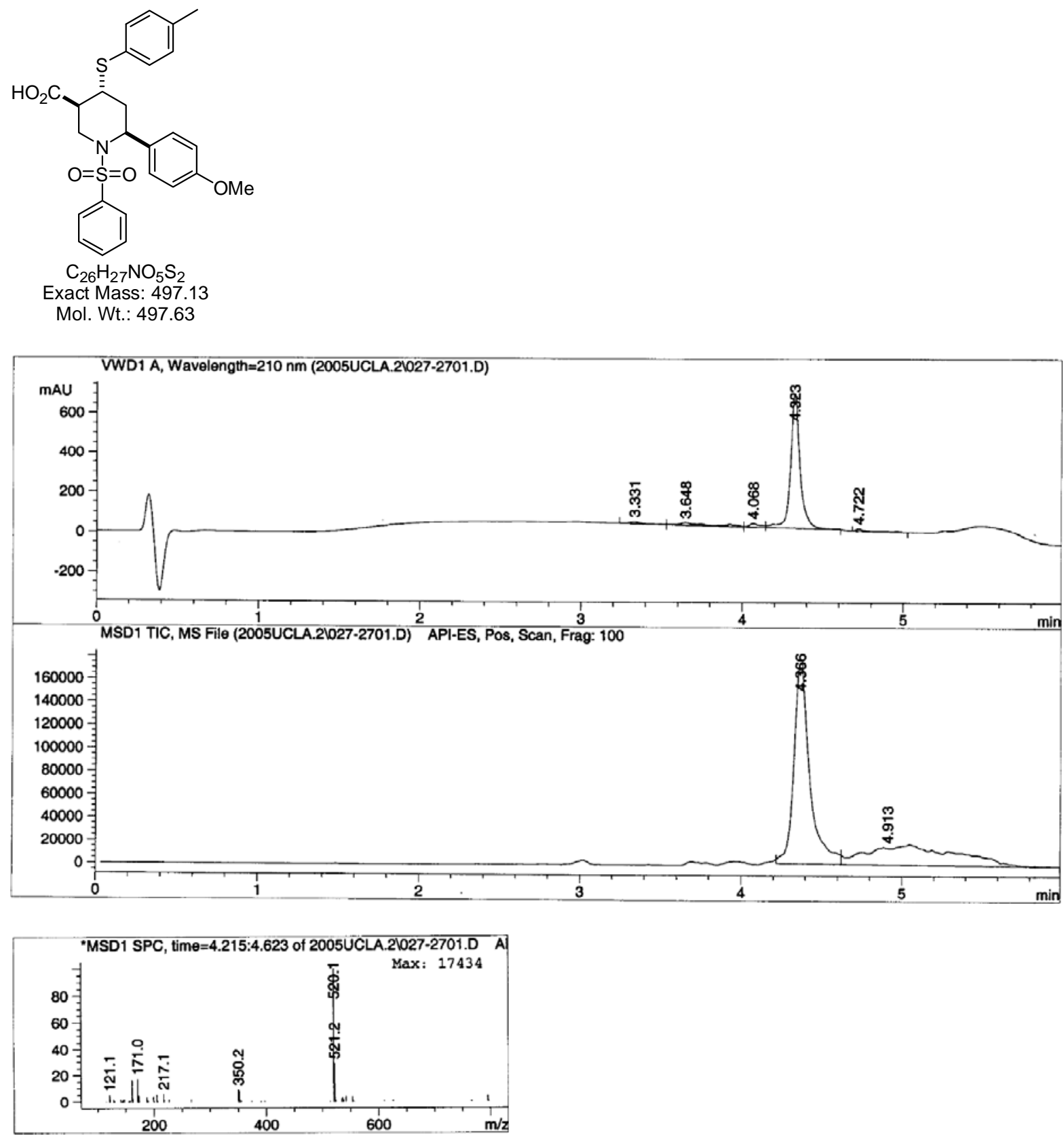